\title{
The unbearable lightness of sequenced-based identification
}

\author{
Valérie Hofstetter $^{1}$ (D) $\cdot$ Bart Buyck $^{2}$ (D) $\cdot$ Guillaume Eyssartier $^{3} \cdot$ Sylvain Schnee $^{1} \cdot$ Katia Gindro $^{2}$
}

Received: 20 February 2019/ Accepted: 8 May 2019/Published online: 24 May 2019

(C) The Author(s) 2019

\begin{abstract}
Using the basic GenBank local alignment search tool program (BLAST) to identify fungi collected in a recently protected beech forest at Montricher (Switzerland), the number of ITS sequences associated to the wrong taxon name appears to be around 30\%, even higher than previously estimated. Such results rely on the in-depth re-examination of BLAST results for the most interesting species that were collected, viz. first records for Switzerland, rare or patrimonial species and problematic species (when BLAST top scores were equally high for different species), all belonging to Agaricomycotina. This paper dissects for the first time a number of sequence-based identifications, thereby showing in every detail—particularly to the user community of taxonomic information-why sequence-based identification in the context of a fungal inventory can easily go wrong. Our first conclusion is that in-depth examination of BLAST results is too time consuming to be considered as a routine approach for future inventories: we spent two months on verification of approx. 20 identifications. Apart from the fact that poor taxon coverage in public depositories remains the principal impediment for successful species identification, it can be deplored that even very recent fungal sequence deposits in GenBank involve an uncomfortably high number of misidentifications or errors with associated metadata. While checking the original publications associated with top score sequences for the few examples that were here re-examined, a positive consequence is that we uncovered over 80 type sequences that were not annotated as types in GenBank. Advantages and pitfalls of sequence-based identification are discussed, particularly in the light of undertaking fungal inventories. Recommendations are made to avoid or reduce some of the major problems with sequence-based identification. Nevertheless, the prospects for a more reliable sequence-based identification of fungi remain quite dim, unless authors are ready to check and update the metadata associated with previously deposited sequences in their publications.
\end{abstract}

Keywords Fungal inventory - GenBank · Nuclear ribosomal DNA internal transcribed spacers (ITS) - Switzerland · Type sequence

\section{Introduction}

Electronic supplementary material The online version of this article (https://doi.org/10.1007/s13225-019-00428-3) contains supplementary material, which is available to authorized users.

Valérie Hofstetter and Bart Buyck equally contributed to this study.

\footnotetext{
Bart Buyck

bart.buyck@mnhn.fr

Valérie Hofstetter

valerie.hofstetter@agroscope.admin.ch

Sylvain Schnee

sylvain.schnee@agroscope.admin.ch

Katia Gindro

katia.gindro@agroscope.admin.ch
}

Until recently, fungi received very little attention in biology conservation (Griffith 2012; Heilmann-Clausen et al. 2014) although they play a key role in terrestrial ecosystems as decomposers of dead plant material, in carbon and nutrient recycling, and as symbionts of most terrestrial

1 Département fédéral de l'économie, de la formation et de la recherche DEFR, Route de Duillier 60, CP 1012, 1260 Nyon 1, Switzerland

2 Institut de Systématique, Evolution, Biodiversité (ISYEB UMR 7205), Muséum National d'Histoire Naturelle, Sorbonne Université, CNRS, CP 39, 12 Rue Buffon, 75005 Paris, France

3 Périgueux, France 
plants to which they provide nutrients and water (van der Heijden et al. 2015). Because of the exponentially growing negative impact of human activities on natural habitats, many saprobic fungi on dead wood (Christensen et al. 2005), as well as many ectomycorrhizal species (Di Marino et al. 2009) are declining or even disappearing in Europe.

The fungal kingdom is one of the most diverse groups of organisms composed of several millions of species (Blackwell 2011; Hibbett et al. 2016; Scheffers et al. 2012; Wijayawardene et al. 2018). With merely 120,000 currently accepted species being named so far (Hawksworth and Lücking 2017), estimation of fungal biodiversity raises serious methodological problems, even when one restricts oneself to the 'larger mushroom-forming fungi' (principally Agaricomycotina), a group that has traditionally been well-studied in Europe. Closely related species in most mushroom genera remain difficult to distinguish and their identification requires the morphological expertise of experienced taxonomists. In Europe, this expertise has been steadily declining in professional circles (Buyck 1999; Samson 1995), and is now mainly found among mycological societies and amateur mycologists, now more and more referred to as "citizen scientists" (Shehan 2017).

Finding the necessary taxonomic expertise (see Box 1) has always been the most limiting factor when undertaking a fungal inventory as it is literally impossible for a single person to acquire sufficient expertise in all fungal groups. Ideally, fungal inventories require the involvement of as many experienced taxonomists as needed to cover all fungal groups. Taxonomic expertise is not only important for correct identification (which is mostly achieved by microscopic examination of dried samples long after these have been collected because of time constraints when in the field), but is also very important at the moment of collecting in the field. Indeed, when mushroom fruiting is peaking and, for example, many hundreds or even thousands of Russula or Cortinarius in all colors and sizes can literally be covering the forest floor, the efficiency of selective collecting will depend on the expertise of the collectors to distinguish already a maximum of different species in the field.
Since two decades, the development of molecular techniques led scientists to use DNA barcode sequences as a new way to circumvent the taxonomic expertise needed to morphologically identify fungal species. For fungi, the best adapted barcode DNA region is presently the ribosomal region including the two internal transcribed spacers ITS1 and ITS2 (ITS) flanking the 5.8S gene (Schoch et al. 2012, 2014). Yet, also molecular-based identification still suffers from important limitations (see Box 2), in particular the degree of taxon coverage offered by public databases and the reliability of the sequence-associated identification (Bidartondo 2008; Kang et al. 2010; Ko Ko et al. 2011; Nilsson et al. 2006, 2012; Vilgalys 2003).

In this paper, the authors discuss the largely underestimated difficulty of sequence-based identification of the larger fungi in Europe, even though Europe is certainly the continent where the conditions for such an approach are the most advantageous because of the high level of taxonomic knowledge on mushrooms.

We used as a test case a pilot study designed at the demand of the Swiss forest authorities to estimate the feasibility of an in-depth fungal inventory of a beechdominated old-growth forest at Montricher (Vaud, Switzerland). One hundred and fifteen hectares of this forest are under protection since 2001, and will remain free from exploitation for at least another four decades. Forest authorities therefore initiated a pilot study to estimate the conservation value of Montricher in view of best practice for future forest management. Practical organization of this inventory, limited taxonomic expertise and funding, as well as time constraints all clearly favored an ITS-based approach to characterize and identify the collected fruiting bodies. This approach offers moreover the advantage to allow for a future, more precise identification once the taxon coverage on public databases will become more complete. Through a detailed discussion of identification problems for each of the most interesting samples, we will show here that the correct interpretation of BLAST results requires considerable taxonomic and molecular expertise and is far too time-consuming to be considered a routine approach when fungal inventories involve large numbers of taxa. 


\section{Box 1: Limitations of morphology-based fungal identification}

- Requires trained field mycologists to distinguish between different species in the field. Unexperienced collectors will either waste their time collecting the same species over and over again or they may overlook the most interesting species in the field being unable to make a difference between what is common or rare.

- Are selective in sampling as later identification may be impossible due to several factors. At moments when mushroom fruiting is peaking, morphology-based identification severely limits the number of samples that can be processed due to time needed to take photographs, necessary notes, labelling, drying and bagging. In such cases, time constraints will push sampling toward the collection of the more easily identified or 'favorite' groups of individual mycologists.

- Can be severely impacted by the poor state or development of fructifications such as too immature, too old or too scanty material, absence of particular developmental stages to observe essential features such as veils, too fast deterioration of fruiting bodies (as for example for genera such as Coprinopsis or Mycena) or the impossibility of obtaining spore prints needed for correct identification.

- Can be severely handicapped by the partial to complete absence of identification tools. In particular when doing inventories in poorly explored parts of the world, the absence of identification keys and the predominant presence of undescribed species renders an inventory quasi impossible.

\section{Box 2: Advantages and limitations of sequence-based fungal identification}

- Are less dependent on expertise as long as mushroom fruiting is not overwhelming and thus as long as nearly everything can be collected. When fruiting is peaking, sampling will become dependent again on taxonomic expertise.

- Are not limited by the necessity of observing certain developmental stages.

- Are unbalanced by rapid deterioration typical of some fungal groups (fungal material can be stored for long term preservation in CTAB buffer [Doyle and Doyle 1987; Cullings 1992]).

- Are less impacted by time constraints for processing collections and are thus less selective in sampling.

- Are less impacted by existence of morphological identification tools (keys, floras etc.)

- Are severely impacted by the coverage of existing species in public sequence databases for their barcode sequence, but offer the tremendous advantage that obtained sequences will allow for future identification once the fungal group becomes sufficiently covered in public databases.

- Are entirely dependent on correct identification of available sequences in public sequence databases.

- Are highly impacted by the quality of sequences and presence of chimeric sequences or heterozygotous sites.

- Are severely dependent on the capacity of correct interpretation of BLAST results, which is in our opinion a highly underestimated problem as it is directly related to sufficient taxonomic and molecular expertise.

- Are dependent on the chosen similarity cut-off for species recognition. The often applied $97 \%$ similarity cut-off (Lindahl et al. 2013; Selosse et al. 2016) is certainly too low for most mushrooms as suggested by several recent taxonomic revisions (Bazzicalupo et al. 2017; Yuan 2014; Miettinen et al. 2018; Örstadius et al. 2015).

- Can be affected by contamination problems, e.g. for older tissues or when PCR favors shorter ITS than those of the mushroom to be identified (e.g. Cantharellus). Cloning may deal with such problems but is costly and timeconsuming.

- Are dependant on whether the resolution or the variation of the ITS marker alone will allow for a precise identification of species. Indeed, in certain taxonomic groups of mushroom forming fungi, but particularly in the case of several important pathogen genera, the (often exaggerated) description of cryptic species that have identical ITS is based on genes such as beta-tubulin and calmodulin, which evolve more rapidly than ITS. An ITS sequence of such cryptic species may typically BLAST with a 100\% similarity for a 100\% coverage against a whole suite of different cryptic species (Beker et al. 2016; Kiss 2012; Seifert 2009a, b; Shivas and Cai 2012). 


\section{Materials and methods}

\section{Collecting site and fungal taxon sampling}

Mushroom forming fungi were collected in four plots, of $200 \mathrm{~m}^{2}$ each, in the protected beech-dominated forest of Montricher (Switzerland). Two plots were delimited in medium-aged forest and two plots in preserved forest, with one plot exploited and the other not in each forest type. Trees, bushes and dead pieces of wood were mapped in each plot as well as each collected mushroom to avoid the repeated sampling of the same individual. All encountered fruiting bodies of macro-fungi have been collected without discrimination during twelve visits between March 2015 and May 2016 (Fig. 1). This collecting period was overall pretty dry compared to previous years, with no substantial or continuous rainfalls. It was consequently a bad year to collect fungi in this region of Switzerland.

Each fungal collection was photographed in the field, packed in aluminium foil, and brought back to the laboratory. Two samples of $0.5 \mathrm{~cm}^{3}$ of each fungal collection were placed individually in an Eppendorf tube containing $500 \mu \mathrm{l}$ of cetyl trimethyl ammonium bromide buffer $(\mathrm{CTAB} 1 \times)$. The remaining material was dried in an incubator at $60{ }^{\circ} \mathrm{C}$ and then placed in sealed plastic bags for voucher reference and future storage in the Mycotheque 'Mycoscope' of Agroscope, Changins-Wädenswil (CH).

\section{Molecular characterization of the fungi and delimitation of the operational taxonomic units}

Fungal collections were characterized by amplification and sequencing of the nrITS using primers ITS1F (or ITS1) and ITS4 (http://sites.biology.duke.edu/fungi/mycolab/primers. $\mathrm{htm})$. Sequencing was performed by (CEurofins Scientific (France). The obtained sequences were assembled in Sequencher v. 4.9 (Gene Codes Corp., USA), aligned in MacClade v. 4.08a (Maddison and Maddison 2005) to delimit ITS1, the 5.8S gene and ITS2 regions, and to remove small and large subunit flanking regions. Once trimmed, ITS sequences were submitted to a similarity search in Sequencher v. 4.9, setting assembling parameters to $100 \%$ to determine the number of ITS genotypes present in our fungal sampling. For each genotype, the sequence similarity search $\left(\right.$ BLAST $^{\circledR}$; https://blast.ncbi.nlm.nih.gov/ Blast.cgi?PAGE_TYPE=BlastSearch\#) in GenBank (National Center for Biotechnology Information; https://www. ncbi.nlm.nih.gov/pmc/articles/PMC5753231/) used the 'blastn' (Megablast) option excluding 'uncultured/environmental sample sequences'. The putative presence of chimera was checked by looking at query coverage for BLAST results (Nilsson et al. 2012). When BLAST top scores were equally high for several GenBank sequences we favored sequences published in taxonomic studies. The cut-offs used to assign a particular precision to the identification of an operational taxonomic unit (OTU) sensu

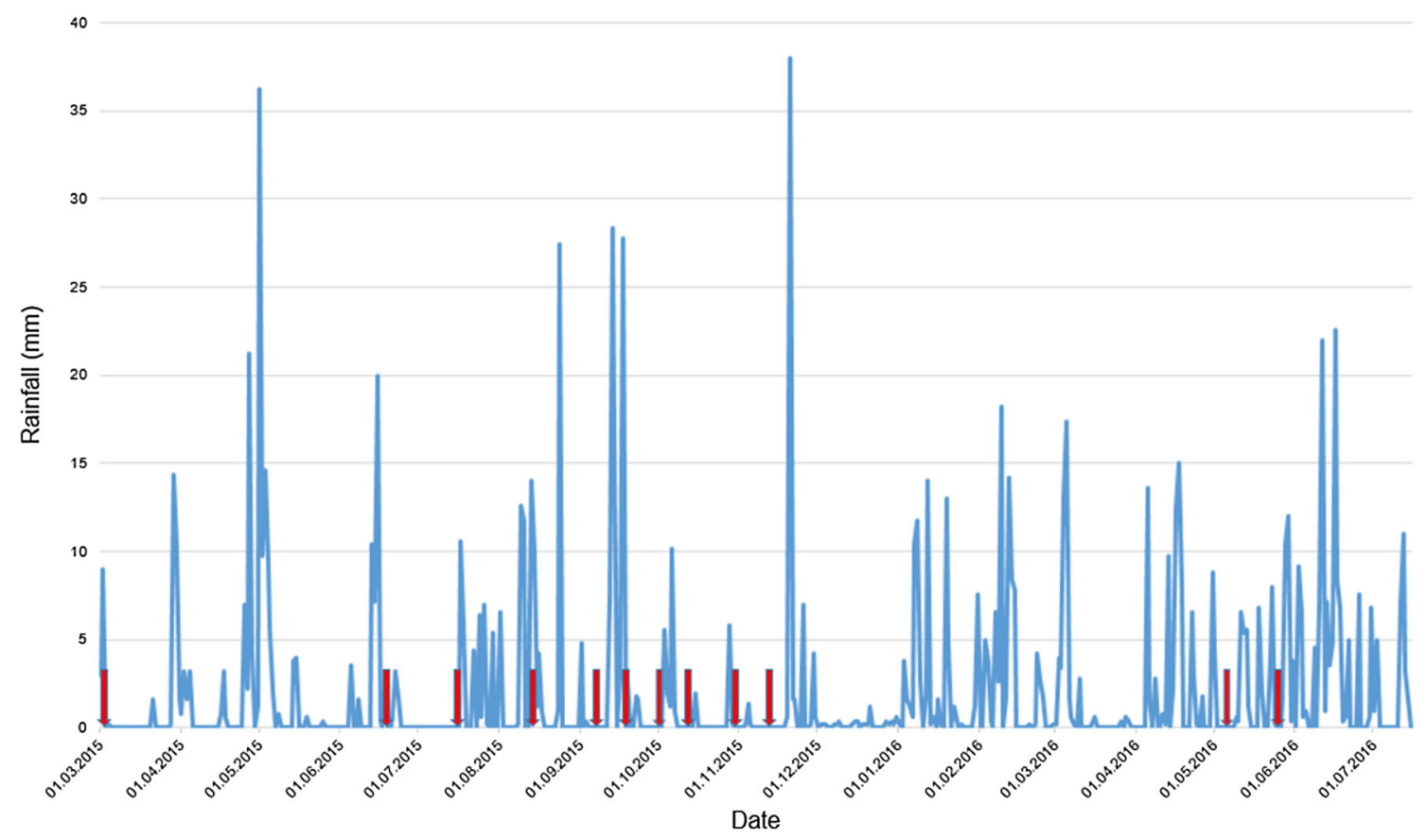

Fig. 1 Rainfall from March 2015 to September 2016 based on data provided by the weather station of Arnex-sur-Orbe, closest weather station $(15 \mathrm{~km})$ to the Montricher forest. Red arrows indicate collecting dates 
Blaxter et al. (2005) based on obtained BLAST results with total or near total coverage were as follows (see Hofstetter et al. 2012 for a more detailed discussion of the cut-offs adopted here)

- Three categories concern species rank:

- sequence similarity of 100\%: positive species identification.

- sequence similarity of 99\%: possibly this species (suffix cf.).

- sequence similarity of $96-98 \%$ or of $100 \%$ with a sequence deposited as being close to a species: certainly not this species, but related (suffix aff.).

- genus rank only was adopted when equal BLAST top score similarity values have been obtained for several species, all from the same genus (ranging from 96 to $100 \%$ ) for different species or BLAST top score inferior to $96 \%$ but with several species belonging to the same genus.

- family rank only was adopted when BLAST top score similarity values were $<96 \%$ for several fungi, all part of the same family).

- similarly, order rank only was adopted when BLAST top score similarity values were $<96 \%$ for several fungi, all part of the same order.

BLAST sequence similarity searches were performed a first time in October 2017, then again in Oct. 2018; see Online Resource 1). As already mentioned, sequence query coverage was an important issue when adopting a particular scientific name associated with the most similar ITS sequences in GenBank, to avoid that identifications would rely on BLAST results for the $5.8 \mathrm{~S}$ alone and/or small parts of either ITS1 or ITS2. We additionally checked metadata for all sequences found among BLAST top scores for the discussed taxa for possible presence of type-derived sequences and performed BLAST also with the option 'Sequence from Type' selected (https://blast.ncbi.nlm.nih. gov/Blast.cgi?PAGE_TYPE=BlastSearch\#).

For fungal collections that could be identified at species rank, species names obtained from GenBank were then verified for nomenclatural and taxonomic synonyms in both Mycobank (http://www.mycobank.org/) and Index Fungorum (http://www.indexfungorum.org/names/names. asp) and current names adopted.

When BLAST results were equally high for several species, and we had reasons to suspect mistakes in associated identifications for deposited sequences, we ran phylogenetic analyses to be able to name correctly the collected fungi. Sequences were aligned by eye in MacClade, and phylogenetic analyses were conducted in PhyML v. 3.0 (Guindon and Gascuel 2003), with evolutionary model $=$ GTR and other parameters estimated during the search for the most likely tree. Branch robustness was evaluated based on 500 bootstrap replicates, with the same settings as for the search for the most likely tree. Branch support was considered significant when bootstrap values were $\geq 70 \%$ (Alfaro et al. 2003).

\section{Frequency of the collected fungal species in Switzerland and indicator species}

When BLAST top score(s) of an ITS sequence allowed us to name the collected fungi at species rank or genus rank, we searched for these species or genus names or any of their synonyms in the "Atlas de la répartition des espèces de champignons de Suisse" (ARCS; Swissfungi; http:// www.wsl.ch/dienstleistungen/inventare/pilze_flechten/ swissfungi/). This atlas reports how many times fungal species have been collected since 1800 in Switzerland. Considering the complexity of forest ecosystems, one way to reduce this complexity when evaluating habitat quality is to identify indicator species (Siddig et al. 2016). The ARCS was used as the basis to create a list of indicator fungal species (= endangered, nearly threatened or vulnerable; Senn-Irlet et al. 2007) for Switzerland. Such information is reported in the ARCS for each fungal species and allowed us to check whether the collected species were indicator species in Swizerland and might thus give us a preliminary appreciation of the quality of the Montricher forest.

\section{Results}

\section{Molecular delimitation and identification of the OTUs (or tentative fungal species)}

A total of 294 collections of fruiting bodies of macro-fungi were harvested. An ITS sequence was obtained for 283 (96.2\%) of these collections. Among the eleven collections for which no ITS sequence was obtained, three were identified morphologically to species (two Tremella mesenterica and one Trametes hirsuta); six would have needed cloning procedures and corresponded to corticioid species generating multiple bands during amplification, while the remaining two collections involved remnants of black perithecia that did not provide enough DNA template for amplification with our standard extraction protocol.

Once the 283 ITS sequences were aligned, delimited, and assembled in Sequencher with a $100 \%$ similarity threshold, we obtained 163 different ITS genotypes. Sequence alignment showed that full ITS1-5.8S s-ITS2 were obtained from all fungal collections, except for two Mycena (Mont-77 [only ITS1 was obtained] and Mont-30 [short parts of ITS1 and ITS2 but 5.8S missing]) and for a 


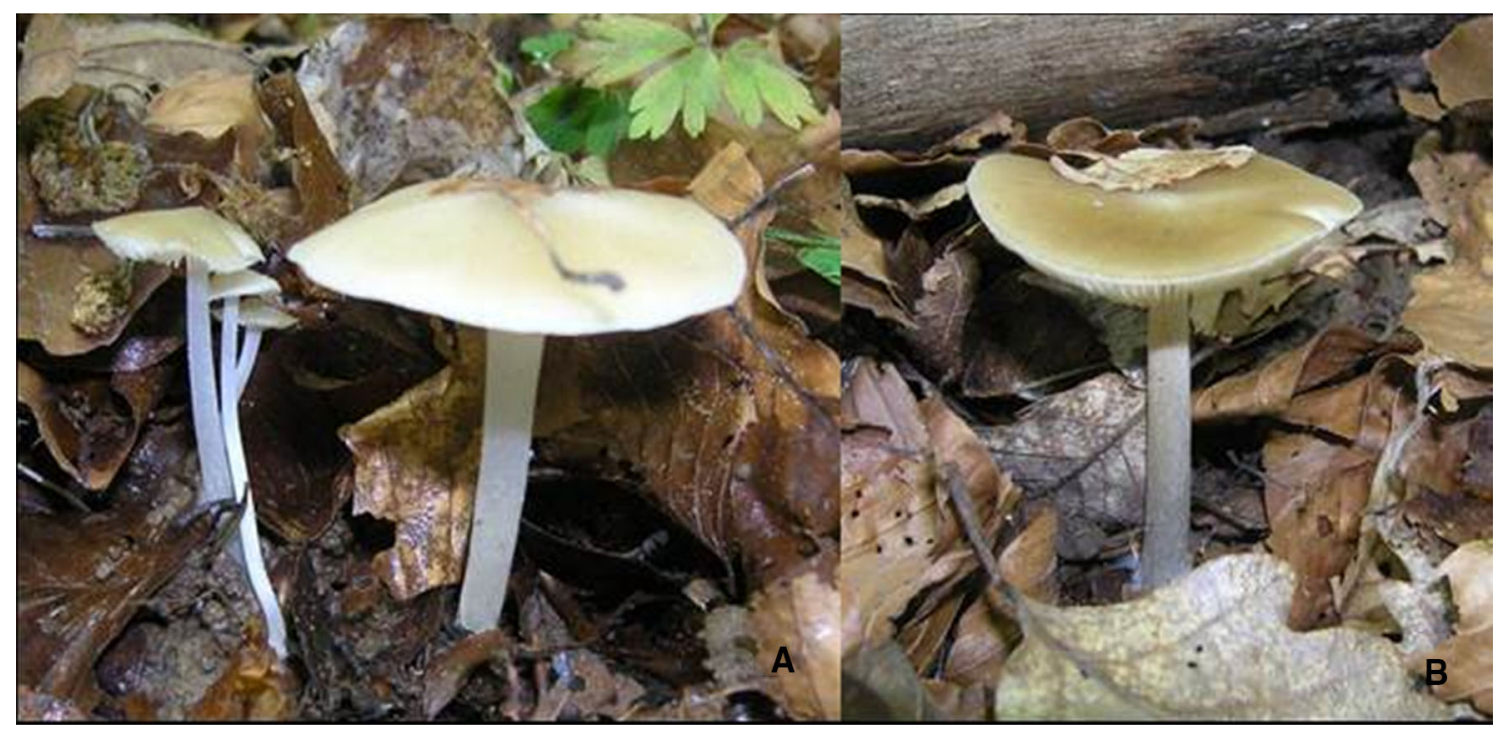

Fig. 2 Hydropus subalpinus (a Mont-322, b Mont-313; Online Resource 1), identified based on morphology by Guillaume Eyssartier

Hygrophorus sequence (Mont-243 [ITS2 missing]. Additionally, some 22 problematic (at first sight potentially chimeric) sequences were retrieved for Hydropus for which the first BLAST search (performed in October 2017) showed that both ITS did not match any fungal sequence (see Online Resource 1). Consequently, those 22 collections were initially identified by BLAST to order rank based on the 5.8S gene (Fig. 2 and Online Resource 1; four different genotypes with BLAST top scores $=93 \%$, identified as Agaricales sp.). Based on morphology, however, these collections were easily identified as Hydropus subalpinus and, indeed, our second BLAST search, performed in October 2018, identified our sequences with new GenBank deposits for Hydropus spp. with 98-99\% of similarity for $100 \%$ of query coverage. Also three Mycena collections (Mont-141, Mont-212 and Mont-248) had an ITS1 sequence that had a much lower BLAST top score than the 5.8S-ITS2 region. For Mycena species the low similarity in BLAST results is very likely to result from homopolymeric regions, in our experience often found in ITS1, that result in a sequencing stop. Many Mycena sequences deposited in Genbank miss the ITS1 region or have only a small part of it. This could explain why we had low similarity for ITS1 region for part of our Mycena sequences.

Sequences of all 163 genotypes were deposited in GenBank (see GenBank accession numbers in Online Resource 1). Two of our 163 genotypes were discarded as fungal contaminants of mushroom fruiting bodies: Penicillium swiecickii and Verticillium sp. (see accession numbers in Online Resource 1). Based on genotypes exhibiting $99 \%$ of similarity between them and thus part of the same OTU (Online Resource 1), our fungal sampling included 124 OTUs (122 OTUs delimited based on molecular data and 2 OTUs [Trametes hirsuta and $\mathrm{Hy}$ dropus subalpinus] identified based on morphology [Online Resource 1]).

BLAST results (sequence similarity searches were performed in October 2017, then again in Oct. 2018; Online Resource 1) of all obtained genotypes allowed us to name 216 fungal samples at species rank (including those with sequence similarity of 99 [suffix cf.]), 24 samples were identified as close to a particular species (suffix aff.), 20 samples were identified to genus, one collection to family rank, and, finally, 22 samples, representing three close genotypes of Hydropus, could only be identified by BLAST to order in 2017, but to species rank in 2018 thanks to new sequence deposits.

\section{Separating the wheat from the chaff: critical re- examination of first records and patrimonial species in Switzerland}

When searching the Swiss fungal Atlas (ARCS, accessed in October 2017) for each of the identified species with the above-mentioned criteria (Online Resources 1, 2), it appeared that six species represented first records for Switzerland: Cibaomyces glutinis Zhu L. Yang, Y.J. Hao \& J. Qin (in Hao et al. 2014), Cortinarius laberiae B. Oertel \& Saar (in Münzmay et al. 2009), Cortinarius subgracilis Moënne-Locc. (in Bideau et al. 2001), Laxitextum incrustatum Hjortstam \& Ryvarden (1981), Oligoporus alni (Niemelä \& Vampola) Piatek (2003) and Russula inamoena Sarnari (1994). An additional seven species among our identifications had been collected less than 10 times in the country since 1801: Antrodiella citrinella Niemelä \& Ryvarden (1983) -five reports, Hygrophoropsis rufa (D.A. 
Reid) Knudsen (in Knudsen and Vesterhold 2008)—one report, Trichoderma polysporum (for which we collected the anamorph, Hypocrea pachybasioides Yoshim. Doi (in Doi 1972)—-two reports, Mycena alniphila Robich (2016)_one report, Pluteus pseudorobertii M.M. Moser (1953)—seven reports, Psathyrella fagetophila Örstadius \& Enderle (Enderle 1996) - two reports, and Sistotrema sernanderi (Litsch.) Donk (1956)_five reports. Finally, five more species had patrimonial value, which need local management and which may be flagship species (Pervanchon 2004), being reported in the ARCS as endangered (EN), vulnerable (VU) or nearly threatened (NT) species in Switzerland: Cortinarius cotoneus Fr. 1838 (VU), Lactarius helvus (Fr.) Fr. 1838 (VU), Pluteus phlebophorus (Ditmar) P. Kumm. 1871 (NT), Pluteus pseudorobertii M.M. Moser 1953 (EN) and Tricholomopsis flammula Métrod ex Holec in Holec (2009) (VU).

Finding six fungal species new for Switzerland, seven species only collected in Switzerland between one and ten times in the past, plus five indicator species was quite an impressive result considering the unfavorable weather conditions, the small plot size and the poor collecting effort. However, such a conclusion may be premature considering the many pitfalls related to sequence-based identification. This is why we submitted the BLAST results obtained for all of these remarkable identifications to a second, in-depth examination taking advantage of all recent taxonomic and phylogenetic studies, nomenclatural issues and, in three cases, even by alignment of our sequences with all of the BLAST top score sequences in view of running phylogenetic analyses. We also paid attention to the available nomenclatural decisions and type information provided by Mycobank (MB), Index Fungorum (IF) and the ARCS for the 95 OTUs that could be identified at species rank (99 [cf.]-100\% of sequence similarity with top score sequence[s], Online Resource 2)

\section{New records for the Atlas of Switzerland}

\section{Antrodiella sp. appeared to be the first European record of Antrodiella stipitata H.S. Yuan \& Y.C. Dai (in Yuan et al. 2006)}

Our collections comprised a few specimens of the polyphyletic (Yuan 2014) polypore genus Antrodiella (Online Resources 1,2). As the genus has rarely been collected in Switzerland we tried to name our collections at species rank. BLAST results for our sequence MK028371 provide a typical example of a problematic to even completely impossible identification with more than a dozen different species blasting at $99 \%$ similarity at $100 \%$ coverage (Fig. 3). The top score hit, A. faginea, evidently seems the most tempting ID considering the dominance of beech at
Montricher. Yet, to confirm this ID, we nevertheless decided to align our sequences together with the top 20 BLAST hits from GenBank. Considering as reference sequences for $A$. faginea the ten sequences deposited by Johannesson et al. (2000) and for A. stipitata the sequence produced by Yuan (2014), this alignment clearly showed that the two top hits in GenBank were misidentifications (KU726586 and KJ668572 are 100\% similar to each other and align better on $A$. stipitata sequences than on $A$. faginea or A. semisupina sequences respectively). As a result, our sequence did not correspond to A. faginea, but to the recently described $A$. stipitata from China, therefore representing first records not only for Switzerland, but also for Europe.

It needs to be mentioned here that species recognition in Antrodiella is based on very slight sequence differences (which is also the case for many other polypores, see Miettinen et al. 2018), in this case mostly in the ITS2. The two identical sequences we obtained for $A$. cf. stipitata (MK028371) have a Y (C or T) at one of the few nucleotide positions that allow to distinguish this species from other Antrodiella species. Part of the observed sequence variation may consequently result from heterozygosy, a problem discussed by Selosse et al. (2016). Additionally, Antrodiella stipitata was described based on morphology and cross-checking between recent publications and public sequence databases (Online Resource 2), showed that there is no ITS sequence deposited for the type specimen of $A$. stipitata.

\section{Cibaomyces glutinis Zhu L. Yang appeared to be common Rhizomarasmius setosus (= Marasmius setosus in the ARCS)}

Identical sequences were obtained from two of our samples (see MK028377, Online Resource 1), each from a single, extremely tiny ( $<2 \mathrm{~mm}$ diam.) white-capped marasmioid species with a long filiform stipe for which BLAST results (Fig. 4) gave a $100 \%$ similarity match for a $99 \%$ sequence coverage (Online Resource 1) with a sequence deposited in GenBank as Cibaomyces glutinis Zhu L. Yang, Y.J. Hao \& J. Qin (KM588673). The second closest BLAST result followed at only $90 \%$ similarity. Cibaomyces glutinis represents a monospecific genus recently described from Asia (Hao et al. 2014). It has since been reported only once in the literature, viz. from France, including from a region near the Alps and thus not that far away from the Montricher forest. As these European specimens had been identified by a taxonomic expert in the group (Moreau et al. 2015), there was little reason to doubt the correctness of the BLAST top hit on Cibaomyces glutinis.

However, when consulting the latter publication, it appeared that, from a morphological point of view, the collected fruiting bodies from Montricher were quite 


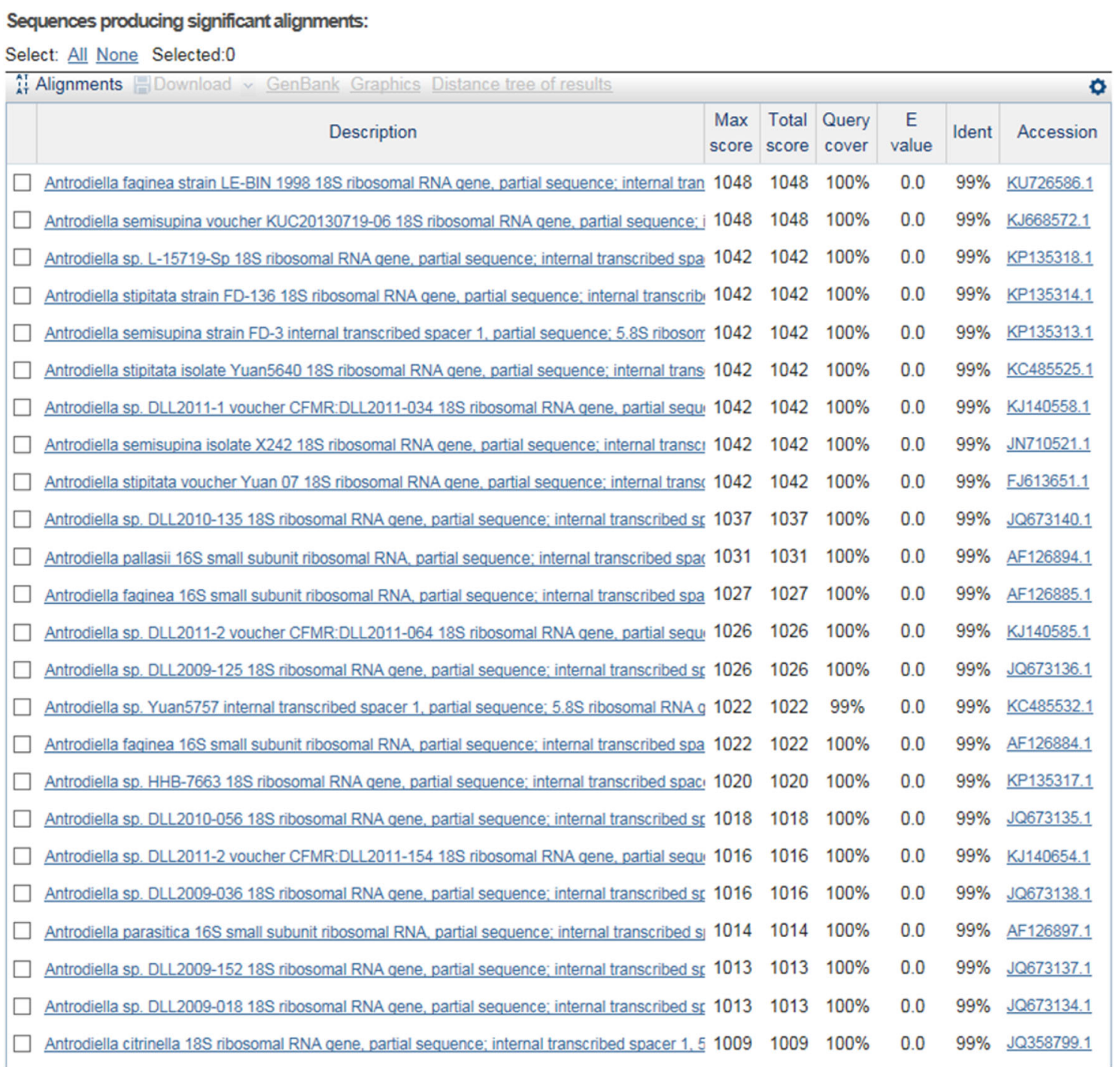

Fig. 3 BLAST top scores for ITS genotype MK028371 for collection Mont-330 = Antrodiella stipitata (see Online Resource 1)

different from the published picture of Cibaomyces, which shows an equally small mushroom but having a more brownish gray color and a brown gill edge. We therefore decided to take a closer look at BLAST results, which then revealed that the sequences of the Asian holo (NR_132898) — and paratype (KJ024100) of Cibaomyces were far down in the BLAST results (Fig. 4) at only 84, resp. $83 \%$ similarity to the European sequence deposited for this species, and for the same query cover (99\%)! When reblasting these Asian type sequences, the only other sequence that comes close (at 95\%) is KM588675, all other sequences were at $87 \%$ similarity and lower. The latter sequence (KM588675) was published in the same paper by Moreau et al. (2015) but is associated in GenBank with data for a Canadian voucher specimen for Rhizomarasmius pyrrocephalus. From the discussion in the Moreau et al. (2015) paper, it is clear that the latter sequence actually represents the French collection of Cibaomyces glutinis (as they interpret the $95 \%$ similarity with the Asian type sequence to intraspecific variation among European and Asian specimens). Being unable to solve the problem, we then contacted the authors of the Moreau et al. (2015) paper who kindly sent us their original sequence dataset. Comparison between the sequences deposited in GenBank and the original sequence dataset clearly showed that some kind of shift between taxon names and corresponding sequences must have occurred at the moment of deposit. The original sequence dataset easily allowed for the correct identification of our specimens as Rhizomarasmius setosus (Online Resources 1, 2).

The Swiss Atlas mentions only two species of Rhizomarasmius ( $R$. undatus and $R$. epidryas), and reports Rhizomarasmius setosus still under its older synonym, 
Sequences producing significant alignments:

Select: All None Selected:0

\begin{tabular}{|c|c|c|c|c|c|c|c|}
\hline \multicolumn{8}{|c|}{ 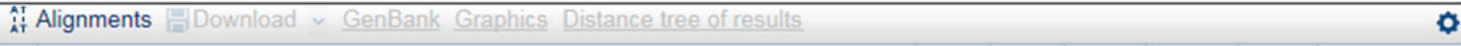 } \\
\hline & Description & $\begin{array}{l}\text { Max } \\
\text { score }\end{array}$ & $\begin{array}{l}\text { Total } \\
\text { score }\end{array}$ & $\begin{array}{l}\text { Query } \\
\text { cover }\end{array}$ & $\begin{array}{c}E \\
\text { value }\end{array}$ & Ident & Accession \\
\hline$\square$ & Cibaomyces qlutinis voucher LIP PAM99082601 internal transcribed spacer 1, 5.8 S ribosomal & 1279 & 1279 & $99 \%$ & 0.0 & $100 \%$ & $\underline{\mathrm{KM} 588673.1}$ \\
\hline$\square$ & Rhizomarasmius setosus voucher BRNM 736121 internal transcribed spacer $1.5 .8 \mathrm{~S}$ ribosomal & 896 & 896 & $99 \%$ & 0.0 & $90 \%$ & $\underline{\mathrm{KM} 588674.1}$ \\
\hline$\square$ & Rhizomarasmius pyrrocephalus strain TENN51091 18S small subunit ribosomal RNA gene, pa & 894 & 894 & $99 \%$ & 0.0 & $90 \%$ & $\underline{\mathrm{DQ097369.1}}$ \\
\hline$\square$ & Marasmius cf. epidrvas $34 \mathrm{~N} 3 \mathrm{~F} 25$ internal transcribed spacer 1 , partial sequence: $5.8 \mathrm{~S}$ ribosor & 850 & 850 & $99 \%$ & 0.0 & $89 \%$ & $\underline{\mathrm{HQ} 445616.1}$ \\
\hline$\square$ & $\underline{\text { Rhizomarasmius undatus voucher LIP PAM07092201 internal transcribed spacer } 1.5 .8 \mathrm{~S} \text { ribos! }}$ & 743 & 743 & $99 \%$ & 0.0 & $86 \%$ & $\underline{\mathrm{KM} 588672.1}$ \\
\hline$\square$ & Physalacriaceae Sp. 2 PRJ-2011 18S ribosomal RNA gene, partial sequence; internal transcrib & 725 & 725 & $99 \%$ & 0.0 & $86 \%$ & $\underline{\mathrm{JN} 225955.1}$ \\
\hline$\square$ & Marasmius epidryas strain KH59 internal transcribed spacer 1, partial sequence: $5.8 \mathrm{~S}$ ribosom: & 704 & 704 & $79 \%$ & 0.0 & $90 \%$ & $\underline{\text { GU234115.1 }}$ \\
\hline$\square$ & Rhizomarasmius oreinus AQUI 6763 ITS reqion; from TYPE material & 701 & 770 & $82 \%$ & 0.0 & $90 \%$ & $\underline{\text { NR } 132910.1}$ \\
\hline$\square$ & Rhizomarasmius oreinus voucher $A Q U 16115$ internal transcribed spacer $1,5.8 \mathrm{~S}$ ribosomal RN & 697 & 766 & $82 \%$ & 0.0 & $90 \%$ & $\underline{K M 588679.1}$ \\
\hline$\square$ & Rhizomarasmius oreinus voucher $A Q U I 6116$ internal transcribed spacer $1.5 .8 \mathrm{~S}$ ribosomal RN & 695 & 764 & $82 \%$ & 0.0 & $90 \%$ & KM588678.1 \\
\hline$\square$ & Rhizomarasmius oreinus voucher BRNM 751553 internal transcribed spacer $1.5 .8 \mathrm{~S}$ ribosomal & 695 & 764 & $82 \%$ & 0.0 & $90 \%$ & $\underline{\mathrm{KM} 588669.1}$ \\
\hline$\square$ & Rhizomarasmius oreinus voucher BRNM 751554 internal transcribed spacer $1.5 .8 \mathrm{~S}$ ribosomal & 691 & 761 & $82 \%$ & 0.0 & $90 \%$ & $\underline{\mathrm{KM} 588670.1}$ \\
\hline$\square$ & Marasmius epidrvas strain KH58 internal transcribed spacer 1, partial sequence: $5.8 \mathrm{~S}$ ribosom: & 691 & 691 & $80 \%$ & 0.0 & $89 \%$ & $\underline{\text { GU234107.1 }}$ \\
\hline$\square$ & Gloiocephala aquatica strain CIEFAP 50 isolate AFTOL-ID 517 internal transcribed spacer $1, D_{\varepsilon}$ & 667 & 746 & $87 \%$ & 0.0 & $90 \%$ & $\underline{\mathrm{DQ097356.1}}$ \\
\hline$\square$ & Gloiocephala resinopunctata strain M703c $18 \mathrm{~S}$ small subunit ribosomal RNA qene, partial seqL & 664 & 664 & $87 \%$ & 0.0 & $87 \%$ & $\underline{\mathrm{DQ} 097360.1}$ \\
\hline$\square$ & Cibaomyces qlutinis HKAS 80855 ITS reqion; from TYPE material & 636 & 636 & $99 \%$ & $3 e-178$ & $84 \%$ & NR 132898.1 \\
\hline
\end{tabular}

Fig. 4 BLAST top scores for ITS genotype MK028377 for collection Mont-155 = (Cibaomyces glutinis) Rizomarasmius setosus (see Online Resource 1). Sequence NR_132898 obtained for the paratype for C. glutinis (HKAS80855; Hao et al. 2014) appears much further down in BLAST results

$$
\begin{aligned}
& \text { Sequences producing significant alignments: } \\
& \text { Select: All None Selected:0 }
\end{aligned}
$$

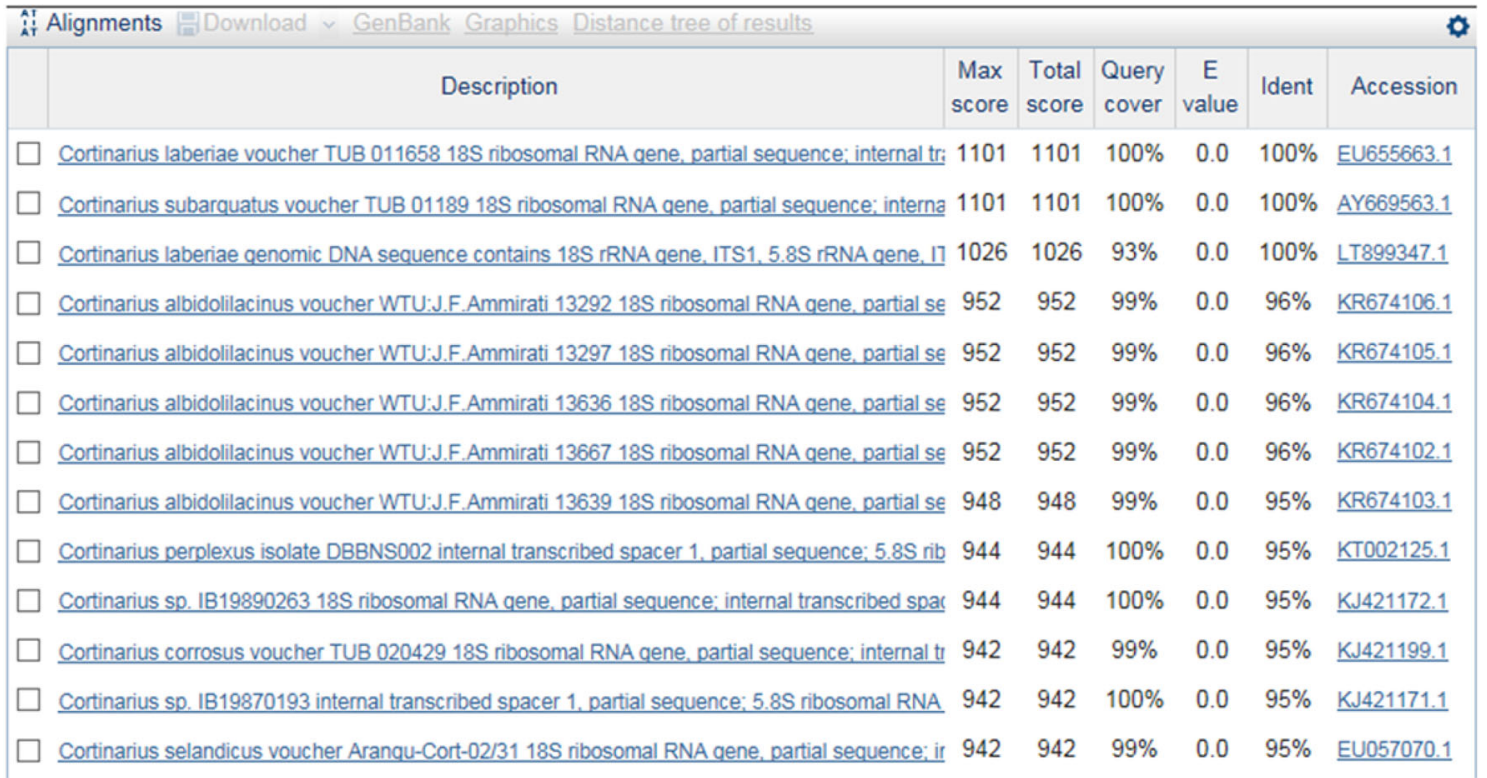

Fig. 5 BLAST top scores for ITS genotype MK028390 for collection Mont-162 = Cortinarius laberiae (see Online Resource 1) 
Marasmius setosus, a common species in Switzerland (Online Resource 2).

\section{Cortinarius laberiae B. Oertel \& Saar (in Münzmay et al. 2009)}

Two of our samples produced an identical ITS sequence (MK028390, Online Resource 1) for which BLAST top scores (Fig. 5) were $100 \%$ similar at $100 \%$ coverage (total score 1101) with GenBank sequences EU655663 (deposited as Cortinarius laberiae voucher TUB 011658) and with sequence AY669563 (deposited as C. subarquatus voucher TUB 01189). Our sequence is also $100 \%$ similar, but at 93\% coverage, with sequence LT899347, equally deposited as $C$. laberiae.

In order to check the correctness of our identification, we consulted the original paper as well as other taxonomic papers reporting on $C$. laberiae. It there appeared that GenBank sequence EU655663 was actually obtained from the holotype collection (TUB011658) for C. laberiae. This was mentioned by Bellanger (2015) and Frøslev et al. (2007), but the sequence was not annotated as type sequence in GenBank (Online Resource 2). The type collection is mentioned in IF (http://www.indexfungorum.org/ names/NamesRecord.asp?RecordID=546599), but not in MB (Online Resource 2).

The sequence AY669563 (from Garnica et al. 2005) was originally deposited as $C$. subarquatus, but later attributed to C. laberiae by Garnica et al. (2009, Suppl. file 3), but remained labeled as $C$. subarquatus in GenBank and also in UNITE (https://unite.ut.ee/) species hypotheses ( $C$. subarquatus M.M. Moser ISH222752.07FUI https://doi.org/ 10.15156/bio/sh222752.07fu).

Cortinarius laberiae remains therefore a first record for Switzerland (Online Resource 2), being represented by two samples producing identical ITS sequences as the holotype. Although straightforward, this identification required tedious searches in literature and nomenclatural as well as molecular public depositories. It also illustrates a frequently encountered fact that holotype sequences are not annotated as such. However, since we performed our first BLAST search (in October 2017) and alerted GenBank on the issue, this type record has been curated by NCBI staff. The reference sequence NR_152992 appears now as BLAST top score for our ITS sequence (MK028390, Online Resource 1) and is identical to EU655663 (Fig. 5; Online Resource 1).

\section{Cortinarius subgracilis Moënne-Locc. in Bidaud et al. (2001)}

Our inventory produced a single ITS sequence (MK028391, Online Resource 1) for which BLAST against GenBank returns a top four group of sequences, all at $99 \%$ similarity (Fig. 6). Three of these had been deposited as Cortinarius subgracilis, the remaining one as "Cortinarius sp. ». Adopting the name of $C$. subgracilis for our sequence (Online Resource 1) therefore seemed, in our opinion, "very likely correct, but not entirely confident". We therefore again examined the associated data for all BLAST top score sequences and went back to the publications where these were produced. We there discovered that sequence DQ323976 (as «Cortinarius sp. », from Frøslev et al. 2006), was annotated as "type strain of

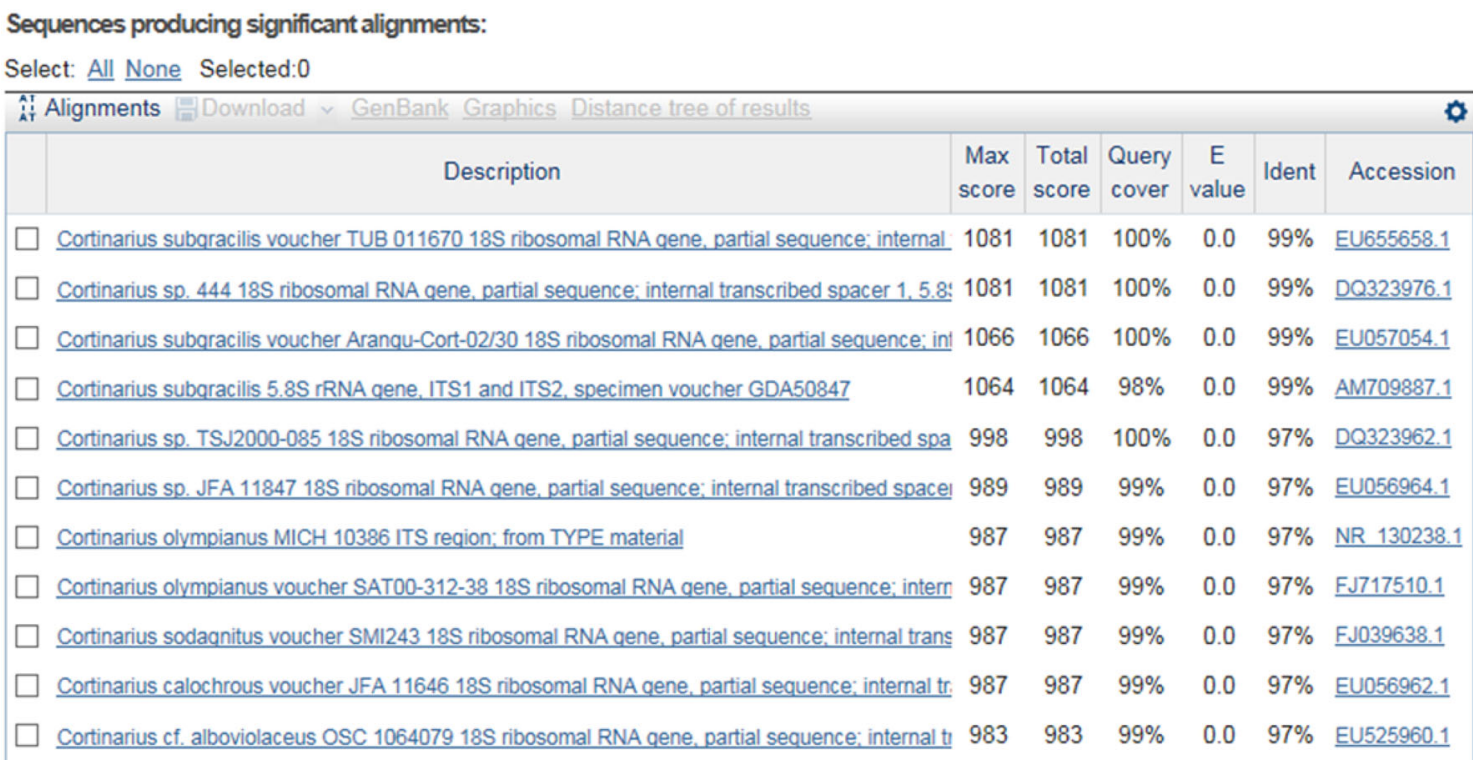

Fig. 6 BLAST top scores for ITS genotype MK028391 for collection Mont-250 = Cortinarius subgracilis (see Online Resource 1) 
Cortinarius sp. 444" (Online Resource 2). This sequence, still labelled as unpublished in GenBank, is linked to a publication titled as «New calochroid and fulvoid species of Cortinarius and their phylogenetic relationships ». Apparently, the authors later decided to publish their study in two parts: a morphological part with a very similar title (Frøslev et al. 2006) and a more phylogenetic part with a completely different title (Frøslev et al. 2007) but its online link to the supplementary material for sequence-associated data is for some reason not functioning. It is finally Bellanger (2015) who explicitedly mentions that sequence DQ323976 was obtained from the holotype for $C$. subgracilis (Cortinarius sp. 444, we now understand, actually stands for the type "Moenne-Loccoz 444"). The holotype is only clearly indicated in the UNITE database (UDB001851, species hypothesis SH452556.07FU). The ITS sequence of the Montricher specimen differs by a single mutation from the holotype sequence (4 instead of 3 T exactly at the point where both ITS1F and ITS4 sequence reads start shifting).

As a result, also this Cortinarius remains a first record for Switzerland. As in the preceding example, a sequence- based identification would have been straightforward if the holotype sequence had been annotated as such in GenBank, problem already pointed out by Nilsson et al. (2014), but now required again considerable time and effort. Cortinarius subgracilis is a conifer associate and is present at Montricher where Picea locally invades the beech forest.

\section{Laxitextum incrustatum Hjortstam \& Ryvarden appeared to be $L$. bicolor (Pers.) Lentz}

Our inventory produced a single ITS sequence (MK028395; Online Resource 1) for which the BLAST top score (Fig. 7) results in $99 \%$ similarity at $84 \%$ coverage with a sequence corresponding to Laxitextum incrustatum. However, much further down the BLAST results, at position 19, was another sequence at $99 \%$ similarity but for merely $55 \%$ sequence coverage including only part of the 5.8S and ITS2. The latter sequence (AF310102) was associated with the name L. bicolor (Pers.) Lentz (Lentz 1955). Correct identification of this sequence required therefore again to have a closer look at the associated data and various taxonomic informations, especially since $L$.

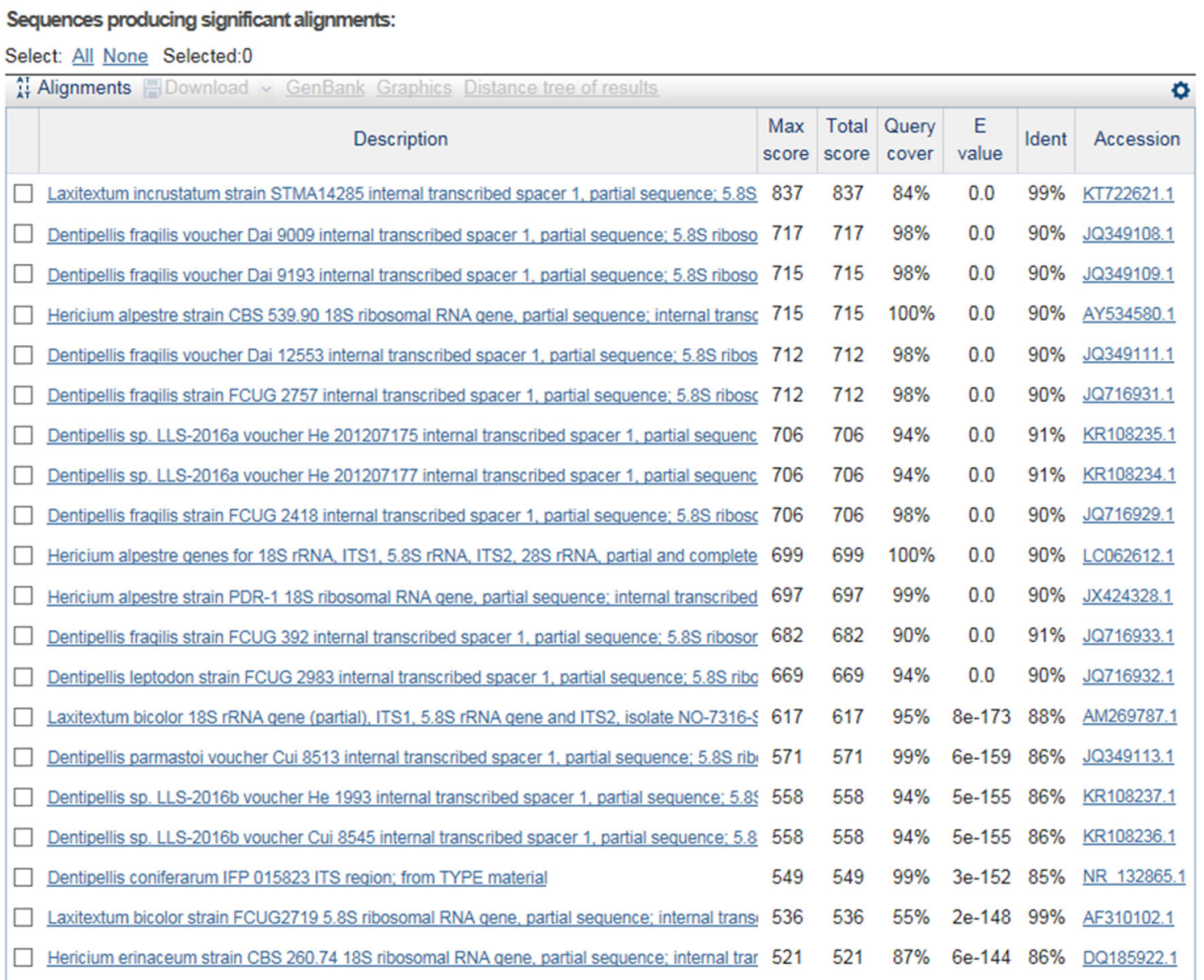

Fig. 7 BLAST top scores for ITS genotype MK028395 for collection Mont-38 = Laxitextum bicolor (see Online Resource 1) 
incrustatum is absent from the ARCS, while L. bicolor is a common species in Switzerland.

It appeared consequently that the genus Laxitextum harbors five published species names for only three recognized species in the genus (correctly indicated in IF, not in MB). Sequence data are only available for both abovementioned species, but was not obtained from type material. Furthermore, the type specimen for L. incrustatum (as well as for L. lutescens) was collected in tropical Africa (Hjortstam and Ryvarden 1981) but the distribution of Laxitextum species (based on morphological concepts) are supposed to be typically very large. To find out whether one of the above names could be applied to our specimen, we therefore decided to align the few available Laxitextum sequences with our ITS sequence. For L. bicolor two sequences were available in GenBank in 2017 when we did our first analysis: sequence AM269787 shows up at 88\% similarity at $95 \%$ coverage and appears to be a misidentification of a Dentipellis. The second, much shorter sequence (AF310102) was deposited by Larsson, known taxonomist for resupinate fungi. The latter sequence is rather short, missing ITS1, and differs from our sequence in the 5.8S and ITS2 regions in three gaps in base repeats and one undetermined nucleotide position. GenBank sequence KT722621, which is the single available ITS sequence deposited for $L$. incrustatum, differs from both our and L. bicolor AF310102 sequences in three transition positions.

Since we performed our first BLAST search (October 2017), four additional sequences exhibiting $99 \%$ of similarity with our Laxitextum sequence (MK028395) have been deposited in 2018: one for L. bicolor (MH855587), one, still unpublished, for L. incrustatum (MG231721), and two unpublished sequences for Hericium alpestre (KY449373; KY449374). The two latter sequences are probably misidentifications as suggested by the placement of two other sequences for $H$. alpestre further down in the list of BLAST top scores (Fig. 7), both exhibiting merely $90 \%$ of similarity with our sequence. After phylogenetic analysis of all available Laxitextum sequences (Fig. 8), using AM269787 (i.e. Dentipellis; see above) as outgroup sequence, the recently deposited sequence for $L$. incrustatum (MG231721) clusters with significant support (MLbs $=76 \%$ ) with three out of the four sequences deposited for L. bicolor, including the one deposited by Larsson. Consequently L. incrustatum sequence MG231721 is most likely a sequence-based misidentification of L. bicolor based on top score similarity as explained above. As a result, we adopt the name L. bicolor for our collection as we suspect that the $99 \%$ similarity resulted from a quality problem with sequence AF310102. Because this sequence was submitted to GenBank in 2000, the quality problem may be related with technical problems when reading sequences, as, at that time, these were mostly performed by eye on gels autoradiograms using a luminescent table (Heather and Chain 2015). The latter sequence is still the only sequence produced by taxonomists that have experience with corticioid fungi. Therefore, sequence based identification of Laxitextum species remains problematic at the moment. Indeed, our

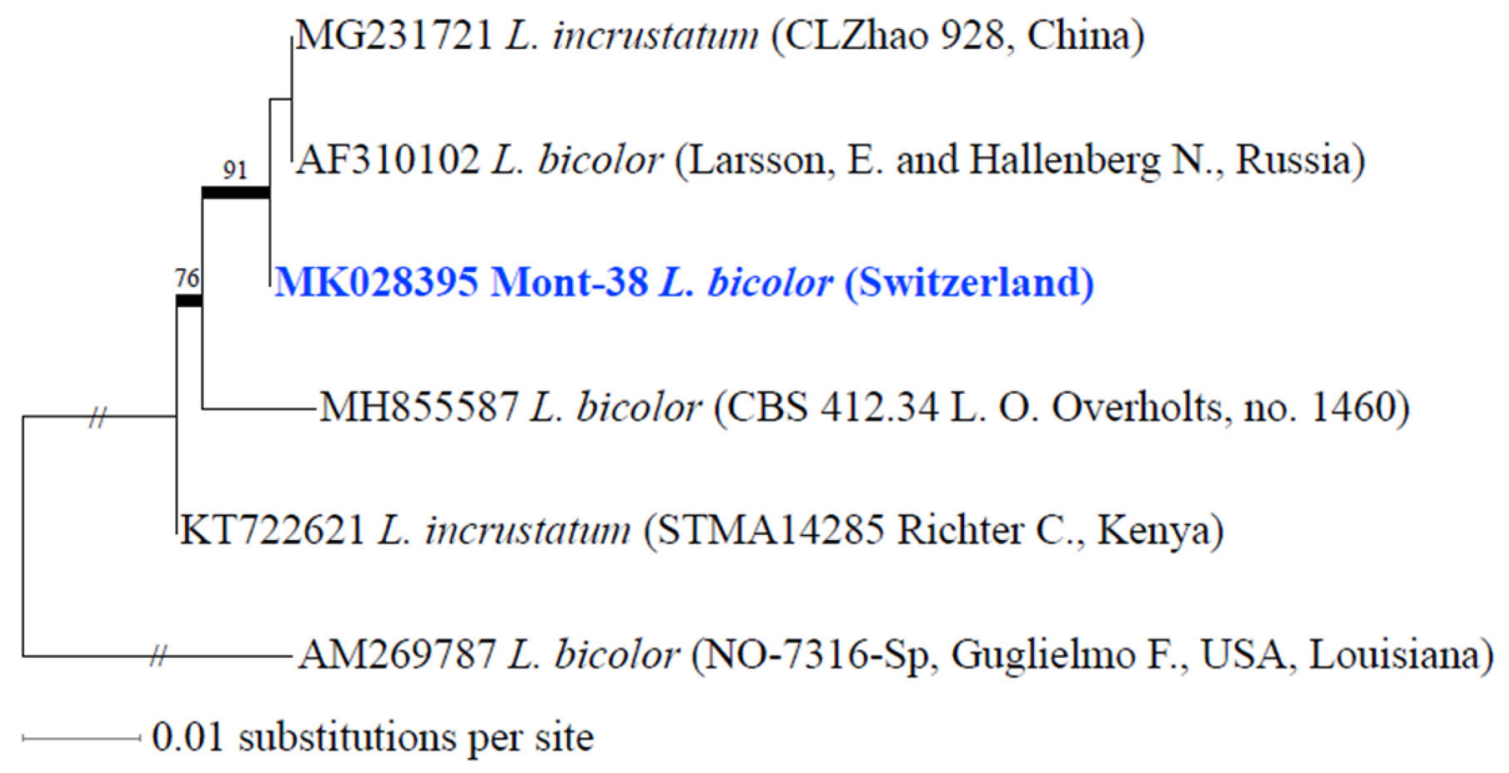

Fig. 8 Most likely tree $(-\ln =1049.35200)$ of ITS sequences for Laxitextum. Sequences sampled in GenBank are in black and the sequence obtained in the present study in bold blue. "//" indicates that branch length has been reduced. Branches in bold received significant bootstrap support $(\geq 70 \%)$ 
phylogenetic analysis suggests that with more than half of the presently deposited names corresponding to misidentifications, including both sequences that were deposited in 2018, the occasional user will now be confronted with top scores in BLAST results where both species are equally represented, whereas the single, but much shorter, authoritative sequence AF310102 remains hidden way down in BLAST results because of low sequence coverage.

\section{Postia alni Niemelä \& Vampola 2001 (see Miettinen et al. 2018)}

This species illustrates a similar aspect of sequenced-based identification as already discussed for Antrodiella, as it demonstrates (BLAST not shown) how the recent description of many cryptic phylogenetic species renders any correct identification impossible without good quality sequence data. Indeed, the Postia-Oligoporus complex is a reputedly difficult taxonomic group both at the species and generic levels (Ortiz-Santana et al. 2013). Polypores belonging to this complex are common brown rotters in most forest habitats, also in Switzerland. Whereas both MB and IF have adopted Oligoporus as the correct generic name for our species (see Online resource 1 and 2), the most recently published phylogeny for this complex (Miettinen et al. 2018) maintains Postia as a separate genus sister to Oligoporus, following Ortiz-Santana et al. (2013), with $P$. alni as one of the core group species.
Because the use of molecular sequence data (Miettinen et al. 2018) suddenly revealed the existence of many 'cryptic' northern hemisphere species, the ARCS-which contained many morphology-based records for Postial Oligoporus species-decided to eliminate all records from this Atlas in the absence of available sequence data to identify these Postia records from Switzerland more reliably. Our sequence therefore suddenly becomes the first positive species identification for the country in this species complex.

\section{Russula inamoena Sarnari, in Sarnari 1994}

Our inventory produced a single sequence (MK028512) for which the two top BLAST scores (Fig. 9) involve sequences with $99 \%$ similarity at $99 \%$ coverage associated with the names $R$. foetens and $R$. putida respectively. In third and fourth position are two sequences for $R$. inamoena, at 100 and $99 \%$ similarity resp., but for $97 \%$ coverage. As the (still unpublished) sequence deposited for $R$. putida (HG798527) was obtained from the holotype, as correctly mentioned in the associated metadata, the choice of the exact name for our sample is problematic and one might be inclined to go for the type sequence, rather than for the $100 \%$ similarity. However, all three non-type sequences have been considered to represent $R$. inamoena in a very recent paper by Swiss and Italian Russula specialists (Melera et al. 2017) and should, therefore, be quite reliable. In the case that $R$. putida is considered conspecific

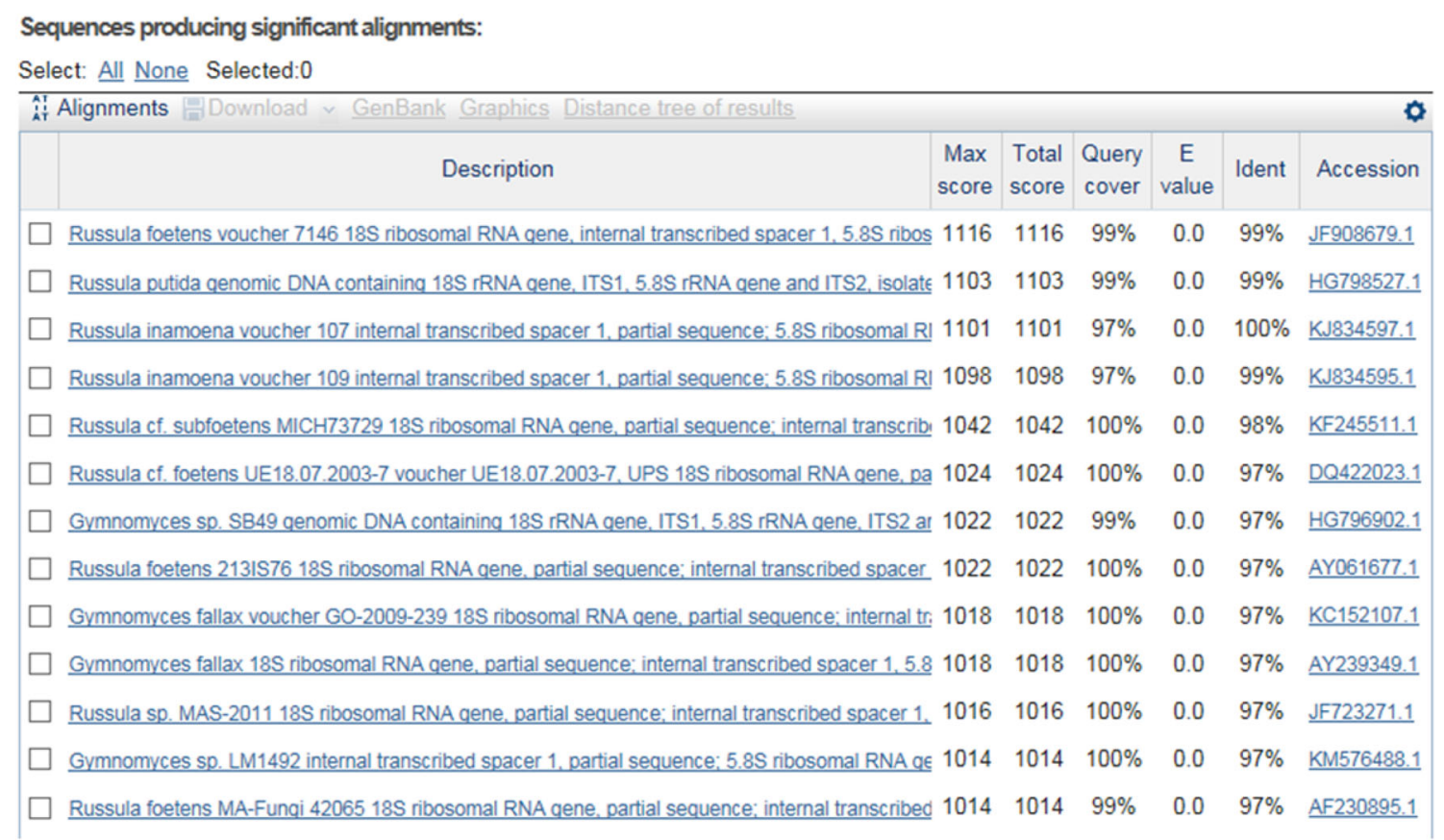

Fig. 9 BLAST top scores for ITS genotype MK028512 For collection Mont-91 = Russula inamoena (see Online Resource 1) 


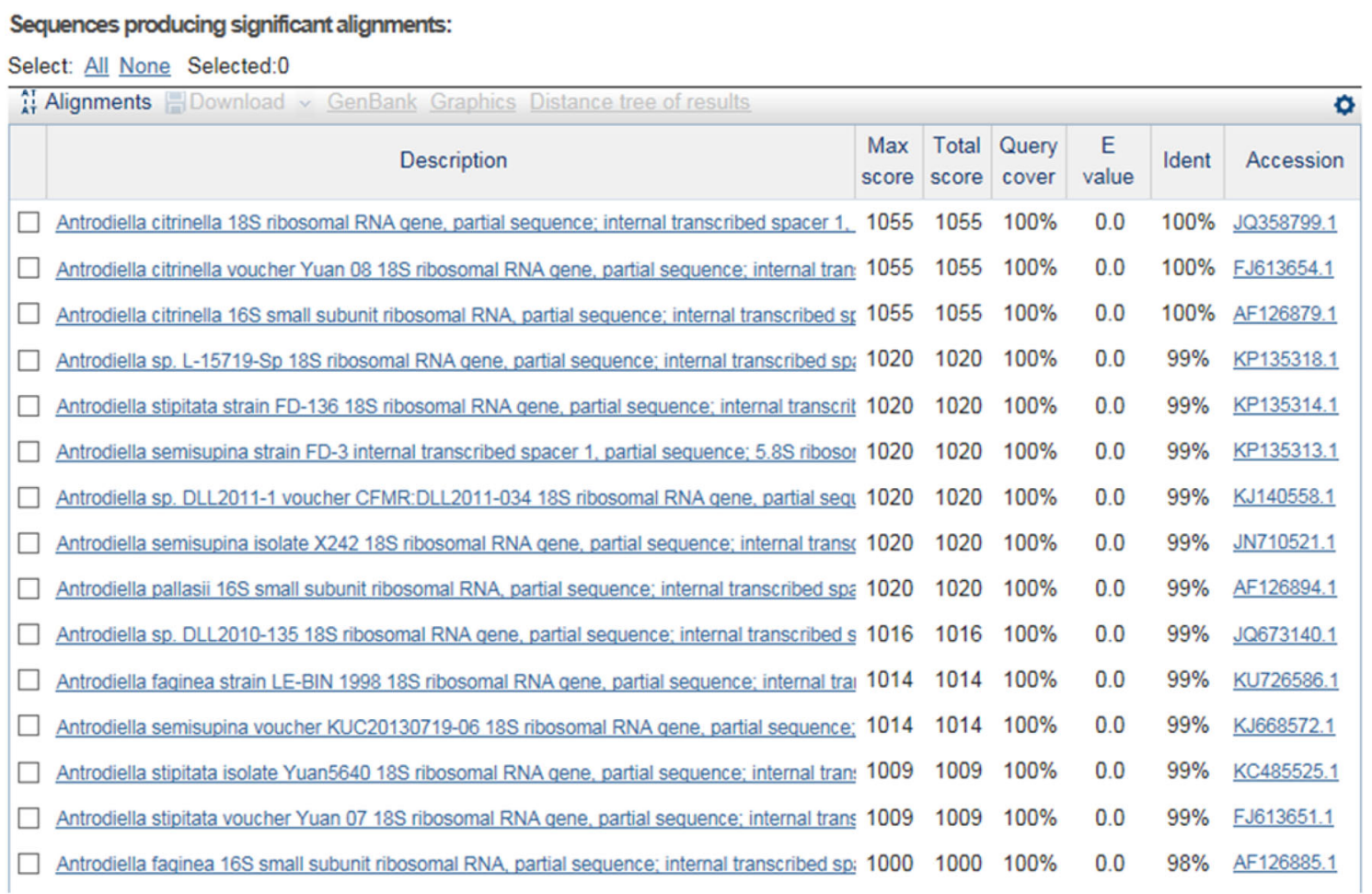

Fig. 10 BLAST top scores for ITS genotype MK028370 for collection Mont-145 = Flaviporus citrinellus (see Online Resource 1)

\begin{tabular}{|c|c|c|c|c|c|c|c|}
\hline \multicolumn{8}{|c|}{ Select: All None Selected:0 } \\
\hline \multicolumn{8}{|c|}{ 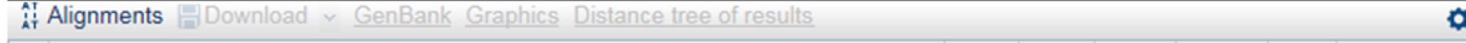 } \\
\hline & Description & $\begin{array}{l}\text { Max } \\
\text { score }\end{array}$ & $\begin{array}{l}\text { Total } \\
\text { score }\end{array}$ & $\begin{array}{l}\text { Query } \\
\text { cover }\end{array}$ & $\begin{array}{c}E \\
\text { value }\end{array}$ & Ident & Accession \\
\hline$\square$ & Hvarophoropsis rufa qenomic DNA containing 18S rRNA gene, ITS1, 5.8S rRNA gene, ITS2, 28ऽ & 1247 & 1247 & $100 \%$ & 0.0 & $99 \%$ & HF951529.1 \\
\hline$\square$ & Hvarophoropsis aurantiaca strain ASIS22496 internal transcribed spacer 1. partial sequence: 5.8 & 941 & 941 & $94 \%$ & 0.0 & $93 \%$ & $\underline{\mathrm{KF} 668314.1}$ \\
\hline$\square$ & Boletales sp. voucher RL019 internal transcribed spacer 1 , partial sequence: $5.8 \mathrm{~S}$ ribosomal RN & 861 & 861 & $85 \%$ & 0.0 & $94 \%$ & $\underline{\mathrm{KY} 826173.1}$ \\
\hline$\square$ & Hvarophoropsis aurantiaca isolate 12 internal transcribed spacer 1 , partial sequence: $5.8 \mathrm{~S}$ ribosc & 861 & 861 & $85 \%$ & 0.0 & $94 \%$ & KM373254.1 \\
\hline$\square$ & Hyarophoropsis aurantiaca isolate 43 internal transcribed spacer 1 , partial sequence: $5.8 \mathrm{~S}$ ribosc & 710 & 710 & $67 \%$ & 0.0 & $95 \%$ & $\underline{\text { KM } 373264.1}$ \\
\hline$\square$ & Hvarophoropsis sp. voucher MES-1300 internal transcribed spacer 1 , partial sequence: $5.8 S$ ribo & 684 & 684 & $65 \%$ & 0.0 & $94 \%$ & $\underline{k Y 462457.1}$ \\
\hline$\square$ & Hvarophoropsis aurantiaca voucher AR09732 partial 18 S ribosomal RNA gene, partial sequence & 675 & 675 & $95 \%$ & 0.0 & $86 \%$ & $\underline{\mathrm{KT} 875014.1}$ \\
\hline$\square$ & Hvarophoropsis aurantiaca genomic DNA containing 18S rRNA gene, ITS1, 5.8S rRNA gene, ITS & 662 & 662 & $86 \%$ & 0.0 & $88 \%$ & HF951531.1 \\
\hline$\square$ & Hyarophoropsis aurantiaca isolate AFTOL-ID 71418 S ribosomal RNA gene, partial sequence; in & 662 & 662 & $86 \%$ & 0.0 & $88 \%$ & AY854067.1 \\
\hline$\square$ & Hvarophoropsis aurantiaca $18 \mathrm{~S}$ rRNA qene, 5.8S rRNA qene, $28 \mathrm{~S}$ rRNA qene, internal transcribi & 662 & 662 & $85 \%$ & 0.0 & $88 \%$ & A 4419202.1 \\
\hline$\square$ & Hyarophoropsis aurantiaca $18 \mathrm{~S}$ rRNA qene, $5.8 \mathrm{~S}$ rRNA gene, $28 \mathrm{~S}$ rRNA gen & 662 & 662 & $86 \%$ & 0.0 & $88 \%$ & A.J419201.1 \\
\hline
\end{tabular}

Fig. 11 BLAST top scores for ITS genotype MK028418 for collection Mont-209 = Hygrophoropsis rufa (see Online Resource 1)

with $R$. inamoena (99\% similarity, resulting from only 3 mutations), the latter name has nomenclatural priority. In either case, our species is a new addition to the fungal inventory of Switzerland. $R$. recondita Melera \& Ostellari, a different species newly described in the latter paper is equally a new (still unrecorded) addition to the ARCS.

\section{Very rare species records for Switzerland}

\section{Antrodiella citrinella Niemelä \& Ryvarden (1983): four reports in the ARCS}

Our inventory produced two identical sequences (MK028370; Fig. 10) for which BLAST top score results 


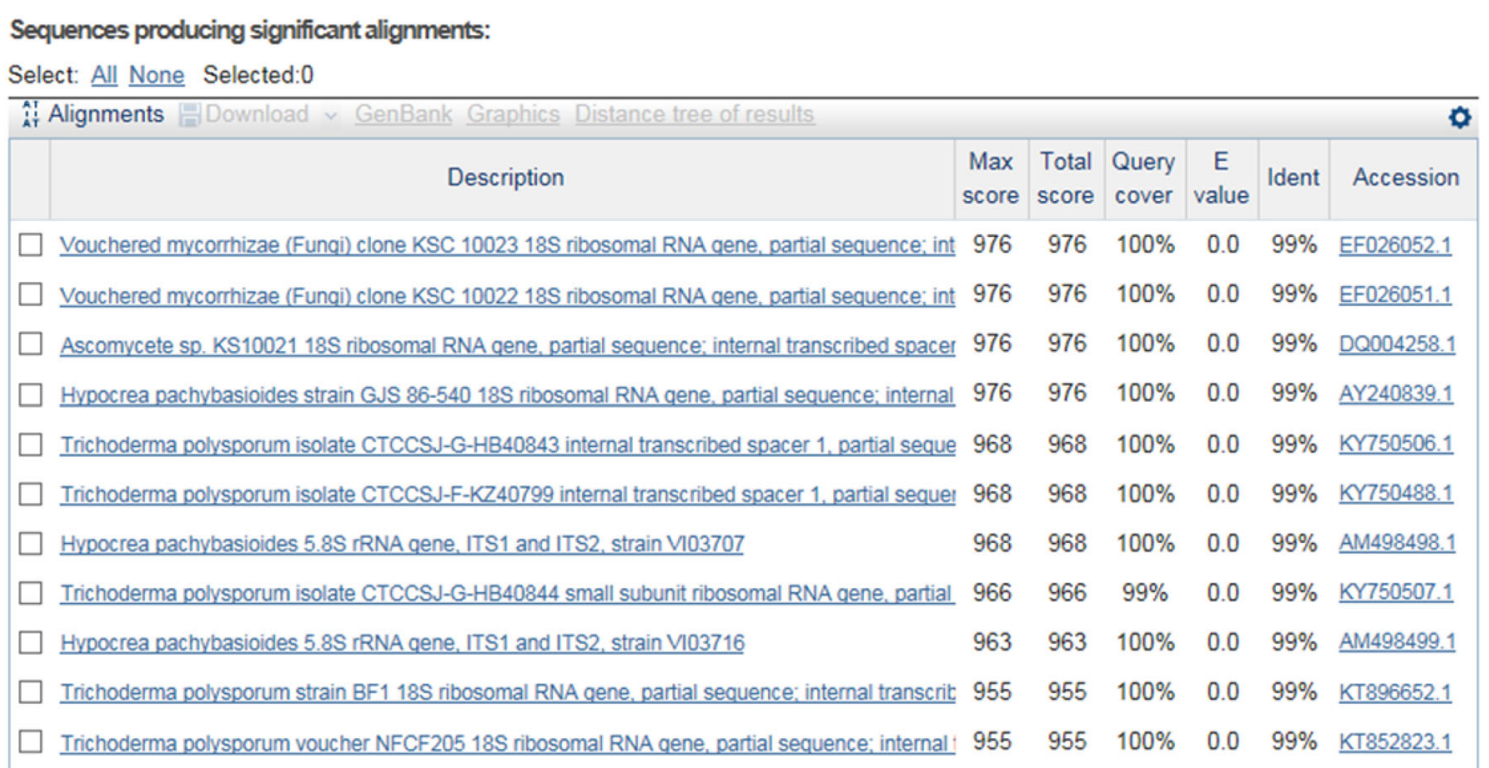

Fig. 12 BLAST top scores for ITS genotype MK028429 for Mont-270 = Hypocrea pachybasioides (see Online Resource 1)

were at $100 \%$ similarity at $100 \%$ coverage with three $A$. citrinella sequences, two of which (Fig. 10, AF126879 and FJ613654) were used in recent phylogenetic revisions of the genus Antrodiella (Johannesson et al. 2000; Yuan 2014). A straightforward identification, were it not that both IF and MB still propose the later recombination (Ginns 1984) into Flaviporus as the current name (see Online Resource 2). For some reason, other apparently correct sequences produced for this species do not show up in BLAST results, e.g. AF126880 corresponding to A. citrinella in the phylogenetic analyses of Yuan (2014)

\section{Hygrophoropsis rufa (D.A. Reid) Knudsen in Knudsen \& Vesterhold (2008): one report in the ARCS}

Our inventory produced a single sequence (MK028418) for which the BLAST top score (Fig. 11) shows 99\% similarity for a $100 \%$ coverage with a sequence deposited as $H$. rufa (Holec and Kolarík 2013). There is no hesitation as to the conspecificity with our sequence as the only other species in Hygrophoropsis (H. aurantiaca) follows at 93\% similarity for a $94 \%$ coverage.

Hygrophoropsis rufa is a widespread but very rare species known from a single or a few collections from several European countries, including one earlier report from Switzerland.
Trichoderma polysporum (Link) Rifai 1969, teleomorph: Hypocrea pachybasioides Yoshim. Doi, in Doi (1972): two reports and no report in the ARCS respectively

This is again an example of a straightforward identification as our sequence (MK028429) blasted against a long list of sequences, all at $99 \%$ similarity (Fig. 12) associated with either the name Trichoderma polysporum or its teleomorph.

A frequent inhabitant of beech and spruce forests in Europe, this nearly cosmopolitan species (northern hemisphere and Oceania) is a parasite of other fungi growing in or on wood. The two records in the Swiss Atlas for that species are located in the canton of Lucerne, both collected in 2014. However its presence has been also reported in the literature with a collection-not reported in the ARCSfrom the vicinity of Davos (Dischmatal, altitude 1500-1700 m, on decorticated wood of Picea sp., 4 Sep 1990, G.J.S. (BPI 1107148; culture G.J.S. 90-28 5 BBA 703105 CBS 112262; see Lu et al. 2004).

\section{Mycena cf. alniphila Robich 2016: one report in the ARCS}

Our pilot study produced a single sequence (MK028460) for which BLAST results (Fig. 13) appeared non-conclusive as several taxa were more or less close, with the closest being Mycena arcangeliana and M. graminicola, both at $98 \%$ similarity for a $98 \%$ coverage. However, further down the list (at position eleven) figured a sequence (JF908482) for M. alniphila with 99\% similarity but for only $50 \%$ coverage, but including the ITS2. Associated metadata in GenBank revealed that it was produced during 


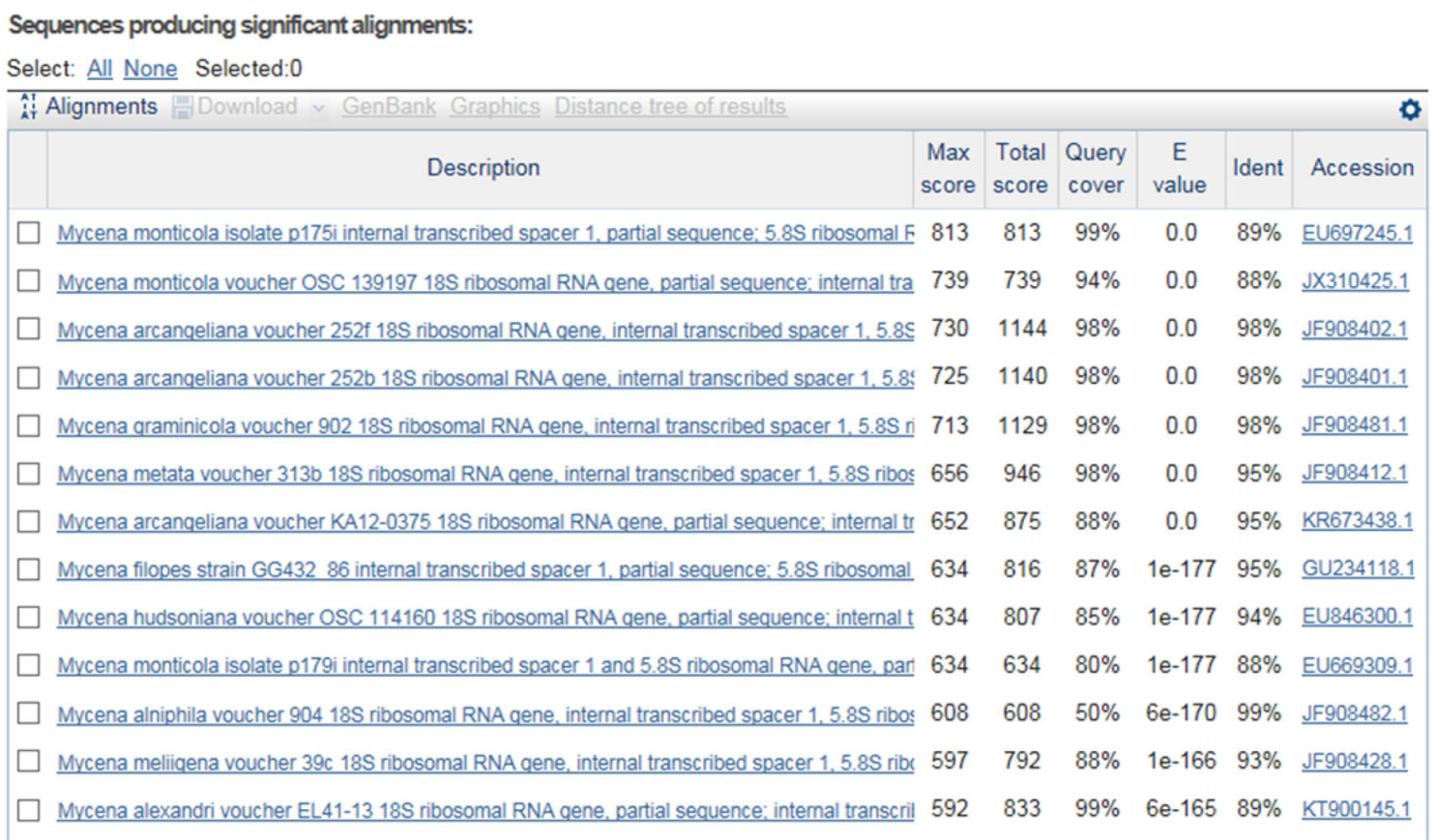

Fig. 13 BLAST top scores for ITS genotype MK028460 for collection Mont-168 = Mycena alniphila (see Online Resource 1)

\begin{tabular}{|c|c|c|c|c|c|c|c|}
\hline \multicolumn{8}{|c|}{ Select: All None Selected:0 } \\
\hline \multicolumn{8}{|c|}{ 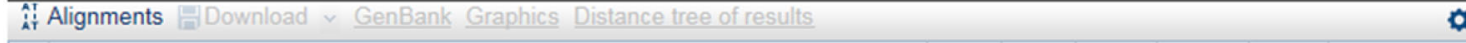 } \\
\hline & Description & $\begin{array}{l}\text { Max } \\
\text { score }\end{array}$ & $\begin{array}{l}\text { Total } \\
\text { score }\end{array}$ & $\begin{array}{l}\text { Query } \\
\text { cover }\end{array}$ & $\begin{array}{c}E \\
\text { value }\end{array}$ & Ident & Accession \\
\hline$\square$ & Pluteus tricuspidatus voucher $1714418 \mathrm{~S}$ ribosomal RNA gene, internal transcribed spacer 1,5 & 1142 & 1142 & $100 \%$ & 0.0 & $100 \%$ & $\underline{\mathrm{JF} 908634.1}$ \\
\hline$\square$ & Pluteus atromarqinatus isolate AFTOL-ID 1340 internal transcribed spacer $1,5.8 \mathrm{~S}$ ribosomal $R$ & 1129 & 1129 & $98 \%$ & 0.0 & $100 \%$ & $\underline{\mathrm{DQ} 494687.1}$ \\
\hline$\square$ & Pluteus pseudorobertii isolate Moser $51 \quad 100$ (Holotype) internal transcribed spacer 1, partial se & 1123 & 1123 & $98 \%$ & 0.0 & $100 \%$ & $\underline{\mathrm{KJ} 009769.1}$ \\
\hline$\square$ & Pluteus atromarqinatus voucher $12918 \mathrm{~S}$ ribosomal RNA gene, internal transcribed spacer 1,5 & 1136 & 1136 & $100 \%$ & 0.0 & $99 \%$ & $\underline{\mathrm{JF} 908601.1}$ \\
\hline$\square$ & Pluteus atromarginatus voucher AN7518S ribosomal RNA gene, partial sequence; internal tran & 1136 & 1136 & $100 \%$ & 0.0 & $99 \%$ & HM562061.1 \\
\hline$\square$ & Pluteus atromarginatus voucher $\mathrm{A}=7618 \mathrm{~S}$ ribosomal RNA gene, partial sequence; internal tran & 1136 & 1136 & $100 \%$ & 0.0 & $99 \%$ & $\underline{\mathrm{HM}} 562040.1$ \\
\hline$\square$ & Pluteus atromarqinatus voucher LE $24608118 \mathrm{~S}$ ribosomal RNA gene, partial sequence; intern; & 1131 & 1131 & $100 \%$ & 0.0 & $99 \%$ & $\underline{F J 774075.1}$ \\
\hline$\square$ & Pluteus atrofibrillosus isolate ECV 4207 internal transcribed spacer 1, partial sequence: $5.8 \mathrm{~S}$ rit & 1094 & 1094 & $98 \%$ & 0.0 & $99 \%$ & $\underline{\mathrm{KJ} 009773.1}$ \\
\hline$\square$ & Pluteus atrofibrillosus isolate ECV4169 internal transcribed spacer 1, partial sequence: $5.8 \mathrm{~S}$ rit & 1086 & 1086 & $97 \%$ & 0.0 & $99 \%$ & $\underline{\mathrm{KJ} 009775.1}$ \\
\hline
\end{tabular}

Fig. 14 BLAST top scores for ITS genotype MK028496 for collection Mont-114 = Pluteus atromarginatus (see Online Resource 1)

a barcoding project of the Vienna Herbarium (Osmundson et al. 2013), which at first sight does not seem to be a very reliable source for identification as herbarium specimens are frequently filed under provisional identifications until they become part of a critical revision. Upon checking the supplementary material of the latter publication, it appeared that the collector of that specimen was Robich, who is not only the author of the species and curator of the Vienna Herbarium, but also one of Europe's leading Mycena experts. When checking the references of the holotype for $M$. alniphila on $\mathrm{MB}$, it appeared that this partial ITS sequence, although not annotated as such, was obtained from the holotype. As a consequence, M. alniphila-for which there exists only a single report from Switzerland since its description-might well be correct name for our sample, but without the ITS1 this remains questionable as most of the sequence variation in Mycena species is located in that region (for more examples and aspects related to Mycena identification, see "Mycena" section below). 


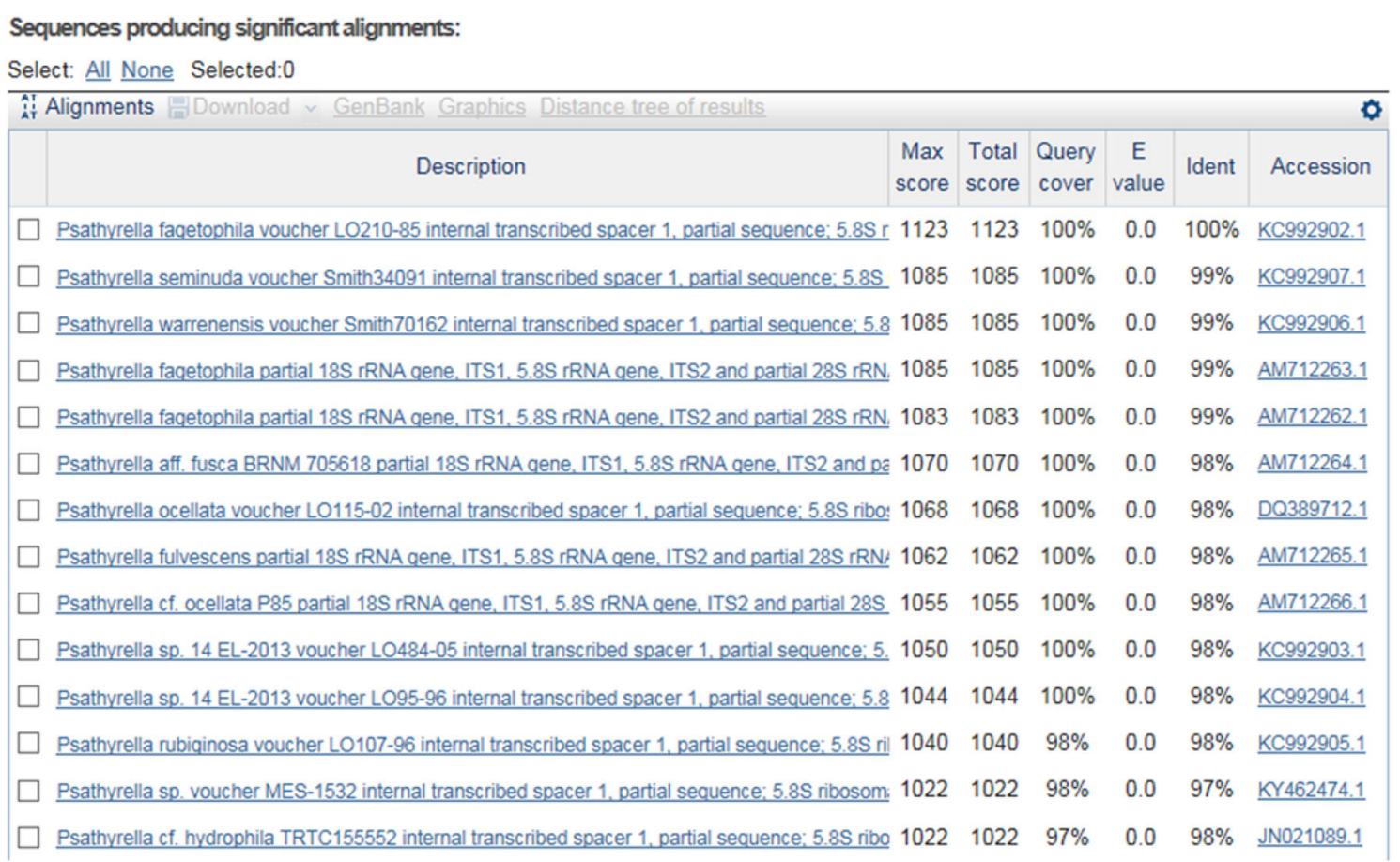

Fig. 15 BLAST top scores for ITS genotype MK028505 for collection Mont-206 = Psathyrella fagetophila (see Online Resource 1)

\section{Pluteus pseudorobertii M.M. Moser 1953: six reports in the ARCS, P. atromarginatus (Konrad) Kühner (1935)- common in the ARCS or P. tricuspidatus Velen. (Velenovský 1939)—absent from the ARCS}

BLAST results of our sequence MK028496 (Fig. 14) confront one with at least three competing names in the top three hits, all at $100 \%$ similarity: $P$. atromarginatus (Singer) Kühner (1935), P. tricuspidatus Velen. (1939) and $P$. pseudorobertii, with the latter sequence (KJ009769) being obtained from the holotype. Since all three names are given in MB as current name for the individual species, $P$. pseudorobertii was initially adopted as correct name and it represented a rare record for Switzerland with only six collections reported so far in the ARCS.

However, when diving deeper in the various taxonomic publications on this genus, one learns that both $P$. tricuspidatus and $P$. pseudorobertii have recently been considered to be synonyms of $P$. atromarginatus on molecular basis (Justo et al. 2014). This reduces our record to a very common, ubiquitous species for Switzerland. In the Swiss Atlas (which usually follows IF), as wel as in MB, all three species are still considered independant species (Online Resource 2).
Psathyrella fagetophila Örstadius \& Enderle (Enderle 1996): two reports in the ARCS

This typical associate of Fagus is a rare fungus in Europe represented by only two known collections in Switzerland. At Montricher we had collected morphologically very similar fruiting bodies at five occasions, but we obtained two slightly different genotypes.

The first genotype (MK028505), represented by four samples at Montricher, exhibits $100 \%$ similarity with GenBank sequence KC992902 (from Örstadius et al. 2015; Fig. 15). Although the associated metadata mention that sequence KC992902 was obtained from the type, it is not highlighted as 'type material' in GenBank, nor are any of the ca. 60 additional holotype sequences generated in the latter study highlighted as type sequences in GenBank. There are two more sequences for P. fagetophila among BLAST top scores (AM712262 and AM712263), although deposited as $P$. fagetophila, the associated metadata still mention the name of $P$. murcida (Vasǔtová et al. 2008).

The second and third top scores, for $P$. seminuda A. H. Sm. (six C-T transitions and one A-G transition) and $P$. warrenensis A. H. Sm. respectively, might represent conspecific or sister taxa in the United States. Interestingly, both these American sequences have also been obtained from the holotype material (again not highlightled as such in GenBank) and, if conspecific with the European material, these American names have priority. 
Sequences producing significant alignments:

Select: All None Selected:0

\begin{tabular}{|c|c|c|c|c|c|c|c|}
\hline \multicolumn{8}{|c|}{ î̀i Alignments 1 Download $\vee$ GenBank Graphics Distance tree of results } \\
\hline & Description & $\begin{array}{l}\text { Max } \\
\text { score }\end{array}$ & $\begin{array}{l}\text { Total } \\
\text { score }\end{array}$ & $\begin{array}{l}\text { Query } \\
\text { cover }\end{array}$ & $\begin{array}{c}E \\
\text { value }\end{array}$ & Ident & Accession \\
\hline$\square$ & Sistotrema sernanderi isolate olrim $21618 \mathrm{~S}$ ribosomal RNA gene, oartial sequence: internal tran & 990 & 990 & $96 \%$ & 0.0 & $99 \%$ & AY805624.1 \\
\hline$\square$ & Burgoa verzuoliana CBS 131.38 ITS reqion; from TYPE & 695 & 695 & $100 \%$ & 0.0 & $89 \%$ & 5334.1 \\
\hline$\square$ & Aqaricomycetes sp. $20 \mathrm{KY} 0618 \mathrm{~S}$ ribosomal RNA, partial sequence; internal transcribed s: & 688 & 688 & $100 \%$ & 0.0 & $89 \%$ & $\underline{\mathrm{JX} 270560.1}$ \\
\hline$\square$ & Sistotrema eximum ITS1, 5.8S rRNA gene and ITS2, isolate FCUG2342 & 595 & 595 & $71 \%$ & $4 e-166$ & $94 \%$ & AM259218.1 \\
\hline$\square$ & Sistotrema sernanderi strain KHL8576 5.8S ribosomal RNA gene, partial sequence; internal trar & 568 & 568 & $56 \%$ & $8 e-158$ & $99 \%$ & 476.1 \\
\hline$\square$ & Burqoa anomala genes for $18 \mathrm{~S}$ rRNA, ITS1, 5.8S rRNA, ITS2, 28S rRNA, partial and complete: & 540 & 540 & $87 \%$ & $2 e-149$ & $87 \%$ & $\underline{\mathrm{AB} 972783.1}$ \\
\hline$\square$ & genes for $18 \mathrm{~S}$ rRNA, ITS1, 5.8S rRNA, ITS2, 28S rRNA, partial and complete: & 540 & 540 & $87 \%$ & $2 e-149$ & $87 \%$ & AB972780.1 \\
\hline$\square$ & Burgoa anomala genes for $18 \mathrm{~S}$ rRNA, ITS1,5.8S rRNA, ITS2 and $28 \mathrm{~S}$ rRNA, partial and compls & 536 & 536 & $87 \%$ & $2 e-148$ & $87 \%$ & $\underline{\underline{L} C 228688.1}$ \\
\hline$\square$ & Burcoa anomala genes for $18 \mathrm{~S}$ rRNA. ITS1,5.8S rRNA, ITS2, 28S rRNA, partial and complete: & 536 & 536 & $87 \%$ & $2 e-148$ & $87 \%$ & AB972782.1 \\
\hline$\square$ & Burgoa anomala genes for $18 \mathrm{~S}$ rRNA, ITS1,5.8S rRNA, ITS2, 28S rRNA, partial and complete: & 532 & 532 & $87 \%$ & $3 e-147$ & $87 \%$ & $\underline{A B 972799.1}$ \\
\hline$\square$ & Aqaricomycetes sp. VL291B $18 \mathrm{~S}$ ribosomal RNA gene, internal transcribed spacer 1.5.8S ribos & 446 & 446 & $87 \%$ & $4 e-121$ & $83 \%$ & $\underline{\mathrm{JF}} 440568.1$ \\
\hline$\square$ & Burqoa verzuoliana strain ATCC 2404025 S large subunit ribosomal RNA gene, partial sequenc & 427 & 427 & $57 \%$ & $1 e-115$ & $91 \%$ & $\underline{\mathrm{DQ} 915475.1}$ \\
\hline$\neg$ & Sinta & 392 & 392 & $64 \%$ & $5 e-105$ & $87 \%$ & KM576416.1 \\
\hline
\end{tabular}

Fig. 16 BLAST top scores for ITS genotype MK028517 for collection Mont-7 = Sistotrema sernanderi (see Online Resource 1)

\begin{tabular}{|c|c|c|c|c|c|c|c|}
\hline & All None Selected:0 & & & & & & \\
\hline \multicolumn{8}{|c|}{ 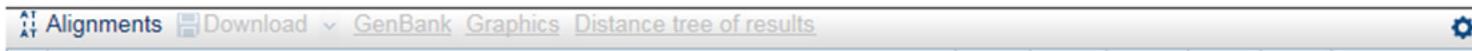 } \\
\hline & Description & $\begin{array}{l}\text { Max } \\
\text { score }\end{array}$ & $\begin{array}{l}\text { Total } \\
\text { score }\end{array}$ & $\begin{array}{l}\text { Query } \\
\text { cover }\end{array}$ & $\begin{array}{c}E \\
\text { value }\end{array}$ & Ident & Accession \\
\hline$\square$ & Cortinarius cotoneus voucher OS579 internal transcribed spacer 1 , partial sequence: $5.8 \mathrm{~S}$ ribosor & 1118 & 1118 & $99 \%$ & 0.0 & $99 \%$ & $\underline{\mathrm{KC} 842423.1}$ \\
\hline$\square$ & Cortinarius cotoneus voucher HMAS: 254210 internal transcribed spacer 1, partial sequence; $5.8 \mathrm{~S}$ & 1116 & 1116 & $100 \%$ & 0.0 & $99 \%$ & $\underline{\mathrm{K} \times 513580.1}$ \\
\hline$\square$ & Cortinarius cotoneus voucher HMAS:254214 internal transcribed spacer 1 , partial sequence; $5.8 \mathrm{~S}$ & 1116 & 1116 & $100 \%$ & 0.0 & $99 \%$ & $\underline{\mathrm{KX} 513579.1}$ \\
\hline$\square$ & Cortinarius cotoneus voucher HMAS: 260331 internal transcribed spacer 1 , partial sequence: $5.8 \mathrm{~S}$ & 1096 & 1096 & $100 \%$ & 0.0 & $99 \%$ & $\underline{K \times 513578.1}$ \\
\hline$\square$ & Cortinarius & 1088 & 1088 & $100 \%$ & 0.0 & $99 \%$ & 597.1 \\
\hline$\square$ & Cortinarius flavifolius strain TLB11 (TENN) internal transcribed spacer 1, partial sequence: $5.8 \mathrm{~S} \mathrm{ri}$ & 1083 & 1083 & $98 \%$ & 0.0 & $99 \%$ & $\underline{\text { MF686506.1 }}$ \\
\hline$\square$ & Cortinarius cotoneus IB19860257 18S ribosomal RNA gene, partial sequence; internal transcribec & 1011 & 1011 & $93 \%$ & 0.0 & $99 \%$ & AF389168.1 \\
\hline$\square$ & Cortinarius venetus voucher HMAS: 274611 internal transcribed spacer 1 , partial sequence: $5.8 \mathrm{~S}$ I & 974 & 974 & $100 \%$ & 0.0 & $95 \%$ & $\underline{\mathrm{KX} 513584.1}$ \\
\hline$\square$ & Cortinarius squamivenetus H 6001874 ITS reqion; from TYPE material & 972 & 972 & $100 \%$ & 0.0 & $95 \%$ & $\underline{\text { NR } 131864.1}$ \\
\hline$\square$ & Cortinarius flavifolius MTS4789 18S ribosomal RNA qene, partial sequence; internal transcribeds & 972 & 972 & $100 \%$ & 0.0 & $95 \%$ & $\underline{\text { AF389166.1 }}$ \\
\hline$\square$ & Cortinarius venetus voucher HMAS: 274352 internal transcribed spacer 1 , partial sequence: $5.8 \mathrm{~S}$ I & 968 & 968 & $100 \%$ & 0.0 & $95 \%$ & $\underline{\mathrm{KX} 513585.1}$ \\
\hline$\square$ & Cortinarius venetus voucher HMAS: 268596 internal transcribed spacer 1, partial sequence: $5.8 \mathrm{~S} \mathrm{I}$ & 963 & 963 & $100 \%$ & 0.0 & $95 \%$ & $\underline{\mathrm{KX} 513586.1}$ \\
\hline$\square$ & nal & 961 & 961 & $100 \%$ & 0.0 & $95 \%$ & KJ 705128.1 \\
\hline
\end{tabular}

Fig. 17 BLAST top scores for ITS genotype MK028384 for collection Mont-87 = Cortinarius cotoneus (see Online Resource 1)

Our second genotype (MK028506) obtained 99\% similarity with the same top score hits but differs in merely two A-G transitions from the holotype sequence for $P$. fagetophila (KC992902, identity: 606/608, gaps: 0/608).

We therefore adopt the name $P$. fagetophila as provisional name for all five of our samples, but the group clearly is in need of further clarification as to the correct application of names. 
Fig. 18 Most likely tree $(-\ln =1121.03266)$ obtained from phylogenetic analysis of an alignment of ITS for eleven Cortinarius sequences (length $=624$ char). Branches significantly supported ( $\geq 70 \%$ ) are in bold and bootstrap values are indicated above the branches. The sequence newly produced for this study is highlighted in blue and sequences for the taxa discussed are highlighted in red

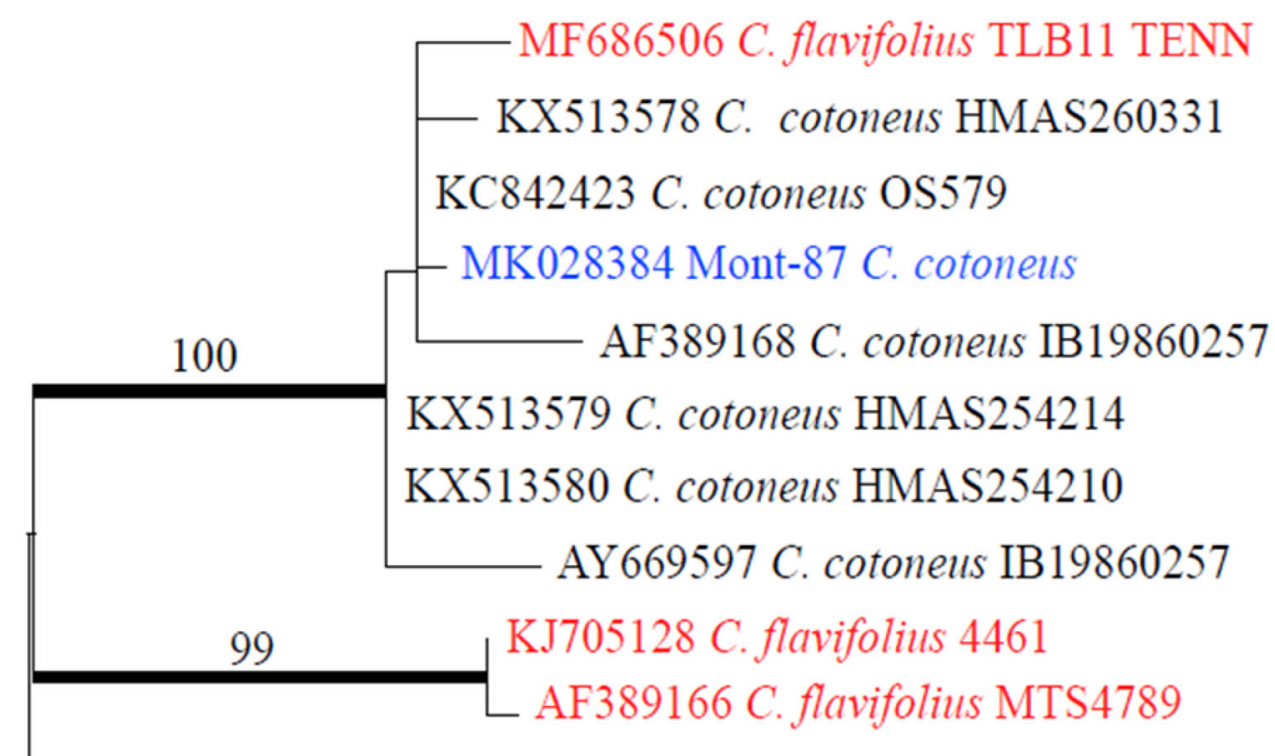

KX513584 C. venetus

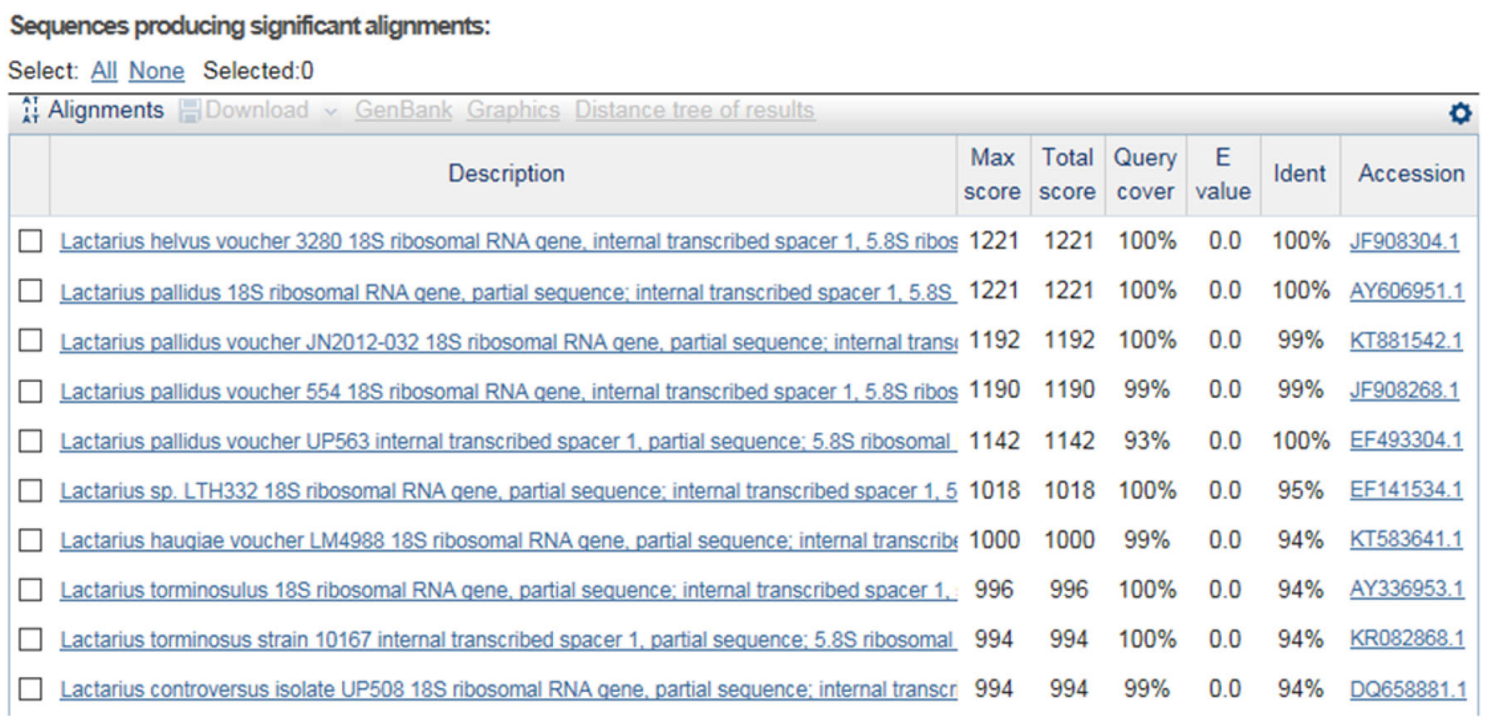

Fig. 19 BLAST top scores for ITS genotype MK028449 for collection Mont-84 = Lactarius pallidus (see Online Resource 1)

\section{Sistotrema sernanderi (Litsch.) Donk in Donk (1956): five reports in the ARCS}

The sequence-based identification (Fig. 16) of the single sample at Montricher (sequence MK028517) was possible thanks to a sequence (AY805624) that was produced during an ecological study (Menkis et al. 2004), but for which one of the authors is K-H Larsson, a well-known specialist of resupinate fungi. We therefore assume that the name is correct.
This species is not specific for our Swiss beech habitat as it grows on dead wood of various conifers and broadleaved trees. Five additional reports, have been published recently for Switzerland (Martini 2016) but are not mentioned in the Swiss Atlas. 


\section{Indicator species for Switzerland}

\section{Cortinarius cotoneus Fr. 1838 (vulnerable species)}

Our ITS sequence MK028384 (Fig. 17) was 99\% similar with several sequences for C. cotoneus with 99-100\% coverage but also for a recently deposited (October 2017) and unpublished sequence for C. flavifolius with $98 \%$ coverage. Further down in BLAST results (position 10) was another sequence for $C$. flavifolius, which exhibited only $95 \%$ similarity but $100 \%$ coverage with our sequence.

To verify the correct identity of our sequence, we decided to import from GenBank all the sequences available for these two species, to align them and to run a phylogenetic analysis using as the outgroup the first BLAST top score sequence for a different Cortinarius after both forementioned species, which was here the case for $C$. venetus. Results of our phylogenetic analyses showed that the recently deposited sequence MF686506 for C. flavifolius nested in the $C$. cotoneus clade with maximum support (BS $=100 \%$, Fig. 18) while the two other sequences for $C$. flavifolius were clearly separated (BS = 99\%) from $C$. cotoneus. We consequently adopted the name $C$. cotoneus for our Montricher sequence, because two of the deposited GenBank sequences for this species were produced in taxonomic papers by known Cortinarius experts: AF389168 by Peintner et al. (2004) and AY669597 by Garnica et al. (2005).

\section{Lactarius helvus (Fr.) Fr. (vulnerable species) appeared to be the common L. pallidus (Pers.) Pers. (Persoon 1797)}

BLAST top score results for our ITS sequence MK028449 (Fig. 19) involved two sequences at $100 \%$ similarity for
100\% coverage; one deposited as Lactarius helvus (Fr.) Fr., considered as indicator species in Switzerland, the other as L. pallidus, which is a very common milk cap in the country. As the first BLAST top score (L. helvus, JF908304) had been deposited by Osmundson et al. (2013) in a recent DNA barcode study, this name was initially adopted, also because Lactarius sequences in that paper had reportedly been checked by a known Lactarius expert (U. Eberhardt, see acknowledgements in Osmundson et al.).

However, as L. helvus and L. pallidus are morphologically very different species, it seemed unlikely that the Venice herbarium would file $L$. pallidus specimens as $L$. helvus. Indeed, a strict associate of Fagus, the common $L$. pallidus has a strongly viscid, pale cream-coloured cap and a weak fruity smell, whereas the rare L. helvus, growing usually in Sphagnum near Picea or Pinus, rarely Betula, has a felty-squamulose, ochraceous-buff-coloured cap and a distinct spicy smell of fenugreek.

In our BLAST results, the top score for L. pallidus (AY606951) was followed by other sequences annotated as belonging to the same species. This top score sequence had been generated in a phylogenetic study on Lactarius (Eberhardt and Verbeken 2004). On the other hand, other sequences deposited as L. helvus in GenBank (and equally generated in phylogenetic studies on Lactarius, e.g. Wisitrassameewong et al. 2016), did not appear until after at least the first 250 BLAST top scores for our sequence. It was therefore clear that sequence JF908304 from Osmundson et al. (2013) was-quite incomprehensiblyassociated with the wrong taxon name and that we had collected the common L. pallidus.

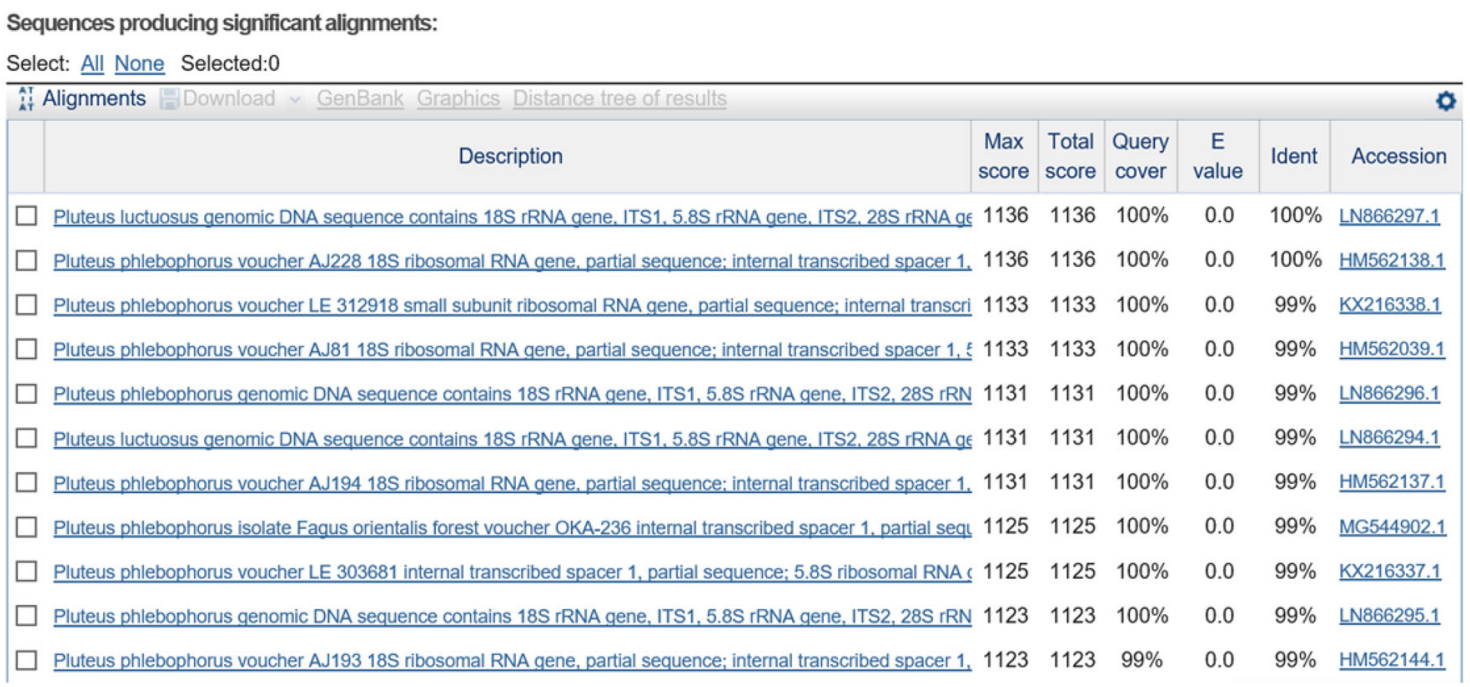

Fig. 20 BLAST top scores for ITS genotype MK028497 for collection Mont-176 = Pluteus phlebophorus (see Online Resource 1) 


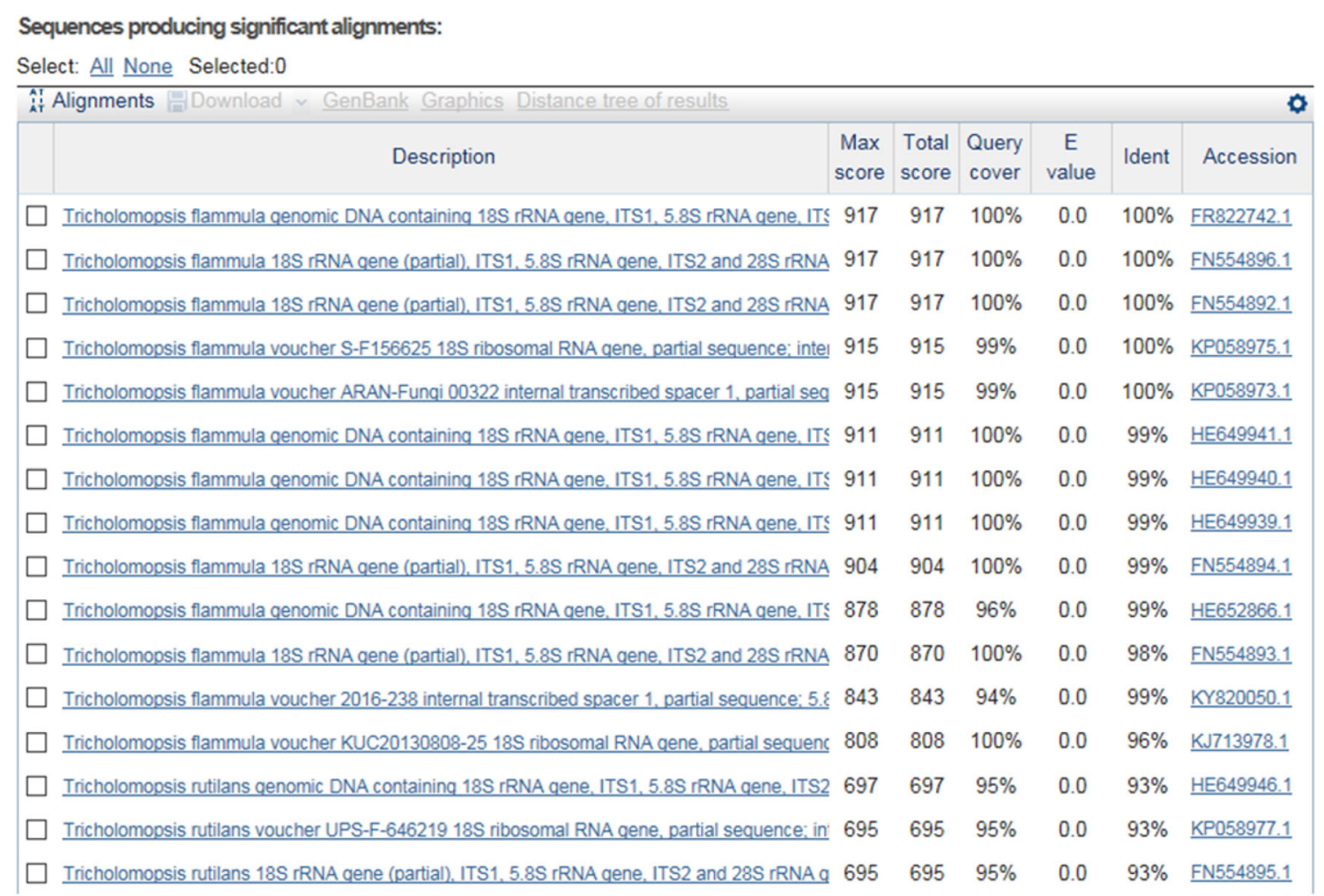

Fig. 21 BLAST top scores for ITS genotype MK028524 for collection Mont-83 = Tricholomopsis flammula (see Online Resource 1)

\section{Pluteus phlebophorus (Ditmar) P. Kumm. (nearly threatened species)}

BLAST of our sequence MK028497 (Fig. 20) resulted in two top scores at $100 \%$ similarity for $100 \%$ coverage, one for Pluteus luctuosus (LN866297) and one for P. phlebophorus (HM562138), followed by several sequences at
$99 \%$, also for $100 \%$ coverage, for either of these two species.

Our specimen misses the typical brown gill edge of $P$. luctuosus. Also a recent publication by Sevcikova and Borovicka (2015) suggested a probable synonymy of these two species based on a phylogenetic analysis of Czech

\begin{tabular}{|c|c|c|c|c|c|c|c|}
\hline \multicolumn{8}{|c|}{ Select: All None Selected:0 } \\
\hline \multicolumn{8}{|c|}{ 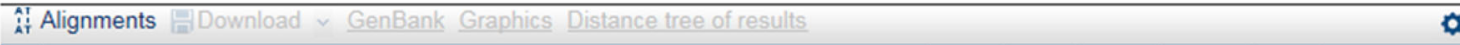 } \\
\hline & Description & $\begin{array}{l}\text { Max } \\
\text { score }\end{array}$ & $\begin{array}{l}\text { Total } \\
\text { score }\end{array}$ & $\begin{array}{l}\text { Query } \\
\text { cover }\end{array}$ & $\begin{array}{c}\mathrm{E} \\
\text { value }\end{array}$ & Ident & Accession \\
\hline$\square$ & Pluteus Sp. KA12-0396 internal transcribed spacer 1, partial sequence: $5.8 \mathrm{~S}$ ribosomal RNA ger & 573 & 753 & $73 \%$ & $2 e-159$ & $93 \%$ & $\underline{\text { KR673451.1 }}$ \\
\hline$\square$ & Clitocybe ulmicola TENN 029208 ITS region; from TYPE material & 368 & 447 & $52 \%$ & $1 e-97$ & $89 \%$ & $\underline{\text { NR } 119887.1}$ \\
\hline$\square$ & Tricholomataceae sp. 29 YS-2010 internal transcribed spacer 1, partial sequence: $5.8 \mathrm{~S}$ ribosom & 363 & 363 & $51 \%$ & $5 e-96$ & $85 \%$ & HM007087.1 \\
\hline$\square$ & Clitocybula aff. lacerata GRSM77072 18S ribosomal RNA gene, partial sequence; internal trans & 353 & 353 & $51 \%$ & $3 e-93$ & $85 \%$ & $\underline{F J 596916.1}$ \\
\hline$\square$ & Clitocybula sp. TENN60306/TFB12058 18 S ribosomal RNA qene, partial sequence; internal trar & 353 & 353 & $51 \%$ & $3 e-93$ & $85 \%$ & EU623637.1 \\
\hline$\square$ & Clitocybula sp. FCME25069 clone c3 18 S ribosomal RNA gene, partial sequence; internal trans! & 344 & 344 & $51 \%$ & $2 e-90$ & $85 \%$ & $\underline{E} \underline{623636.1}$ \\
\hline$\square$ & Clitocybula sp. FCME25069 clone c1 18 S ribosomal RNA gene, partial sequence; internal trans: & 339 & 339 & $51 \%$ & $8 e-89$ & $84 \%$ & EU623635.1 \\
\hline$\square$ & Trogia venenata strain $X Y 14$ internal transcribed spacer 1 , partial sequence: $5.8 \mathrm{~S}$ ribosomal RN & 333 & 333 & $45 \%$ & $4 e-87$ & $87 \%$ & $\underline{\mathrm{KT} 968071.1}$ \\
\hline$\square$ & Trogia venenata $18 \mathrm{~S}$ ribosomal RNA qene, partial sequence; internal transcribed spacer $1.5 .8 \mathrm{E}$ & 331 & 331 & $44 \%$ & $1 e-86$ & $87 \%$ & $\underline{\mathrm{KX} 268227.1}$ \\
\hline$\square$ & Troqia venenata strain $T C 2-28$ internal transcribed spacer 1 , partial sequence: $5.8 S$ ribosomal F & 331 & 331 & $44 \%$ & $1 e-86$ & $87 \%$ & $\underline{\mathrm{KT} 968080.1}$ \\
\hline
\end{tabular}

Fig. 22 BLAST top scores for ITS genotype MK028414 for collection Mont-291 = Hydropus subalpinus (genotype 1; see Online Resource 1) 
collections. We consequently adopted $P$. phlebophorus for the Mont-176 collection (Online Resources 1, 2).

\section{Pluteus pseudorobertii (endangered species)}

Critical reexamination of BLAST results and recent literature have shown (see "Pluteus pseudorobertii M.M. Moser 1953: six reports in the ARCS, $P$. atromarginatus (Konrad) Kühner (1935)—common in the ARCS or $P$. tricuspidatus Velen. (Velenovský 1939)—absent from the ARCS" section) that this species is a synonym of $P$. atromarginatus (Singer) Kühner (1935), a very common species in Switzerland based on the ARCS.

\section{Tricholomopsis flammula Métrod ex Holec in Holec (2009) (vulnerable species)}

BLAST of our sequence MK028524 (Fig. 21) resulted in 13 top scores at $98-100 \%$ similarity for $99-100 \%$ coverage, and all deposited in GenBank as Tricholomopsis flammula, while sequences for the closest species, T. rutilans, started only at $93 \%$ similarity. A straightforward identification.

\section{Problematic issues with common genera}

Finally, we would also like to comment on some genera that represented a large amount of generated sequences in our pilot study, but for which interpretation of BLAST results presented major problems: Hydropus (22 sequences, 4 genotypes) and Mycena (33 sequences, 25 genotypes), together representing ca $20 \%$ of obtained sequences in this pilot study.

\section{Hydropus}

During this study, we obtained perfect, near-identical ITS sequences for 21 samples (three genotypes differed slightly from all others as collection 291 [MK028414] had one deletion in a $\mathrm{C}$ and a $\mathrm{T}$ repeat compared to collection 312 [MK028415] and 323 [MK028416], while the latter sample had an additional AT transversion compared to the two other sequences). To our surprise, however, it appeared impossible in 2017 to identify this apparently common species by BLAST, not even to the level of genus or family.

When looking at BLAST results (Fig. 22) it can easily be seen that coverage drops immediately to $45-52 \%$ as the ITS1 gives no result at all. The only GenBank deposit that gives a significant hit (93\% similarity for $73 \%$ coverage) is associated with a Pluteus sp. (Kim et al. 2015) and represents a morphology-based misidentification. Why these authors maintained this same name for their sequence- based identification (as they compare both types of identification) is a mystery because a BLAST of their sequence (KR673451) results in a Hydropus species for the three top hits (although again only for $48-61 \%$ coverage) and included various Tricholomataceae further down the list, but no Pluteus. All of these Montricher sequences would have remained unnamed, if it were not that one of us (GE) could identify the species immediately from field pictures as Hydropus subalpinus (Fig. 2).

Our sampling also generated an additional Hydropus sequence (MK028417 from collection Mont-294) with a similar BLAST result. This sequence is of very high quality, aligns very well on the Hydropus subalpinus sequences but differs significantly (671-673/687 [98\%], gaps 4-5/687) from the three ITS genotypes above (99\% similarity between them, Online Resource 1) using the blastn-suite-2sequences tool available in GenBank to align pairs of these sequences. Sequence MK028417 might therefore correspond to a different Hydropus species even if this collection is morphologically very similar to $H$. subalpinus.

Since we first performed our BLAST searches (October 2017), two sequences were newly deposited for Hydropus species (Online Resource 1): one for $H$. subalpinus (MF039248) and one for H. trichoderma (MF039249) resulting from a paper by Eberhardt et al. (2018). Three out of our four Hydropus genotypes exhibit $99 \%$ of similarity with both these new sequences, while the remaining one was less similar (98\%) with these two sequences. However, in the phylogeny published in Eberhardt et al., sequence MF039249 (deposited as H. trichoderma) was finally also identified as representative for $H$. alpinus and, therefore, needs to be updated in GenBank with the correct name.

\section{Mycena}

Sequence-based identification of Mycena species poses major problems as already demonstrated above (see $M$. cf. alniphila, "Mycena cf. alniphila Robich 2016: one report in the ARCS" section) and this is again demonstrated in the following paragraphs. These problems appear to be due not only to poor taxon sampling in GenBank, but also to a high percentage of apparent misidentifications among GenBank deposits considering the low number of deposited sequences. To this should be added the fact that Mycena poses problems during sequencing as evidenced by the many partial ITS sequences deposited in GenBank. Although amplification and sequencing worked very well in our study (except in one case) there is an evident problem of slippage in sequence reads in the ITS1 region.

In addition to the rare M. cf. alniphila (see "Mycena cf. alniphila Robich 2016: one report in the ARCS" section), we therefore tried to identify some species that belong to 


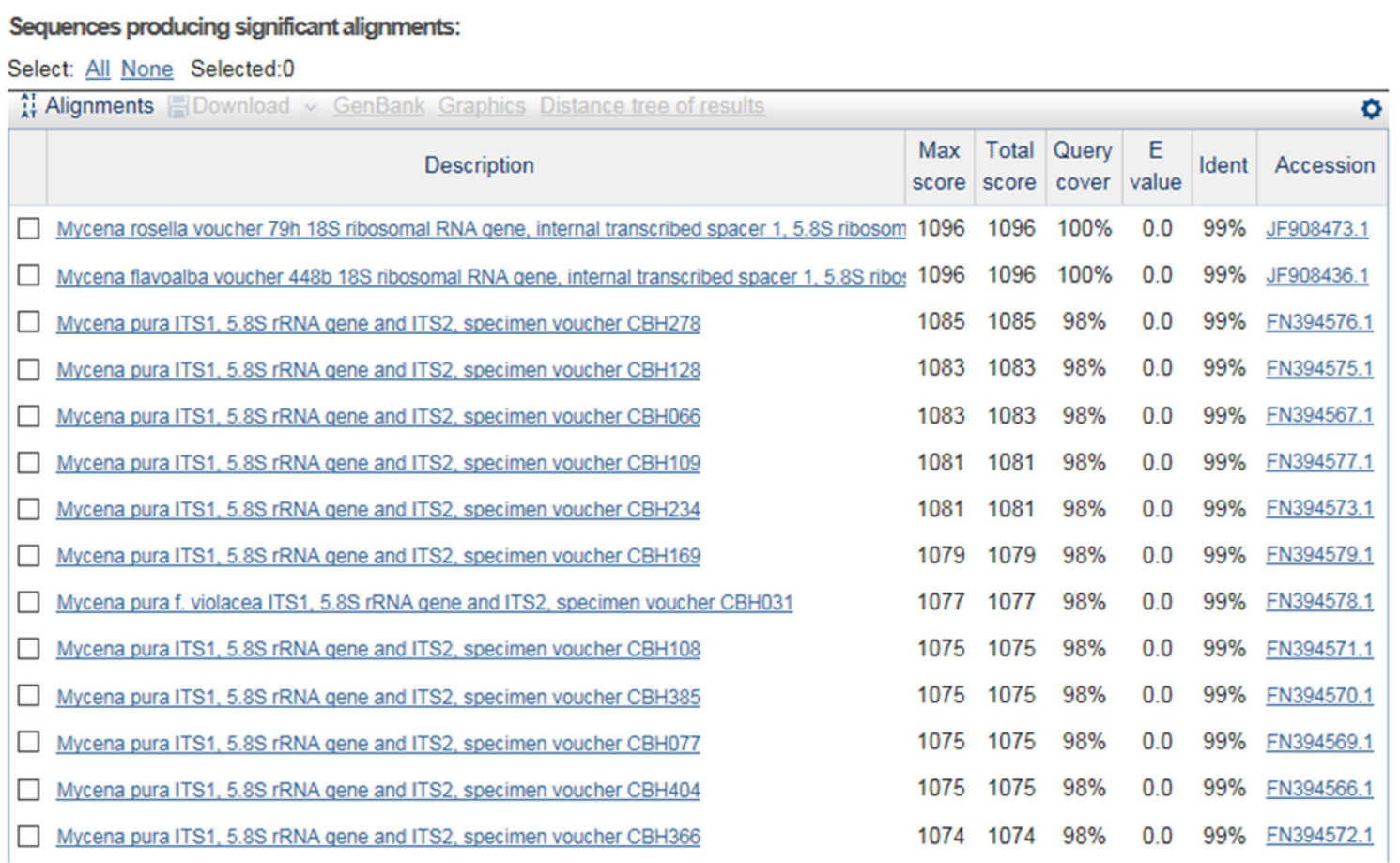

Fig. 23 BLAST top scores for ITS genotype MK028471 for collection Mont-198 = Mycena pura (see Online Resource 1)

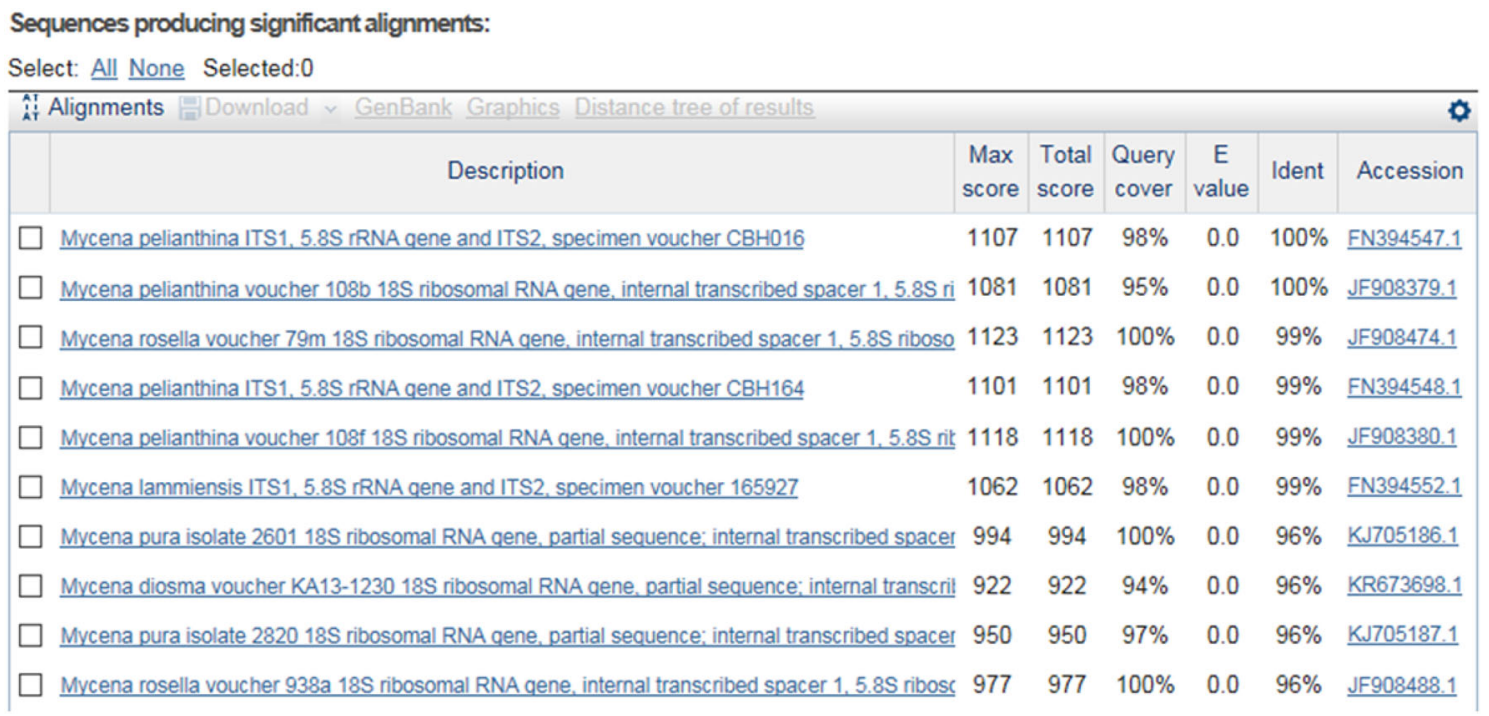

Fig. 24 BLAST top scores for ITS genotype MK028467 for collection Mont-137 = Mycena pelianthina (see Online Resource 1)

easily recognizable species complexes in the field and for which we had collected many samples, such as-for species in Mycena sect. Purae (Konr. \& Maubl.) Maas Geest (also classified as Mycena sect. Calodontes subsect. Purae). When blasting our sequences MK028471 and MK028467 (see Figs. 23, 24), it was rapidly clear that there were several misidentifications among the equally highest top scores. Indeed, a BLAST of our sequence MK028471 (Fig. 23, Online Resource 1) returned equally high top bit scores (99\% of similarity) for Mycena species that belong to very different species groups: for $M$. $f l a-$ voalba of sect. Adonideae (JF908436), for M. rosella (Fr.) P. Kumm. of sect. Luculentae Maas Geest. subsect. Rosellae Singer ex Maas Geest. (JF908473), and for M. pura (Pers.) P. Kumm of sect. Purae (FN394576). When checking the voucher table provided by Osmundson et al. (2013, Suppl. material Table S2), the associated identification for some of those $M$. rosella sequence deposits in GenBank (JF908473, JF908474, JF908487 and JF908488) had been corrected as $M$. rosea. This correction is more 


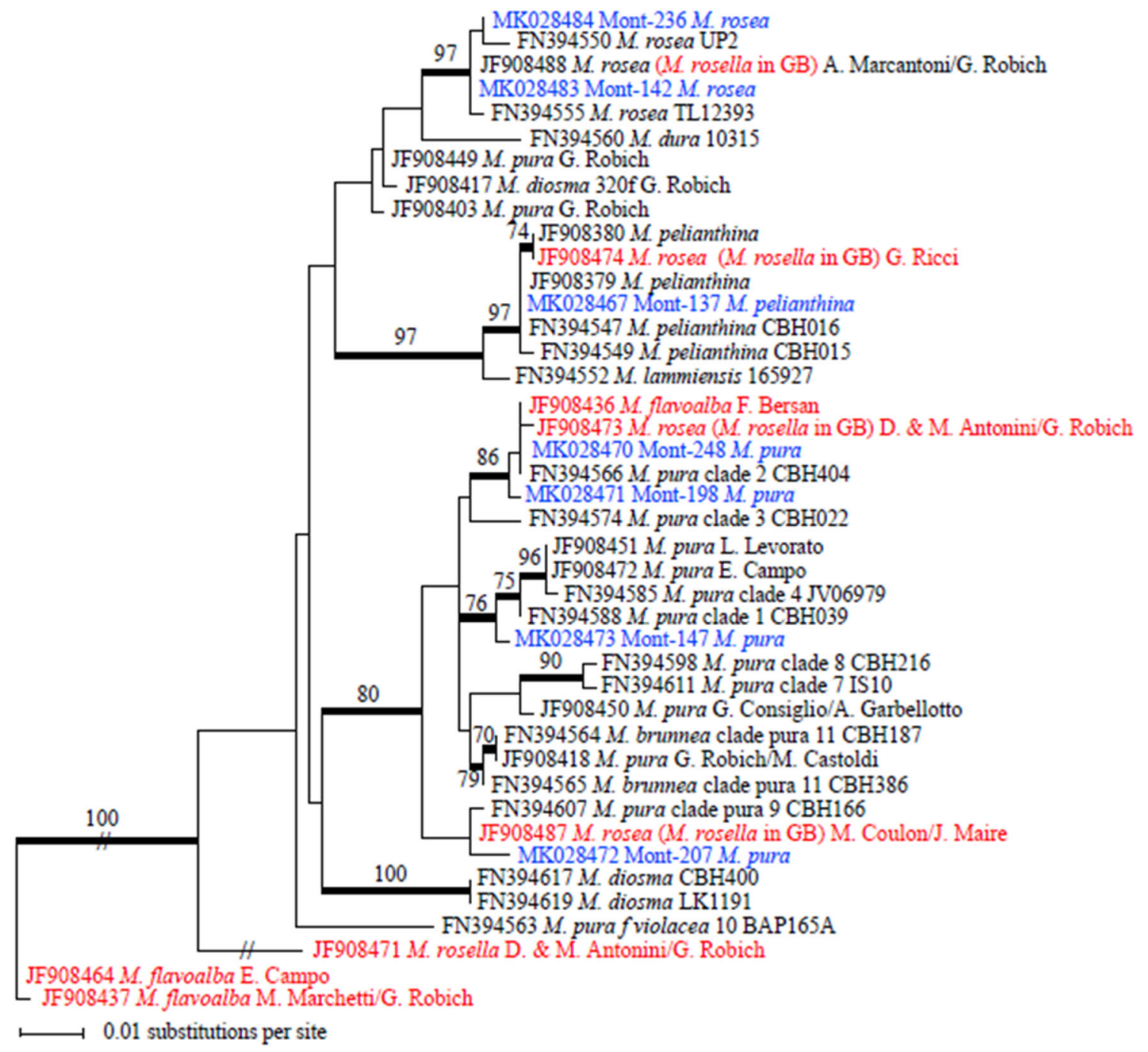

Fig. 25 Most likely tree $(-\ln =2392.39402)$ obtained from phylogenetic analysis of an alignment of ITS for 42 Mycena sequences (full alignment length $=690$ characters, length after exclusion of ambiguously aligned regions $=614$ characters). Branches significantly supported are in bold and bootstrap values indicated along the

than surprising as $M$. rosella and $M$. rosea are not only morphologically very different species, but both have also a very different ecology (acid Picea woods versus calcareous Fagus woods, respectively). The metadata associated with e.g. sequence JF908473 correspond indeed to a sample cited under examined material for M. rosella in the Mycena monograph of Robich (2016) and was even collected by himself. It is therefore quite difficult to imagine that Robich himself would have mistaken a $M$. rosea for $M$. rosella.

BLAST results for our sequence MK028467 resulted also in equally high BLAST top scores (Fig. 24) for very different species: $M$. pelianthina (Fr.) Quél. of sect. Marginatae and the above-mentioned sequence JF908474 for M. rosella (Osmundson et al. 2013). branches when significant $(\geq 70 \%)$. Sequences newly produced for this study are highlighted in blue and the taxa discussed are highlighted in red. GenBank accessions starting by ' $\mathrm{FN}$ ' and by 'JF' have been sampled from the study by Harder et al. (2013) and by Osmundson et al. (2013) respectively

We thus aligned our ITS sequences with representative sequences from GenBank for sect. Purae benefitting from recently published phylogenetic studies (Harder et al. 2010, 2013) and the authoritative but apparently problematic Mycena sequences from the Venice barcode project (Osmundson et al. 2013). Our phylogenetic analyses (Fig. 25) confirmed-as already suggested by BLAST results-that several GenBank deposits clearly involved misidentifications for several vouchers of the authoritative European Mycena monograph (Robich 2016). The most likely tree depicted in Fig. 25 shows clearly that three out of the four $M$. rosellalrosea sequences deposited by Osmundson et al. do not cluster in the correct clade, and this irrespective of adopting either M. rosella or M. rosea as the correct name. With the exception of sequence 
JF908488, which nests within a significantly supported clade exclusively composed of $M$. rosea sequences (correctly named in the voucher table of Osmundson et al., but not in the corresponding GenBank deposits), the other $M$. rosella/rosea sequences (JF908473, JF908474, JF908487 plus JF908471) involve incomprehensible misidentifications. Sequences JF908473 and JF908487 appear to be $M$. pura senso lato according to our phylogeny (Fig. 25) while sequence JF908471 remains unidentified but is neither a $M$. rosea nor a $M$. rosella sequence. Sequence JF908474, as already suggested by BLAST results (Fig. 24), is clearly a sequence obtained from a sample of $M$. pelianthina of sect. Marginatae, a species with a colored gill edge and therefore not rapidly confused with other species in the field. Another misidentification concerns sequences of $M$. flavoalba according to both GenBank deposits and the voucher table in Osmundson et al. (2013). Indeed, sequence JF908436 (actually corresponding to M. pura based on our phylogenetic analyses-Fig. 25), does not cluster with the two other sequences for that same species (see outgroup sequences in Fig. 25). These misidentifications are of particular concern since the Osmundson et al. paper is so far the only major contribution to the barcoding of European mushrooms. Consequently, the Venice sequences, in particular those corresponding to vouchers from the Mycena monograph of Robich (2016) are likely to be considered a reference for Mycena identification in future sequencing projects on European mushrooms, e.g. $\mathrm{Vu}$ et al. (2019). Such a practice might rapidly lead to a perpetuation of these misidentifications.

In addition to the presence of misidentifications, another problem with the Osmundson et al. paper concerns the absence of type annotations for their deposits in GenBank. Among the $>1100$ ITS sequences for European mushrooms produced by the Venice barcode initiative (Osmundson et al. 2013), a total of 130 ITS sequences (from a total of 1753 Mycena collections deposited at Vienna!) have been published by Osmundson et al. (loc. cit.). Most of these sequences correspond to material studied by G. Robich in the context of his European Mycena monographs (Robich 2016). A laborious comparison and cross-checking between the supplementary voucher information in Osmundson et al., and metadata for type vouchers on MB and IF against the list of examined material cited under the individual species in the Mycena monographs, reveals that twelve Mycena holotypes have been sequenced in the Osmundson et al. paper, although this is mentioned nowhere and some have just been deposited as Mycena sp. in GenBank. In fact, both the voucher table and associated sequence data in Osmundson et al. do not allow to trace the actual voucher number as only the recent MCVE herbarium accession code is provided (which is not found in older taxonomic papers which still cite the old MCVE numbering). Fortunately, Mycena is the only exception as the older collection nrs are found in the column for 'habitat'.

The same absence of type annotations applies also to GenBank deposits related to other European Mycena studies, e.g. for the epitype of $M$. pearsoniana (Harder et al. 2012), the holotypes of $M$. dura and M. luteovariegata (Harder et al. 2013), several potential topotypes for older species such as M. pura, M. pelianthina and M. rosea (species that have no physical type specimen) or to the types sequenced by Olariaga et al. (2015) in his study of Mycena sect. Calodontes. Presently, there is not a single

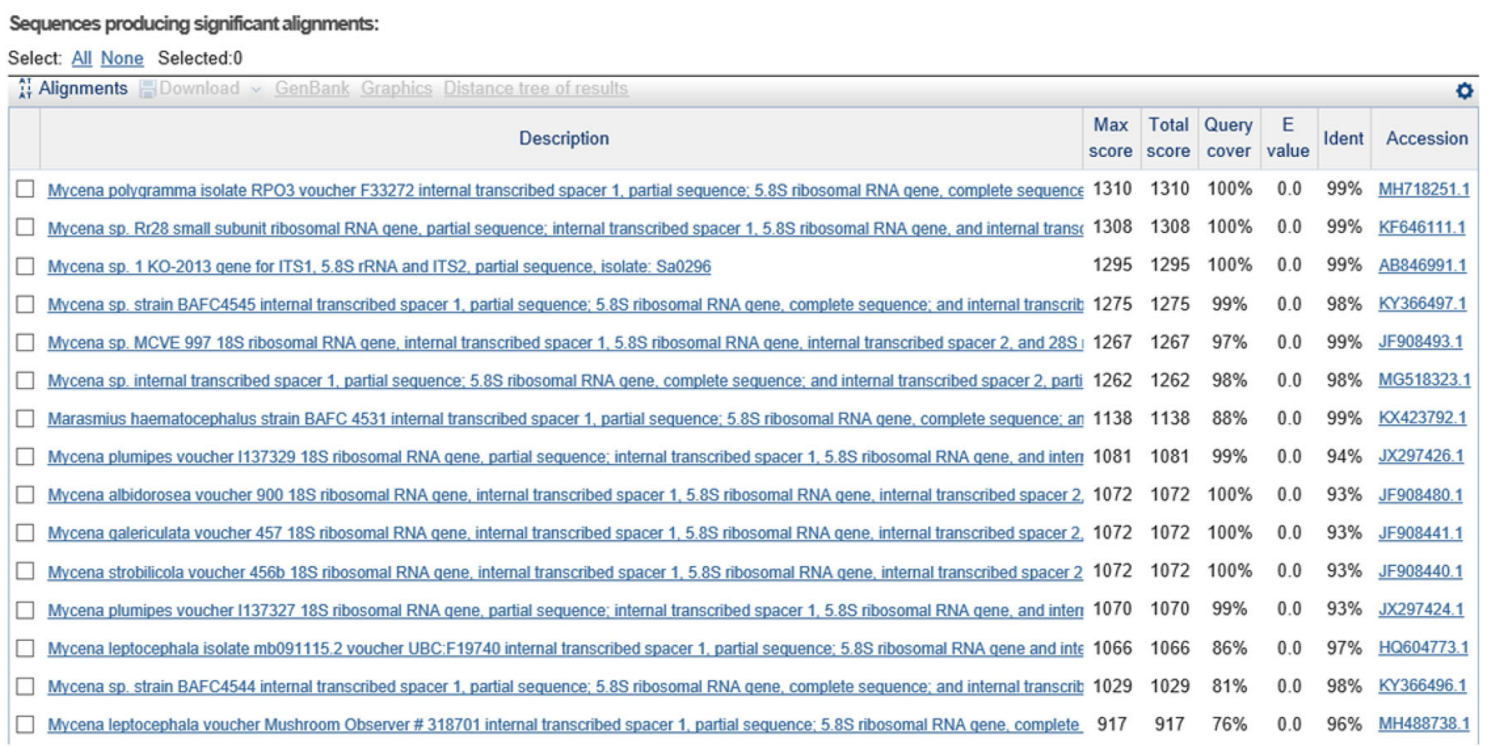

Fig. 26 BLAST top scores for ITS genotypes MK028478, MK028479, MK028480 for collections Mont-273, Mont-281, Mont-277 respectively = Mycena pruinatipes $($ see Online Resource 1 ) 


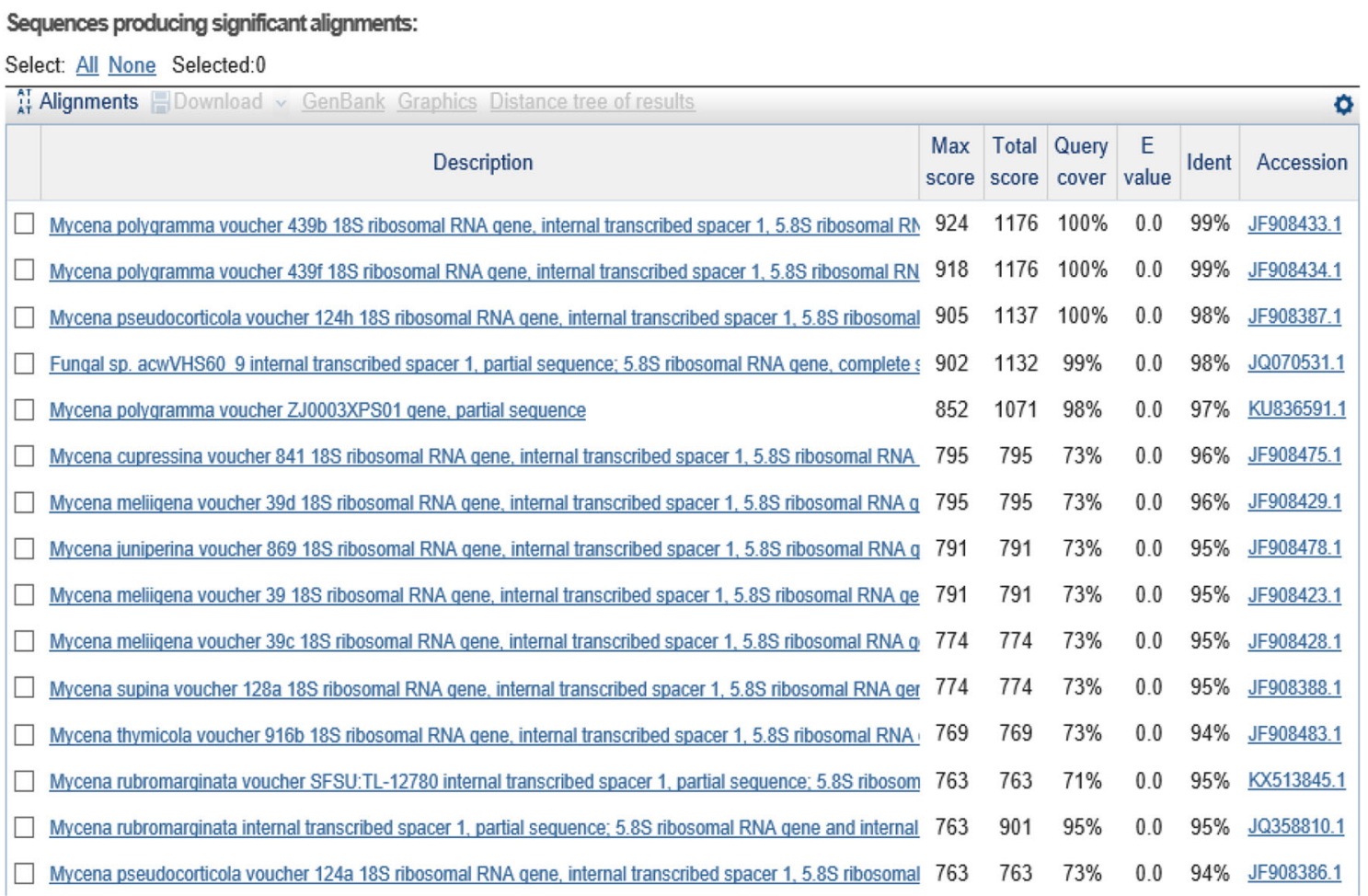

Fig. 27 BLAST top scores for ITS genotype MK028468 for collection Mont-258 = Mycena polygramma (see Online Resource 1)

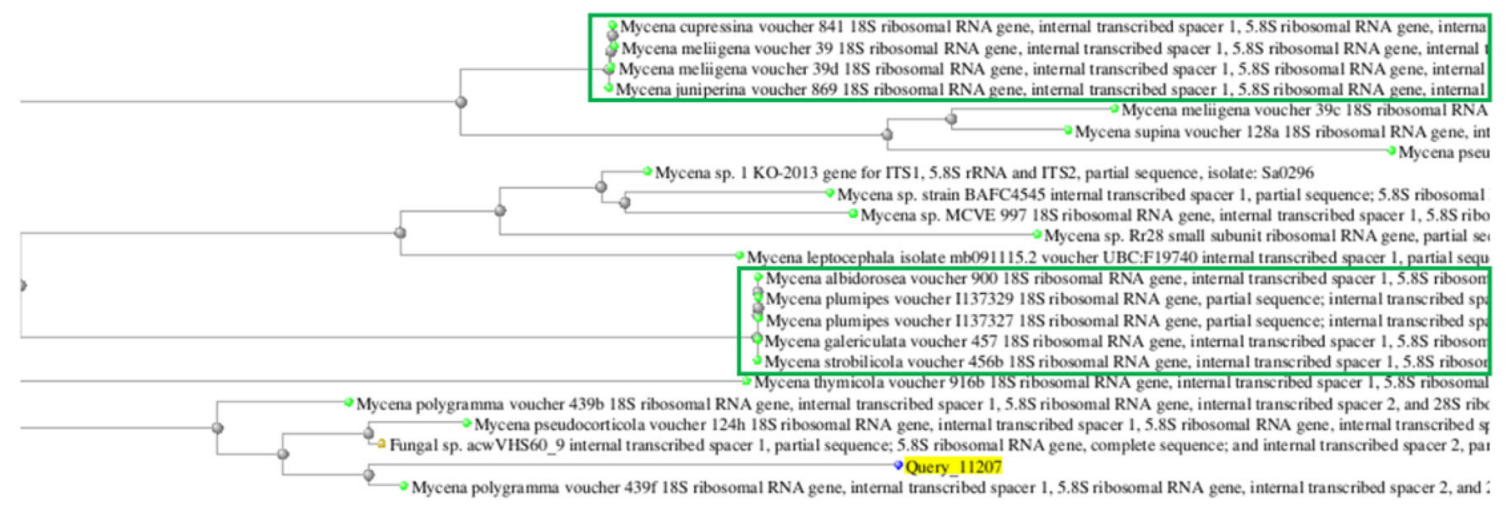

Fig. 28 GenBank distance tree of results for ITS genotype MK028468 for collection Mont-258 = Mycena polygramma (see Online Resource 1). Green boxes highlight the two clades discussed

type specimen for European Mycena annotated as such in GenBank, although there might be more than twenty type sequences deposited for European Mycena.

To illustrate the purpose of bad annotation, we discuss here BLAST results for three of our nearly identical sequences (MK028478, MK028479, MK028480; Online Resource 1) generated by three Swiss samples. Making abstraction of the evidently erroneous sequence deposited in GenBank for Marasmius haematocephalus (in position seven at $99 \%$ identity, Fig. 26), BLAST results of these sequences comprise species that, except for $M$. plumipes (at 94\% identity), all belong in Mycena sect. Fragilipedes (Fr.)
Quél. The top score (99\% identity at $100 \%$ coverage) is a recently deposited sequence for Mycena polygramma (MH718251). All other top scores at 98-99\% similarity are unidentified "Mycena sp." The occasional user would therefore assume that $M$. polygramma might be the correct name, were it not that sequences deposited by Osmundson et al. (2013) for $M$. polygramma are far down in BLAST results at 93-94\% similarity with our sequences, which suggests that the top score sequence MH718251 (corresponding to a specimen collected on the American West coast) might be misidentified. Among the remaining top score sequences vouchered as unidentified Mycena, 
sequence JF908493 (for Mycena sp. voucher MCVE 997, also at $99 \%$ similarity, see Fig. 26) actually corresponds to M. pruinatipes Robich in the Osmundson et al. paper (this time, the name is correctly cited in Osmundson et al. Suppl. Online Resource 2). When checking voucher data in the Mycena monograph of Robich (2016), this sequence comes from the holotype (MCVE 997 in the old MCVE numbering), but type information is missing both in GenBank and in the Osmundson et al. paper. Mycena cf. pruinatipes - mentioned as a 'vulnerable' indicator species for Switzerland in the ARCS-would therefore seem to offer the most precise identification for this BLAST on the condition that one can be confident that sequence JF908493 was indeed obtained from this holotype, something that could actually be questioned in the light of what we discussed in the preceding paragraphs. Further down BLAST results features another 'hidden' holotype sequence, viz. sequence JF908480 for M. albidorosea Robich (at 94\% similarity) which is also from the holotype (MCVE 900).

BLAST results for most of our other Mycena samples were inconclusive. This is due either to the fact that sequence similarity does not exceed $96-98 \%$, or because the sequences of several related species have $99 \%$ of similarity with our sequence query and equally high BLAST topscores, in which case only phylogenetic analysis can possibly resolve the identification.

In most cases, sequence based identification of Mycena requires not only a considerable degree of familiarity with this genus but it also requires access to a well-documented library. Indeed, when looking at screen shots of BLAST results for sequence MK028468 (Figs. 27, 28), the two sequences deposited by Osmundsen et al. for M. pseudocorticola, JF908386 (for voucher MCVE 124a) and JF908387 (for MCVE 124 h), are clearly different species, being at 94 and $98 \%$ similarity (Fig. 27), respectively, with our query sequence (MK028468). In Robich (2016), however, both collections are mentioned in examined material for M. pseudocorticola.

Moreover, a distance tree of BLAST results for the same query sequence (MK028468-Fig. 27) shows that $M$. cupressina Antonin \& Maas Geest. 1998 (JF908475), M. meliigena (Berk. \& Cooke) Sacc. 1887 (JF908423, JF908429) and M. juniperina Aronsen 1996 (JF908478) share nearly identical sequences. All three species (as well as $M$. supina and M. pseudocorticola that figure just below in BLAST results) are all closely related, bark-dwelling species constituting sect. Supinae Konrad \& Maubl., and are basically distinguished by tree host preference and minor morphological differences including variations in general color. Anybody who wants to identify species from this complex based on sequence data is confronted with the impossibility of putting a correct name given the available public sequence data. If ITS sequences were to be taken as informative for species distinction, than our BLAST seems to indicate that $M$. cupressina (growing on Cupressus) is a later synonym of $M$. juniperina (growing on Juniperus), but possibly both species are later synonyms of $M$. meliigena (on deciduous trees). However, as long as no reliable sequences for $M$. meliigena become available, no solution is possible. The general neotypification vacuum for older European names constitutes a major problem for any sequence based identification project of European mushrooms. In the case of Mycena, this might concern well over $50 \%$ of the commonly encountered species. And, again, when cross-checking GenBank metadata deposited with these sequences against the voucher information mentioned in Osmundson et al. (2013, suppl. Data S2), as well as voucher information provided by the Venice herbarium or in various taxonomic publications, one has to conclude that the sequence for $M$. cupressina, although not from the holotype, could easily be considered a paratype or at least a representative or authoratative sequence, as it was collected during the same foray, at the same location and at the same date as the holotype specimen (see Antonín and Maas Geesteranus 1998), although the date indicated in the GenBank deposit does not correspond to the MCVE voucher file).

Still referring to Fig. 28, there is a second clade where near identical sequences have very different names, in casu M. albidorosea (JF908480), M. plumipes (Kalcchbr) P-A Moreau 2003 (JX297426, JX297424), M. galericulata (JF908441) and M. strobilicola J. Favre \& Kühner 1938 (JF908440). As stated above, the M. albidorosea sequence is from the holotype, but the date indicated in the GenBank deposit is again different from the one indicated in the MCVE vouchers and in the original publications. If these five Mycena sequences were a top BLAST score result, then it surely represents an inextricable problem for sequence-based identification as without access to difficultto-find publications, and without a well-above average awareness of nomenclatural rules, it is impossible to understand that M. albidorosea and M. strobilicola are now considered later synonyms of M. plumipes (Moreau 2003), a species growing typically on conifer pines. The sequence for $M$. galericulata, a very common species, is another inexplainable misidentification of a Robich collection considering the important macro- and microscopic differences with all of the above-mentioned species (see Robich 2016).

As mentioned in the preceding paragraphs, dates provided for Mycena vouchers in Osmundson et al. (2013) do not correspond to the remainder of metadata provided for these same vouchers. Dates are nevertheless very important information when trying to locate type strains. The following example comparing different voucher sources for three consecutive entries in GenBank clearly suggests that 
the problem is related to data association when preparing the file for submission to GenBank:

\section{for sequence JF908495:}

- voucher info deposited in GenBank states 'Mycena sp. MCVE 997 voucher 998b', with no other information

- in the suppl. file S2 we read for the same sequence: Mycena sp., MVCE 20841, G. Robich, 21-août-2002, Switzerland.

- in the MCVE herbarium catalogue, it states: MCVE 20841, Mycena pullicaulis Robich, MALVOGLIAPIANTAGIONE, CANTON TICINO-CH, 21/08/02, Ex N. 998/B, coll. G. Robich

The information seems to correspond between the three sources, except that the MCVE 997 in the GenBank deposit cannot be explained.

\section{for sequence JF908494:}

- voucher info deposited in GenBank states 'Mycena sp. MCVE 997 voucher 998', with no additional information

- in the suppl. file S2 we read for the same sequence: Mycena sp., MCVE 20839, G. Robich, 3-juil-2004, Italy

- in the MCVE herbarium catalogue, it states: MCVE 20839, Mycena pullicaulis Robich, BOSCO CANSIGLIO-PIAN CANAIE TAMBRE-BL $1150 \quad 064 \quad 4$ FARRA D'ALPAGO, 03/07/04, Ex N. 998 n. sp., coll. G. Robich

Again, this information seems largely OK, except that MCVE 997 is repeated here again and corresponds to nothing that makes sense, while neither the species name, nor the fact that it is a holotype is mentioned in the GenBank deposit.

\section{for sequence JF908493:}

- voucher info deposited in GenBank states 'Mycena sp. MCVE 997', with additional information that it corresponds to 'voucher 997', and date 11 Oct. 2007

- in the suppl. file S2 we read for the same sequence: Mycena sp., MCVE 20838, G. Robich, 5-déc-2003, Italy

- in the MCVE herbarium catalogue, it states: MCVE 20838, Mycena pruinatipes Robich, TRIESTE-S.LORENZO, TRIESTE 1102 SAN DORLIGO VALLE, 05/12/03, Ex N. 997 n. sp.

Here, it becomes finally clear that MCVE 997 was the correct voucher number for this sequence, but has erroneously been repeated in the next two sequence deposits (JF908494 and JF908495). Yet, for this sequence (JF908493) there is now the problem that the date in the GenBank deposit does not correspond with those from both other sources, and again, the GenBank deposit neither mentions the species name nor the fact that this is a holotype sequence. In such cases it becomes very difficult for someone who depends on sequence-based identification to decide what name to adopt (assuming he/she wants to spend enough time to find things out).

Finally, the herbarium catalogue of the Venice fungal collections holds also a few dozen records for collections made in Switzerland, which are not present in the ARCS, including species that are new records for this country, e.g. Mycena pullicaulis Robich, a collection made by G. Robbich in Ticino $(\mathrm{CH})$. The latter species is another example of a Mycena sequence deposited as «Mycena sp. » in GenBank, although it is actually the paratype (same collector, same locality, and same day as the holotype).

\section{Discussion}

It is important to understand that the main objective of this study was to examine the feasibility of a mushroom inventory in Switzerland knowing that taxonomic expertise in mushroom forming fungi has been crumbling for decades in the country (Buyck 1999). Therefore, a fungal inventory would, other than a possible involvement of citizen scientists (e.g. the swiss mycological society), inevitably require a sequence-based approach in the absence of sufficient taxonomic expertise. But how reliable is sequence-based identification when you are unfamiliar with the organisms in question? This is an aspect most end users of taxonomic information have to face when they are interested in putting species names on obtained sequences from biodiversity studies.

Thus, the adopted strategy for this inventory of mushroom-forming fungi was to use in an initial phase solely ITS sequences and similarity search in GenBank to identify the collected mushroom-forming fungi. This corresponds to the most frequently adopted identification strategy by soil biologists, molecular ecologists and researchers in the medical sciences (Nilsson et al. 2014). It was only after the list of sequence-based identifications was produced, that the most interesting results of this pilot study were reexamined by experienced mushroom taxonomists, and this in order to answer three questions: (1) how reliable is sequence-based identification when performed by persons not familiar with the collected organisms; (2) would the same result be obtained when experienced taxonomists of the concerned organisms look at BLAST results? and (3) what does it actually take, in terms of time and various other ressources, to be confident in the obtained identifications. The last question is easy to answer: the in-depth reexamination was here deliberately limited to ca 20 of the most interesting identifications, but it took us nearly two 
full-time months of work. Needless to say that this is beyond the scope of any larger fungal inventory program implicating several hundreds or even thousands of specimens.

Barcoding has been naively embraced by some as "the" solution to eliminate any need of taxonomic expertise during the identification process (Godfray 2007; Hebert et al. 2003), This view has repeatedly been critized for the various groups of organisms (Begerow et al. 2010; de Carvalho et al. 2007; Jeewon and Hyde 2016; Nguyen et al. 2016; Peay 2014) and our in-depth re-examination clearly supports this criticism. The discussed examples demonstrate that a reliable interpretation of BLAST results is impossible unless one has a more than average awareness of taxonomic, systematic and nomenclatural aspects of the organisms that are being identified, in addition to easy access to taxonomic literature.

Even if the results of this preliminary inventory are already impressive in the context of the fungal Atlas for Switzerland, a contribution to the Swiss fungal inventory was not the primary objective of this study. The present study wanted to illustrate above all what is actually needed before one can be confident that the obtained species name using BLAST is correct, and for this, we used a very descriptive, step by step approach. Our approach is quite different from previous papers that discussed issues with sequence-based identification in terms of numbers and percentages for the various shortcomings or errors (Bidartondo 2008; Kang et al. 2010; Ko Ko et al. 2011; Nilsson et al. 2006, 2012; Vilgalys 2003). With the present approach, we hope to render the problematics that are inherent to the taxonomic impediment more concrete, not to the taxonomists (who are sufficiently aware and familiar with these aspects) but to the user community so that they will better understand what is needed to provide the 'simple service' of identification. In the following paragraphs we will highlight some of the main aspects of sequence-based identification of mushrooms as encountered in this study.

\section{The taxonomic impediment}

While the number of newly described taxa these past years remained overall more or less stable (Costello et al. 2013) or was slowly increasing for species-rich groups such as Diptera (Santos et al. 2017), the most destabilizing factor for the taxonomic community has particularly been the more realistic, recent estimates of extant biodiversity. The total fungal biodiversity, for example, was initially estimated to amount to a few hundreds of thousands of extant species at most (Bisby and Ainsworth 1943; Martin 1951), until this number was first revised to at least 1.5 million fungal species (Hawksworth 1991) and then up to anywhere between 5 and 10 million fungal species in more recent estimates (Blackwell 2011; Hawksworth and Lücking 2017; O'Brien et al. 2005; Taylor et al. 2010). The "taxonomic impediment" or taxonomic bottleneck was seen as the insufficience or incapacity of existing taxonomic expertise to describe this gigantic-yet rapidly vanishing - biodiversity on Earth. With the realization that most of Earth's biodiversity has become seriously threatened during the last decades, the users of taxonomic information, particularly ecologists and conservationists, have since become the greatest allies in the defense of taxonomy as they need species names for evaluation, comparison and conservation arguments for threatened habitats. Even the fungal inventory in this study was not undertaken because of any particular taxonomic interest in the fungi of Montricher, but because of a request emanating from a third party with an interest in habitat evaluation for the purpose of conservation and adequate habitat management. Notwithstanding this important line of support for taxonomy, many taxonomists remain frustrated with the way identification is viewed by these same endusers, in particular their request for what these users interpret as a 'simple service', in contrast to what taxonomists would like them to understand: i.e. that every species name is merely an evolving hypothesis that is constantly questioned in the light of new data or new analyses or techniques, and possibly perceived differently by fellow taxonomists depending on applied species concepts or personal experience (Lipscomb et al. 2003; Seberg et al. 2003).

In the case of mushrooms, it did of course not benefit the image of fungal taxonomists when the molecular revolution has demonstrated that the entire traditional (Friesian) classification was based on morphological convergences, thereby contributing greatly to what is perceived by endusers of taxonomy as 'anarchy and chaos' in taxonomic information (Garnett and Christidis 2017). Even within the taxonomist community, there is a growing uneasiness with the legitimacy of recent cascades of name changes that are resulting from phylogenetic studies (e.g. Vellinga et al. 2015 on the current oversplitting of boletes).

Because of its long history in European countries, one might presume that the taxonomy of most macroscopic organisms is well advanced and that the species inventory nears completion, while being coupled with a broad array of life history data for a better understanding of this biodiversity. The present study, however, although focusing on what has been referred to as the 'charismatic megaflora' (Seifert 2009a, b), clearly demonstrates that, even in the cradle of mycology, we are still very far from stable species concepts and from the possibility of a reliable sequence-based identification. While progress is undeniable, it is far too slow, even when considering that 
most of our sequence-based identifications would have been difficult or impossible merely ten years ago without the following taxonomic papers: Antrodiella citrinella (= Flaviporus citrinellus) and Antrodiella faginea (Johannesson et al. 2000), Antrodiella stipitata (Floudas and Hibbett 2015), Rhizomarasmius setosus (Moreau 2017 pers com.), Cortinarius cotoneus (Garnica et al. 2005), Cortinarius laberiae and Cortinarius subgracilis (Bellanger 2015), Postia alni (Ortiz-Santana et al. 2013; Miettinen et al. 2018), Hydropus subalpinus (Eberhardt et al. 2018), Hypocrea pachybasioides (Lu et al. 2004), Hygrophoropsis rufa (Holec and Kolarík 2013), Mycena alniphila (Osmundson et al. 2013), Pluteus atromarginatus (Justo et al. 2014), Psathyrella fagetophila and P. obtusata (Örstadius et al. 2015), Russula inamoena (Melera et al. 2017), Sistotrema oblongisporum (Kotiranta and Larsson 2013), Sistotrema sernanderi (Menkis et al. 2004), and Tricholomopsis flammula (Holec and Kolarík 2016). In this regard, we subscribe to the conclusion of Nilsson et al. (2006) that the greatest challenges for sequence-based identification will be taxonomical rather than technical.

But while technical advances in molecular screening of biodiversity through next generation sequencing are very promising to get a more accurate picture of extant biodiversity, international conventions, such as the Nagoya protocol (https://www.cbd.int/abs/doc/protocol/nagoya-pro tocol-en.pdf), as well as protective governmental (Audisio 2017; Bockmann et al. 2018) or institutional decisions (such as the recent ban on movement of type specimens by the Paris' National History Museum) are severely limiting access to-and movement of - these same national biodiversity resources for taxonomic study. International taxonomic approaches become consequently either extremely laborious or quite impossible. Yet, it has repeatedly been stated (e.g. Hawksworth and Mueller 2005; Piepenbring et al. 2012) that monographic work-typically on species groups not limited by political boundaries-is essential for correct identification.

There are more reasons why traditional taxonomic approaches are no longer popular, at least in Europe. The necessary funding for monographic work is frequently 'siphoned away by the misuse of the great potentials of molecular biology' (Korf 2007; Lipscomb et al. 2003; see Online Ressource 3 in Wheeler 2004). Researchers are under strong pressure to publish, bibliometric data steering the allocation of faculty and state funding (Eriksson and Helgesson 2017). Monographic work is rarely an option for a PhD thesis (Korf 2007) because of the "publish or perish" principle (Quake 2009; Tijdink et al. 2014), pushing students constantly to publish their results in small papers that, too frequently, put an overwhelming emphasis on molecular data while reducing morphological descriptions almost to a caricature when describing new species (Bauer
2013; Jeewon and Hyde 2016; Maharachchikumbura et al. 2016; Peay 2014). Very few top-ranking journals will consider the publication of lengthy taxonomic revisions, while taxonomic expertise is rarely required-if not judged irrelevant-when it comes to find a job (Agnarsson and Kuntner 2007; Raposo et al. 2017). The recent publication pressure is also largely responsible for what has been referred to as "predatory publishing" (Beall 2015; Demir 2018; Shashok 2017) implicating journals for which science is a business like any other commercial endeavor and, therefore, quantity is preferred over quality (Carpenter et al. 2014; Edwards and Roy 2016; Van Noorden 2010; Werner 2015; Nilsson et al. 2014). Many papers get published this way with no or little peer review as long as the authors will honour the (often excessive) page charges (Bowman 2014; Shashok 2017). From personal experience, we can state that such journals insist on acceptation of papers, irrespective of bad taxonomy or bad phylogenetic analyses, and reprimand reviewers for excessive severity (we have been ourselves confronted with remarks such as "Why do you refuse this paper? You know it is going to be published anyway").

We may hope that the rapidly rising world powers or BRIC's [Brazil, Russia, India and China], some of which are presently investing a lot in the description of their largely unknown biodiversity (Santos et al. 2017), may inverse this trend. In sharp contrast to the ageing taxonomists in many European countries, these parts of the world are raising an impressive generation of young taxonomists (see e.g. Roy et al. 2017) that combine descriptive taxonomy with phylogenetics in an often well-funded scientific environment. These regions are likely part of the most important cradles of biodiversity, but also those where our ignorance of that diversity is presently the worst (Hyde et al. 2018).

\section{Poor sequence coverage of fungal taxa}

The major reason why sequenced-based identification of fungi remains unsatisfactory is simply because ITS sequences for the corresponding taxon are not present in public depositories. In this context, it is applaudable that description of new taxa is currently mostly accompanied by the deposit of at least a barcode sequence. Even if the coverage by sequence data deposits for formally recognized fungal names in GenBank has grown from 493 taxa in 1993 to as many as 28340 taxa in 2014 (Federhen 2015), this increase remains nevertheless a drop in the ocean considering recent conservative estimates of several millions of fungal species on earth (Hawksworth and Lücking 2017). In our study, this was particularly evident for the genus Hydropus, but it is also reflected by the many other samples (here not further investigated) for which BLAST 
similarity top scores were too low to allow for any kind of identification beyond genus level (e.g. Clavariodelphus, most Inocybe and Mycena, several Cortinarius, etc.[see Online Resource 1]). We are forced to conclude that sequence-based taxon coverage for European mushrooms is still very poor, and this while Europe is about the only continent where the inventory of mushrooms is rather well covered. We should indeed be very concerned for the future. One of the first important contributions toward the barcoding of European mushrooms (Osmundson et al. 2013) was emanating from California (USA), even when it probably suffers from problems related to the association of metadata as repeatedly discussed here. It is high time that European mycologists take up their responsibility to provide reference sequences. European mycologists should combine forces with the European amateur societies in an international European project that will yield extensive and (hopefully) decent quality barcodes tied to good collection data, similar to the recent MycoFlora 2.0 initiative in North America (see http://mycoflora.org/about/overview).

\section{The RefSeq Targeted Loci (RTL) database for ITS type sequence data for fungi and the urgent need for epitypification}

More than a simple coverage of fungal taxa, we need a coverage of fungal taxa by carefully chosen and reliable reference sequences! (De Carvalho et al. 2007; Goldstein and DeSalle 2011; Kõljalg et al. 2013; Jeewon and Hyde 2016; Nguyen et al. 2016; Nilsson et al. 2008, 2011, 2014; Stoeckle 2003; Tedersoo et al. 2018). In contrast to North America, where most of the earliest mycologists have left a well-conserved herbarium of their specimens, the large majority of European fungal descriptions (dating from the 18 th or 19 th century, but also many species from the 20th century-see Online Resource 2 to appreciate the importance of missing type vouchers!), the absence of reliable sequences for European species is directly related to the absence of physical vouchers for the types. The number of European fungi that is implicated is huge, but sequencebased identification can only become efficient when reliable reference sequences are deposited for these older European names through the process of epitypification. This issue applies not only to those species that have no physical type, but also to nearly all species for which the type specimens are too old to yield high quality sequences. This concerns of course a large part of European species, but also nearly all of the mushrooms described from Africa, Australia and other parts of the world by the first naturalist explorers. One must realize that the European model for species protection and conservation, which is based on the availability and evaluation of distribution data over time, is not applicable in most of the rapidly disappearing habitats in the rest of the world because we will never have enough distribution data to evaluate the necessity of protection for the various species. Buchanan and May (2003), for example, stated that ca. $25 \%$ of the described species from New Zealand and Australia (a small percentage of the locally extant fungal biodiversity) were still known from a single collection, viz. the holotype, with the overwhelming majority of these lacking associated sequence data. Also most of the known tropical African mushroom-forming fungi have been described well before the advent of sequencing techniques, mainly in the "Flore iconographique des champignons du Congo" and its successor, the "Flore illustree des champignons d'Afrique centrale" (see http://www.br.fgov.be/). Compared to the enormous fungal biodiversity in tropical Africa, the absence of reliable sequences for such a small proportion of described taxa created already many misapplied names, uncertain identifications and conflicting viewpoints among mycologists. The profound impact that epitypification can have on species concepts is easily illustrated by the recent studies on Central African Cantharellus (Buyck and Hofstetter 2018; Buyck et al. 2019a, b).

In recent years, INSDC created 'sequence from type' databases for the different groups of organisms in GenBank and the RefSeq Targeted Loci (RTL) database for ITS type sequence data for fungi. In 2012, the RefSeq reference set for all groups of fungi contained 2235 reference sequences including 2130 sequences from types, growing to 2600 sequences for ca. 2500 species hardly two years later (Schoch et al. 2014) to have reached now-in Jan. 201910,000 sequences, although not from 10,000 different species (Nilsson, pers. comm.). The principal source for updates on fungal types and fungal type sequences are Mycobank and Index Fungorum (Federhen 2015), but to some extent input comes also through contributions from taxonomic experts and individual taxonomic publications. As far as Agaricomycetes are concerned, Schoch et al. (2014) state that these were represented by only 418 type sequences. In the light of the many thousands of Agaricomycetes that are presently part of the national fungal inventory of France (Eyssartier and Roux 2017), one can imagine that reliable identification remains virtually impossible.

A positive result of this study is that many more types have apparently been sequenced than what can be seen in the RefSeq Targeted Loci (RTL) or sequence from type database. In many instances, this was also not visible from associated metadata, which implies that one can only discover such type sequences by going back to the original publications and voucher tables. Three examples to illustrate our purpose: 
1. When taking again the example of Mycena, a polyphyletic genus (Matheny et al. 2006) for which there are presently about 300 recognized species in Europe (approximative estimate based on Robich 2016 and Aronsen and Læssøe 2016, even when considering that these two authors have different views on species concepts) a normal BLAST in GenBank will generate a list of several hundreds of deposited sequences. However, when using a BLAST which is limited to type sequences, the number of listed Mycena sequences in BLAST results drops down to four species, none from Europe. In this study we have revealed 'hidden' type sequences for at least 15 (but possibly 20) European Mycena species among existing GenBank deposits by Osmundson et al. (2013) and Harder et al. $(2010,2012,2013)$, and the potential for the recognition of an additional number of reference sequences among the remainder of the 130 Mycena sequences obtained from the Robich collection in the herbarium of Venice (Osmundson et al. 2013).

2. Similarly, re-examination of BLAST results for our samples of Psathyrella fagetophila, revealed that the top three hits comprised three holotype sequences, none of them flagged as such in GenBank. These holotype sequences were produced in a recent phylogenetic study (Örstadius et al. 2015) on Psathyrella and closely related genera which presented sequence data for more than 30 holotype specimens that are not flagged as types in GenBank. Unflagged partial ITS-LSU sequences are also available for some Psathyrella holotypes studied by Vasǔtová et al. (2008). A BLAST of our P. fagetophila sample against all type sequences in GenBank generated a list comprising merely eleven type sequences for Psathyrella species of which only four are NR-prefixed as part the RefSeq Targeted Loci (RTL) database. Equally, both of the Cortinarius species (C. laberiae, $C$. subgracilis) for which BLAST results have here been reexamined, are unrecognized and unreferenced holotype sequences deposited in GenBank.

3. When blasting sequences for Entoloma, for example, one should be aware that, presently (late 2018), some 55 type sequences generated by Kokkonen (2015) are not yet visible in normal BLAST as part of the RefSeq Targeted Loci (RTL) database, but they are already visible when performing BLAST limited to 'sequences from type'. Therefore, there seems to be a considerable time of lapse between deposition of clearly annotated type sequences and their being prefixed as part of the RefSeq Targeted Loci (RTL) database.

\section{Poor or erroneous metadata for sequences}

Taxonomists frequently pay unsufficient attention to the annotations when submitting sequences in GenBank. The proportion of such poorly annotated sequences was quite important for the examined sequences in this study. This confirms the general experience of GenBank staff with sequence submissions (Schoch et al. 2014). Poor-quality metadata is particularly troublesome for sequenced holotype specimens as sequence-based identification is entirely dependant on reliable sequences (Schoch et al. 2012, 2014). Therefore, perfect correspondance between the information that is entered at the time of sequence deposit and the information provided in publications, in particular for the holotype, is essential in order to be confident in the deposited sequences. One of the first requirements is of course to annotate such sequence as produced from the type collection. This information is usually indicated in the printed publication, but frequently not in the deposit of the corresponding sequence in GenBank (see preceding paragraph).

Also other metadata are often affected. For instance, several of the Mycena ITS deposits from the Fungal Barcode paper on the Venice Herbarium (Osmundson et al. 2013) presented dates deviating sometimes by more than a decennium from the original voucher information. In other instances, title and metadata referred to two distinct vouchers for the same sequence, including for several of the here examined holotype sequences, and none of these sequences produced from types were annotated as 'type'. It took one of us (BB) nearly two full days to locate thirteen Mycena type sequences with a high degree of confidence based on comparison of voucher data from various sources.

\section{ITS can be an inappropriate choice to serve as barcode sequence for several genera}

Our samples of Antrodiella species ("Antrodiella sp. appeared to be the first European record of Antrodiella stipitata H.S. Yuan \& Y.C. Dai (in Yuan et al. 2006)" section) and Postia species ("Postia alni Niemelä \& Vampola 2001 (see Miettinen et al. 2018)" section) illustrate very well the impossibility of identification when top BLAST scores result in $99 \%$ similarity for a whole suite of closely related species. In such cases only time-consuming (that is, if one wants to do it correctly) sequence alignment can contribute to a more precise identification but this is hardly an option for fungal inventories comprising sequence-based identification of hundreds to thousands of samples. 


\section{Reliability of publicly deposited barcode sequences}

In a utopic world where there would be a reliable (!) reference sequence available for every extant species in a public sequence depository and where every species has a unique barcode sequence (which is not the case), it would indeed be possible to identify any species using these barcodes. Unfortunately, inherent limitations of short barcode sequences and the terrifying speed at which natural habitats are disappearing are already enough reasons to dismiss such a scenario as very unrealistic.

An apparently growing problem in GenBank is that one can often not rely on already deposited sequences to name species. Indeed, a relatively high proportion of publicly deposited sequences are associated with the wrong taxon names, an aspect that has repeatedly been discussed (Bidartondo 2008; De Carvalho et al. 2007; Herr et al. 2015; Hongsanan et al. 2018; Kang et al. 2010; Lindahl et al. 2013; Nilsson et al. 2006, 2014). The proportion of misidentified fungal sequences in public databases was estimated upwards 10 or even $20 \%$ (Nilsson et al. 2006; Vilgalys 2003). Our study now suggests that this proportion has grown since, being closer to $30 \%$ now. This evaluation of the taxonomic reliability of submitted sequences is not only very time consuming, it also supposes a solid taxonomic and even phylogenetic background to retrieve such errors. The present study encountered several identification errors, which were clearly the result of shifts in data association when submitting batches of sequences to GenBank. Sequence-based identification tends to propagate errors and even in the present study, several of our apparently straightforward identifications would clearly have resulted in deposits of wrong taxonomic names if these had not been re-examined (e.g. Cibaomyces glutinis, ["Cibaomyces glutinis Zhu L. Yang appeared to be common Rhizomarasmius setosus (= Marasmius setosus in the ARCS)" section] in Moreau et al. (2015), Lactarius helvus ["Lactarius helvus (Fr.) Fr. (vulnerable species) appeared to be the common L. pallidus (Pers.) Pers. (Persoon 1797)" section] in Osmundson et al. 2013 and various Mycena spp. ["Mycena" section]).

The 'taxonomic impediment' that has often been mentioned when referring to the insufficience of existing taxonomic expertise in the face of recent estimates of extant biodiversity, is now shifting toward the incapacity of taxonomists to deal with the tsunami of unsufficiently identified or misidentified sequences and with errors in associated metadata (De Carvalho et al. 2007; Goldstein and DeSalle 2011; Nilsson et al. 2005, 2008, 2011, 2014; Tedersoo et al. 2018; Tedersoo and Smith 2017).

\section{Environmental sequences}

When identifying fungi by BLAST, it is hightly recommended to activate the option that excludes environmental sequences from the BLAST in order to avoid being submerged by unvouchered sequences for 'uncultured fungus' . Already in 2014, there were in excess of 100 environmental sequences deposited for every single sequence that was associated with a vouchered specimen (Hawksworth et al. 2016) and this gap is steadily widening.

As already mentioned, metadata for vouchered sequences are extremely important for both taxonomists and endusers of taxonomic information, but this applies also to metadata associated with environmental sequences (Ryberg et al. 2008). More and more papers, e.g. on ectomycorrhizal mushrooms, exploit metadata for environmental sequences to appreciate distribution, ecology or hostspecificity of particular species. Wang et al. (2019), for example, described a new section in Russula based on the discovery of two new species in China. Thanks to the metadata from highly similar environmental ITS sequences as part of their phylogenetic analysis, these authors demonstrate that more, still undescribed species of this new subsection remain to be discovered on at least two more continents. Additionally, the environmental sequences allowed these authors to establish that Russula species in this new subsection associate with different host families on different continents, and that they are exploited by mycoheterotrophic orchids and monotropoids. It is, therefore, regretful that there is no possibility to update or annotate identifications directly in GenBank and to offer more precise systematic placements to replace the extremely vague notion of 'uncultured fungus'. In this context, a very promising initiative is the creation of 'species hypotheses' in UNITE (Kõljalg et al. 2013).

\section{Poor quality control of deposited sequences}

One elementary verification of the quality of obtained sequences is of course to BLAST sequences before depositing them in GenBank in order to see whether they correspond to the correct organism. This procedure seems obvious, especially since many sequences will be published as part of phylogenies. However, it seems worthwile to mention this once more judging from the surprising number of sequences that come up in BLAST results, but were clearly obtained from different genera, families or even different kingdoms than the one expected.

The only case of problematic identification that was presumably due to poor sequence quality was here for Laxitextum (see "Laxitextum incrustatum Hjortstam \& Ryvarden appeared to be L. bicolor (Pers.) Lentz" section), 


\section{3-2004 new russulas}

\section{Europe}

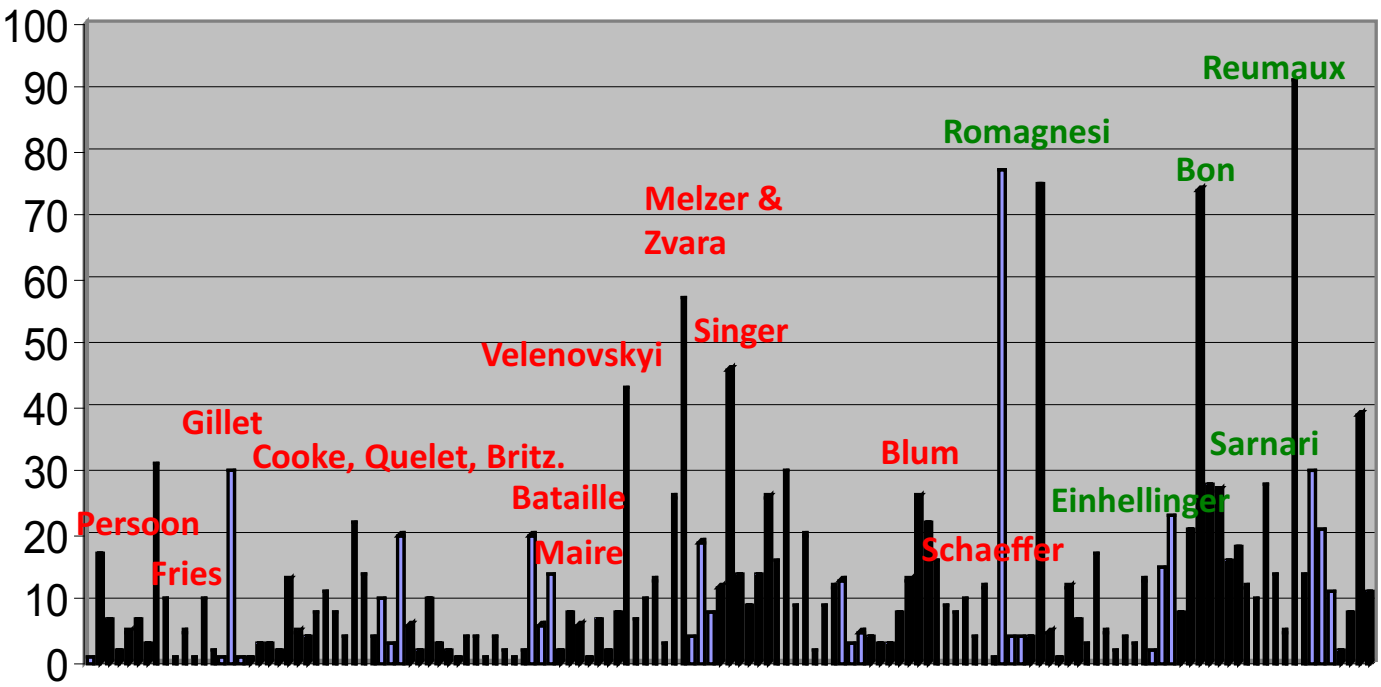

$1796 . .1838 \ldots . . .1874 \ldots \ldots .1888 \ldots 1893 \ldots \ldots$

1910..1920.1927.1932.

$.1952 . .1962 / 67 \ldots \ldots .1986 \ldots . .1996 / 98 . .2006$

\section{United States}

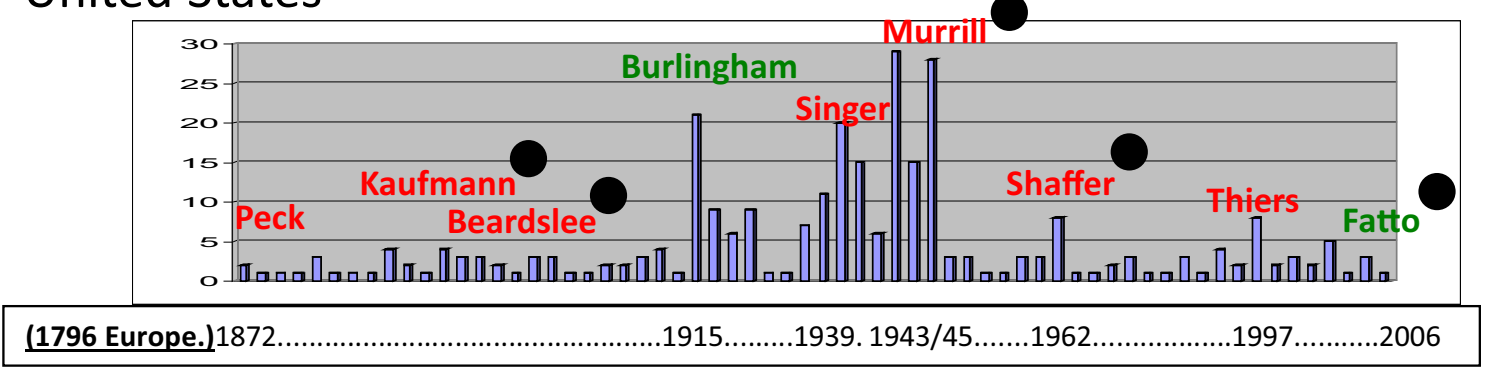

\section{= no or very limited monograph}

Fig. 29 Comparison of the study of the genus Russula between Europe and North America with indication of number of species described and published in (regional) monographs and revisions since the beginning of taxonomic mycology, up to 2004. The graph for

which was deposited in GenBank in the year 2000. Because of the technical limitations of first generation sequencing methods, many of the earliest produced sequences are likely to be partial and less reliable compared to recent sequence deposits (Heather and Chain 2015). Another problem recently highlighted by Nilsson et al. (2017) is the deposition of poorly trimmed sequences, which may mask biological signal in sequence similarity searches and phylogenetic analyses.

Ideally, submission should involve the deposit of the corresponding ABI chromatogram files so that one can better appreciate differences between very similar sequences, but this seems very difficult to put in practice (C. Schoch, pers. comm.). At least, it seems highly
Europe shows the replacement of professional mycologist (in red) by contributions of citizen scientists (in green) since the 1960s, contrary to North America, where professional mycologists still are responsible for most of the advances in taxonomy

recommendable that reviewers of papers that introduce barcode sequences for newly described species should systematically verify sequence quality of these barcodes. Indeed, in the personal experience of some of the authors of this study, new species are sometimes proposed based on "sufficient genetic difference" with all other known species in the same group. When asking for the chromatogram that is associated with the fasta file (in many cases for the holotype), this conclusion was in some cases clearly based on bad sequence quality. The problem is that GenBank, who receives only the FASTA file, cannot retrieve such kind of quality problem. Other types of errors (e.g. chimera) in deposited sequences may come from poorly verified environmental sequences (see for ex. Buyck et al. 
2016), but are rarely encountered with Sanger sequencing of DNA extracted from fruiting bodies such as in this study.

\section{The growing implication of citizen sciencists in sequence-based identification}

The recent cascade of phylogenetic studies that propose changing species and genus concepts involving many species recombinations due to an often exagerated splitting of the traditional genera into smaller satellite genera (see Vellinga et al. 2015), is rapidly becoming a burden to all users of taxonomic information (Garnett and Christidis 2017). The flood of newly recognized genera for wellknown species is not only discouraging, it poses unsurmountable problems for part of the amateur mycological community in Europe. This is particularly regretful because most of the inventory and description of the European larger 'mushroom' biodiversity is nowadays generated almost exclusively by these same citizen scientsts, as a consequence of the steady decline of professional European mushroom taxonomists since the 1960s. This is easily illustrated by comparing published monographs on the genus Russula, one of the most species-rich mushroom genera in woody vegetation types on earth (see Fig. 29).

The power and profound impact of sequences and phylogenetic analyses on species recognition and generic concepts now also starts to seduce a growing number of citizen scientists toward the integration of sequence-based identification and toward the use of phylogenetic approaches for the identification of mushroom forming fungi. Alvarado Lab (Spain, http://www.alvalab.es) and Mycoseq (French Mycological Society, http://www.mycofrance.fr/ projets/mycoseq/) are two European initiatives in which professional mycologists support the integration of a sequence-based approach in the context of taxonomic studies produced by-or coproduced with-citizen scientists. Also the more recently launched Mycoflora project in North America (mycoflora.org) is a consortium of citizen scientists and professional mycologists that integrates sequence data associated with field collections to perform a biological survey of all the macrofungi that occur in North America. Therefore, sequence-based identification is going to become very rapidly important to a much wider community. While this trend is already very visible in Europe and North America, participative science (science projects implicating the participation of citizen scientists) are also emerging in other parts of the world (Gryzenhout 2015).

\section{The rapidly growing challenge of updating taxonomic databases}

Huge amounts of money and effort are spent in the compilation of various regional and international databases for names or sequences, often with insufficient funds for quality control or the need for continuous updating (Nilsson et al. 2014; Bidartondo 2008; Kang et al. 2010). Even the most important online taxonomic databases cannot keep up with incessant name changes and evolving species concepts (see Online Resource 2). This is clearly illustrated by the conflicting taxonomies adopted between $\mathrm{MB}$ and IF-often again different from the taxonomy adopted by GenBank-when looking for the "current name" to use for the submission of sequences to GenBank. In some cases, GenBank itself can be responsible for the perpetuation of misidentifications when submitting sequences, as we indeed experienced ourselves with our deposits for the present study: GenBank changed the correct ID's of two of our sequences submitted as Mycena rosea (Mont-142) and Mycena $c f$. rosea (Mont-236) into $M$. rosella and $M$. $c f$. rosella, respectively, during the submission process, on the basis of current names adopted in earlier submissions by Osmundson et al. (Fig. 25). This probably also explains the recent deposits for $M$. rosella by $\mathrm{Na}$ and $\mathrm{Bau}$ (2019) which clearly correspond to $M$. rosea or one of its close relatives.

In the examples discussed in this study, IF performed overall better than $\mathrm{MB}$, but $\mathrm{MB}$ and $\mathrm{IF}$ do not present exactly the same type of information. Both will provide the current name for a species as well as a list of nomenclatural or taxonomic synonyms, but for the species discussed in this study MB provided generally more detailed information on the type specimen compared to IF (Online Resource 2 ). On the other hand, IF usually provides images of the protologue for older descriptions and is in our experience more up to date with taxonomic/systematic changes proposed in recent publications. Although this aspect hardly impacted the few in-depth re-examined BLAST results in this study, it did result in inextricable problems for some of the other taxa in our pilot study because of evident conflicts between current names adopted by MB versus those proposed in IF. Three examples to illustrate our purpose (Online Resource 2):

1. Our sequence MK028405 (Online Resource 1) was initially identified as Gymnopilus penetrans (Fr.) Murrill following the 'current name' according to IF. However, following MB, this name should have been replaced by $G$. sapineus (Fr.) Maire 1938, as both species are considered conspecific in MB, contrary to the opinion of IF where both species are treated as distinct entities. In the Swiss Atlas (which is generally following IF) both species are also recognized as 
distinct entities, although one might question the basis underlying the attribution of either species name to Swiss samples. When trying to find the solution in the pertinent taxonomic literature, one eventually may come across the publication by Holec (2005). In this morphological revision of European Gymnopilus, Holec accepts the synonymy of both names. Yet, Holec further explains that the name $G$. sapineus has been used in a different sense by different European mycologists, and that there are distinct differences between $G$. sapineus sensu Kühner and Romagnesi (1953), Moser (1983), Ludwig (2000, 2001) or Breitenbach and Kränzlin (2000), compared to G. sapineus sensu Fries (1838) or Høiland (1990), which is a synonym of $G$. penetrans. Chosing the correct current name that leaves no ambiguity in our case would imply to adopt «G. sapineus sensu Fries (1838) and Høiland (1990) » until sequence data can solve the issue because this species complex is clearly in need of more molecular data (Guzmán-Dávalos et al. 2003). However, a GenBank deposit does not allow for such subtle interpretations and forces one to adopt a potentially wrong identification.

2. When checking for the current name of our samples identified as Entoloma nidorosum (Fr.) Quél. 1872, MB advocates the use of E. rhodopolium f. nidorosum (Fr.) Noordeloos 1989 as current name, while IF accepts $E$. nidorosum as the current name, being considered a distinct species following Kokkonen (2015). The latter paper neotypified E. rhodopolium with a sequenced specimen from Sweden, as both species are genetically sufficiently different to be accepted as separate species. Hence, we here used Entoloma nidorosum (Fr.) Quél. 1872 as the current name.

3. The BLAST top score for our sequence MK028488 (see Online Resource 1) exhibited 100\% similarity with sequence FJ770396 deposited under the name Parasola conopila (Online Resource 2). The latter name, is not returning any results when doing a search in both MB and IF, although the species strain itself was deposited in Westerdijk institute (previously CBS). We thus checked the GenBank metadata for sequence FJ770396 and the adopted species name (under 'organism") was Parasola conopilea, which is different from the name adopted in the definition line. The latter species name ( $P$. conopilea) is the current name adopted by IF where it is a synonym for Psathyrella conopilea (Fr.) A. Pearson \& Dennis 1948 (both this current name and its synonym are not found in $\mathrm{MB}$ ). When trying to understand why these names were absent from $\mathrm{MB}$, we consulted then the publication of Larsson and Örstadius (2008), and found that the comb. nov. Parasola conopilus was given as current name for Psathyrella conopilus (Fries) A. Pearson \& Dennis 1949 (note that this date is again different from the one cited in taxonomic publications, as well as from the bibliographic references in $\mathrm{MB}$ itself (http://www.mycobank.org/BioloMICS.aspx?Ta bleKey $=14682616000000061 \&$ Rec $=15810 \&$ Fields $=$ All-see Online Resource 2). Consequently, both MB and IF are in disagreement with the Larsson and Örstadius (2008) and the Muñoz and Caballero (2013) papers in applying Psathyrella conopilus (Fries) A. Pearson \& Dennis 1948 and Parasola conopilea (Fries) Örstadius \& E. Larsson 2008 respectively. One must admit that contradictions like this cause total incomprehension for the occasional user. At the time of revision after this paper's initial submission, this issue is still under debate in discussions between GenBank and prominent experts in fungal nomenclature.

\section{Recommendations for fungal taxonomists}

In guise of a conclusion, we would like to translate our experience into a number of recommendations for good practice, several of which are repeating recent conclusions on the taxonomic annotation of public fungal ITS sequences from the built environment (Nilsson et al. 2018). Nearly all of these recommendations are specifically addressing fungal taxonomists:

1. All mycologists (clearly also including ourselves) need to care more about submitting correct and complete metadata. When doing so, great care should be taken about correct formatting-e.g. use Darwin Core format and the correct biocollections acronyms (see: https:// www.ncbi.nlm.nih.gov/biocollections/). In addition, when submitting larger files that contain batches of sequences, these should be double- or even triplechecked before submission so as to be certain that each sequence is correctly associated with its corresponding metadata.

2. Several of the taxonomic names associated with published sequences were clearly provisional at the time of submission to GenBank, and differ from those that were finally adopted at the time of final acceptance of the submitted papers, or they differ from the adopted names at the time of formal description of these taxa (ex. given, in the case of large phylogenies that include still undescribed taxa for which formal descriptions are published often several years later referring to the already submitted sequences but without updating the associated metadata in GenBank). Taxonomists are therefore strongly encouraged to check whether all of their previously submitted type sequences have been correctly flagged as such in GenBank or other public 
depositories and to report unflagged type sequences or missing metadata to GenBank (contact email: gbadmin@ncbi.nlm.nih.gov).

3. Taxonomic papers should, whenever possible, contribute to the epitypification of older taxa for which physical types do not exist or when these are too old to be sequenced. As of 1 January 2019, it is now obligatory to deposit details of lecto-, neo-, and epitypifications in one of the recognized repositories of fungal names in order for them to be validly published and to establish their priority (see Hawksworth and Lücking 2017, https://www.ncbi.nlm.nih. gov/pubmed/29242772).

4. Many sequences (particularly for the ITS gene region) have been generated by research groups or individual taxonomists in the context of taxonomic revisions of larger genera that will take many years, decennia or even more than a life time to complete. In such cases, it is frequently observed that many hundreds or even thousands of sequences remain purposely hidden for many years or decennia in personal computers of individual scientists. We know of fellow taxonomists that postpone to deposit their sequences for as long as possible for the sake of keeping some kind of advantage against the competition. Considering the time and funding that were spent in producing DNA sequences, keeping many thousands of sequences sometimes for several decennia in private computers represents an almost unacceptable risk and waste of money. Various reasons, such as technical problems, changes in career or study orientation, retirement, etc. can be the cause that these sequences will be permanently lost for the scientific community. For this reason, it would be preferable that solutions be found that favor more rapid deposits of sequences with some kind of guarantee as to their use. GenBank might consider the possibility to deposit 'locked sequences' (a possibility offered in UNITE, i.e. sequences that have been deposited will be incorporated in BLAST searches but are not accessible as fasta file without consent of the original submitter). This would be a much better option than the present notion of 'unpublished' sequences, a mention that is usually either outdated or simply ignored. However, such a possibility of 'locked' sequences seems very difficult to organize in GenBank (C. Schoch pers. comm.)

5. Finally, as for the issue of providing complete metadata with deposited sequences, it might also be up to the taxonomic community to annotate public depositories such as $\mathrm{MB}$ in order to update the information associated with fungal names. This study has highlighted the often contradicting information provided between MB and IF and it is clear that the "current opinion' on the correct application of names is way out of date in many cases. At least MB (Pedro Crous, pers. comm.) plays already with the idea of allowing 'third parties' to give their opinion on 'current names' for fungal taxa, enabling a more "citizen science" approach, so that users can see who changed the name, or what is the argument behind the choice of the current name, even when opinions may differ among experts.

Acknowledgements We thank the 'Département du territoire et de l'environnement du Canton de Vaud' (Switzerland), which provided fundings for this study. We also thank Marc-André Silva, forest inspector at Montricher, and Anne-Lise Fabre, Corinne Julmi, Eric Remolif and Jean-Pierre De Joffrey for technical help in the lab and/ or in the field. We also thank Conrad Schoch, Barbara Robbertse (NCBI GenBank, USA), Henrik Nilsson (Univ. of Gothenburg, Sweden) for comments on an earlier version of the manuscript, Shaun Pennycook (Landcare Research, New Zealand) for nomenclatural advice, Pedro Crous (Westerdijkinstituut, NL) and Scott Redhead (Agriculture and Agri-Food, Canada) for very useful exchanges on this subject.

Open Access This article is distributed under the terms of the Creative Commons Attribution 4.0 International License (http://creative commons.org/licenses/by/4.0/), which permits unrestricted use, distribution, and reproduction in any medium, provided you give appropriate credit to the original author(s) and the source, provide a link to the Creative Commons license, and indicate if changes were made.

\section{References}

Agnarsson I, Kuntner M (2007) Taxonomy in a changing world: seeking solutions for a science in crisis. Syst Biol 56(3):531-539

Alfaro ME, Zoller S, Lutzoni FM (2003) Bayes or bootstrap? A simulation study comparing the performance of Bayesian Markov Chain Monte Carlo sampling and bootstrapping in assessing phylogenetic confidence. Mol Biol Evol 20:255-266

Antonín V, Maas Geesteranus RA (1998) Mycena cupressina, a new species of section Supinae from Italy. Persoonia 16(4):545-547

Aronsen A, Læssøe T (2016) The genus Mycena s.l. Fungi Northern Europe 5:1-373

Audisio P (2017) Editorial: insect taxonomy, biodiversity research and the new taxonomic impediments. Fragm Entomol 49(2):121-124

Bauer H (2013) Decadent science: does fake differ from genuine? If so, how? https://scimedskeptic.wordpress.com/2013/04/24/deca dent-science-does-fake-differ-from-genuine-if-so-how/. Accessed 04 Jan 2019

Bazzicalupo AL, Buyck B, Saar I, Vauras J, Carmean D, Berbee ML (2017) Troubles with mycorrhizal mushroom identification where morphological differentiation lags behind barcode sequence divergence. Taxon 66(4):791-810

Beall J (2015) Criteria for determining predatory open-access publishers. J Informetr 12(2018):1296-1311

Begerow D, Nilsson H, Unterseher M, Maier W (2010) Current state and perspectives of fungal DNA barcoding and rapid identification procedures. Appl Microbiol Biotechnol 87(1):99-108

Beker HJ, Eberhardt U, Vesterholt J (2016) Hebeloma (Fr.) P. Kumm. Fungi Europaei 14:1-1218 
Bellanger JM (2015) Les cortinaires calochroïdes: une mise au point taxinomique. Doc Mycol 36:3-34

Bidartondo MI (2008) Preserving accuracy in GenBank. Science 319(5870):1616. https://doi.org/10.1126/science.319.5870.1616a

Bidaud A, Moënne-Loccoz P, Reumaux P (2001) Atlas des Cortinaires 11:527-626. Fédération Mycologique et Botanique Dauphiné-Savoie, France

Bisby GR, Ainsworth GC (1943) The numbers of fungi. Trans Br Mycol Soc 26:16-19

Blackwell M (2011) The fungi: 1, 2, 3.. 5.1 million species? Am J Bot 98(3):426-438

Blaxter M, Mann J, Chapman T, Thomas F, Whitton C, Floyd R, Abebe E (2005) Defining operational taxonomic units using DNA barcode data. Philos Trans $\mathrm{R}$ Soc Lond $\mathrm{B}$ 360(1462):1935-1943

Bockmann FA, Rodrigues MT, Kohsldorf T, Straker LC, Grant T, Cardodso de Pina MC, Mantelatto FLM, Datovo A, Pombal JP, McNamara JC, Botelho de Almeida EA, Klein W, Hsiou AS, Groppo M, Correa e Castro RM, de Souza Amorin D (2018) Brazil's government attacks biodiversity. Science 360(6391):865

Bowman JD (2014) Predatory publishing, questionable peer review, and fraudulent conferences. Am J Pharm Educ 78(10):1-6

Breitenbach J, Kränzlin F (2000) Pilze der Schweiz. Band 5, Blätterpilze 3, Teil 1-340. Mykologia, Luzern

Buchanan P, May T (2003) Conservation of New Zealand and Australian fungi. N Z J. Bot 41:407-421

Buyck B (1999) Taxonomists are an endangered species in Europe. Nature 401:321

Buyck B, Hofstetter V (2018) Cantharellus Subg. Pseudocantharellus (Hydnaceae, Cantharellales) revisited: one epityfication, one new synonym and one new species. Mycosphere 9(1):141-1498

Buyck B, Hosaka K, Masi S (2016) Molecular analyses of first collections of Elaphomyces Nees (Elaphomycetaceae, Eurotiales, Ascomycota) from Africa and Madagascar indicate that the current concept of Elaphomyces is polyphyletic. Crypto Myco 37(1):3-14

Buyck B, Henkel TW, Hofstetter V (2019a) The Cantharellus isabellinus species complex (Cantharellales, Hydnaceae) in tropical Africa. Mycosphere 9(6):1209-1221

Buyck B, Henkel TW, Hofstetter V (2019b) Epitypification oft he Central African Cantharellus densifolius and C. luteopunctatus allows fort he recognition of two additional species. MycoKeys 49:49-72. https://doi.org/10.3897/mycokeys.49.32034

Carpenter CR, Cone DC, Sarli CC (2014) Using publication metrics to highlight academic productivity and research impact. Acad Emerg Med 21:1160

Christensen M, Hahn K, Mountford EP, Ódor P, Standovár T, Rozenbergar D, Diaci J, Wijdeven S, Meyer P, Winter S, Vrska $\mathrm{T}$ (2005) Dead wood in European beech (Fagus sylvatica) forest reserves. For Ecol Manag 210(1-2):267-282

Costello MJ, Wilson S, Houlding B (2013) More taxonomists describing significant fewer species per unit effort may indicate that most species have been discovered. Syst Biol 63(4):616-624

Cullings KW (1992) Design and testing of a plant-specific PCR primer for ecological and evolutionary studies. Mol Ecol $1: 233-240$

De Carvalho MR, Bockmann FA, Amorim DS, Brandao CRF, Vivo $M$ et al (2007) Taxonomic impediment or impediment to taxonomy? A commentary on systematics and the cybertaxonomic-automation paradigm. Evol Biol 34:140-143

Demir SB (2018) Predatory journals: who publishes in them and why? J Informetr 12:1296-1311

Di Marino E, Montecchio L, Scattolin L, Abs C, Aegerer R (2009) The ectomycorrhizal community structure in European beech forests differing in coppice shoot age and stand features. J For 107(5):250-259
Doi Y (1972) Revision of the Hypocreales with cultural observations. IV. The genus Hypocrea and its allies in Japan (2). Enumeration of the species. Bull Natl Sci Mus Tokyo 15:649-751

Donk MA (1956) Notes on resupinate Hymenomycetes-III. Fungus 26:3-24

Doyle JJ, Doyle JL (1987) A rapid DNA isolation procedure for small quantities of fresh leaf tissue. Phytochem Bull 19:11-15

Eberhardt U, Verbeken A (2004) Sequestrate Lactarius species from tropical Africa: L. angiocarpus sp. nov. and L. dolichocaulis comb. nov. Mycol Res 108(9):1042-1052

Eberhardt U, Schuetz N, Krause C, Beker HJ (2018) Hebelomina revisited and abandoned. Plant Ecol Evol 151(1):96-109

Edwards MA, Roy S (2016) Academic research in the 21st century: maintaining scientific integrity in a climate of perverse incentives and hypercompetition. Environ Eng Sci 34(1):51-61

Enderle M (1996) Studien in der Gattung Psathyrella IV. Beiträge zur Kenntnis der Pilze Mitteleuropas 10:35-58

Eriksson S, Helgesson G (2017) The false academy: predatory publishing in science and bioethics. Med Health Care Philos 20(2):163-170

Eyssartier G, Roux P (2017) Guide des champignons-France et Europe, 4th edn. Collection Guides Nature références, Belin

Federhen S (2015) Type material in the NCBI taxonomy database. Nucleic Acids Res 43(Database issue):D1086-D1098

Floudas D, Hibbett DS (2015) Revisiting the taxonomy of Phanerochaete (Polyporales, Basidiomycota) using a four gene dataset and extensive ITS sampling. Fungal Biol 119(8):679-719

Fries E (1838) Epicrisis systematis mycologici. Typographia Academica, Uppsala

Frøslev TG, Jeppesen TS, Læssøe T (2006) Seven new calochroid and fulvoid species of Cortinarius. Mycol Res 110:1148-1160

Frøslev TG, Jeppesen TS, Laessøe TL, Kjøller R (2007) Molecular phylogenetics and delimitation of species in Cortinarius section Calochroi (Basidiomycota, Agaricales) in Europe. Mol Phyl Evol 44(1):217-227

Garnett ST, Christidis L (2017) Taxonomy anarchy hampers conservation. Nature 546:25-27

Garnica S, Weiss M, Oertel B, Oberwinkler F (2005) A framework for a phylogenetic classification in the genus Cortinarius (Basidiomycota, Agaricales) derived from morphological and molecular data. Can J Bot 83:1457-1477

Garnica S, Weiss M, Oertel B, Ammirati J, Oberwinkler F (2009) Phylogenetic relationships in Cortinarius, section Calochroi, inferred from nuclear DNA sequences. BMC Evol Biol 9:1

Ginns J (1984) New names, new combinations and new synonymy in the Corticiaceae, Hymenochaetaceae and Polyporaceae. Mycotaxon 21:325-333

Godfray HCJ (2007) Linnaeus in the information age. Nature 446:259-260

Goldstein PZ, DeSalle R (2011) Integrating DNA barcode data and taxonomic practice: determination, discovery, and description. BioEssays 33:135-147

Griffith GW (2012) Do we need a global strategy for microbial conservation? Trends Ecol Evol 27:1-2

Gryzenhout M (2015) The need to engage with citizen scientists to study the rich fungal biodiversity in South Africa. IMA Fungus 6(2):58-64

Guindon S, Gascuel O (2003) A simple, fast, and accurate algorithm to estimate large phylogenies by maximum likelihood. Syst Biol 52(5):696-704

Guzmán-Dávalos L, Mueller GM, Cifuentes J, Miller AN, Santerre A (2003) Traditional infrageneric classification of Gymnopilus is not supported by ribosomal DNA sequence data. Mycologia 95(6): 1204-1214

Hao YJ, Qin J, Yang ZL (2014) Cibaomyces, a new genus of Physalacriaceae from East Asia. Phytotaxa 162(4):198-210 
Harder CB, Læssøe T, Kjøller R, Frøslev TG (2010) A comparison between ITS phylogenetic relationships and morphological species recognition within Mycena sect. Calodontes in Northern Europe. Mycol Progress 9:395-405

Harder CB, Lodge DJ, Peterson RH, Hughes KW, Blanco JC, Frøslev TG, Laessøe T (2012) Amyloidity is not diagnostic for species in the Mycena pearsoniana complex (Mycena sectio Calodontes). Mycol Prog 11:725-732

Harder CB, Læssøe T, Frøslev TG, Ekelund F, Rosendahl S, Kjøller R (2013) A three-gene phylogeny of the Mycena pura complex reveals 11 phylogenetic species and shows ITS to be unreliable for species identification. Fungal Biol 117(11-12):764-775

Hawksworth DL (1991) The fungal dimension of biodiversity: magnitude, significance, and conservation. Mycol Res 95:641-655

Hawksworth DL, Lücking R (2017) Fungal diversity revisited: 2.2 to 3.8 million species. Microbiol Spectr. https://doi.org/10.1128/ microbiolspec.funk-0052-2016

Hawksworth DL, Mueller GM (2005) Fungal communities: their diversity and distribution. In: Dighton J, White JF, Oudemans P (eds) The fungal community: its organization and role in the ecosystem, 3rd edn. Taylor \& Francis, New York, pp 27-37

Hawksworth DL, Hibbett DS, Kirk PM, Lücking R (2016) Proposals to permit DNA sequence data to serve as types of names of fungi. Taxon 65(4):899-900

Heather J, Chain B (2015) The sequence of sequencers: the history of sequencing DNA. Genomics 107(2016):1-8

Hebert PDN, Cywinska A, Ball SL, deWaard JR (2003) Biological identifications through DNA barcodes. Proc R Soc Lond B 270:313-322

Heilmann-Clausen J, Barron ES, Boddy L, Dahlberg A, Griffith GW, Nordén J, Ovaskainen O, Perini C, Senn-Irlet B, Halme P (2014) A fungal perspective on conservation biology. Conserv Biol 29(1):61-68

Herr JR, Öpik M, Hibbett D (2015) Towards the unification of sequenced-based classification and sequenced-based identification of host-associated microorganisms. New Phytol 205:27-31

Hibbett D, Abarenkov K, Kõljalg U, Öpik M, Chai B, Cole J, Wang Q, Crous P, Robert V, Helgason T, Herr JR, Kirk P, Lueschow S, O'Donnell KR, Nilsson H, Oono R, Schoch C, Smyth C, Walker DM, Porras-Alfaro A, Taylor JW, Geiser DM (2016) Sequencebased classification and identification of Fungi. Mycologia 108(6):1049-1068

Hjortstam K, Ryvarden L (1981) Studies in tropical Corticiaceae (Basidiomycetes) III. Two new species of Laxitextum. Mycotaxon 13(1):35-40

Hofstetter V, Buyck B, Croll D, Viret O, Couloux A, Gindro K (2012) What if esca disease of grapevine were not a fungal disease? Fungal Divers 54:51-67

Høiland K (1990) The genus Gymnopilus in Norway. Mycotaxon $39: 257-279$

Holec J (2005) The genus Gymnopilus (Fungi, Agaricales) in the Czech Republic with respect to collections from other European countries. Acta Mus Nat Pragae, ser B, Hist Nat 61(1-2):1-52

Holec J (2009) Valid publication of the name Tricholomopsis flammula (Fungi, Basidiomycota, Tricholomataceae), a species clearly separated from $T$. rutilans. J Nat Mus 178:7-13

Holec J, Kolařík M (2013) Notes on the identity of Hygrophoropsis rufa (Basidiomycota, Boletales). Czech Mycol 65(1):15-24

Holec J, Kolařík M (2016) Tricholomopsis flammula (Basidiomycota, Agaricales)-molecular taxonomy, delimitation, variability and ecology. Mycol Prog. https://doi.org/10.1007/s11557-010-06790

Hongsanan S, Jeewon R, Purahong W, Xie N, Liu J-K et al (2018) Can we use environmental DNA as holotypes? Fungal Divers 92:1-30
Hyde KD, Norphanphoun C, Chen J, Dissanayake AJ, Doilom M, Hongsanan S, Jayawardena RS, Jeewon R, Perera RH, Thongbai $\mathrm{B}$, Wanasinghe DN, Wisitrassameewong $\mathrm{K}$, Tibpromma $\mathrm{S}$, Stadler M (2018) Thailand's amazing diversity: up to $96 \%$ of fungi in northern Thailand may be novel. Fungal Divers 93:215-239

Jeewon R, Hyde KD (2016) Establishing species boundaries and new taxa among fungi: recommendations to resolve taxonomic ambiguities. Mycosphere 7(11):1669-1677

Johannesson H, Renvall P, Stenlid J (2000) Taxonomy of Antrodiella inferred from morphological and molecular data. Mycol Res 104(1):92-99

Justo A, Malysheva E, Bulyonkova T, Vellinga EC, Cobian G, Nguyen N, Minnis AM, Hibbett DS (2014) Molecular phylogeny and phylogeography of Holarctic species of Pluteus section Pluteus (Agaricales: Pluteaceae), with description of twelve new species. Phytotaxa 180(1):1-85

Kang S, Mansfield MA, Park B, Geiser DM, Ivors KL, Coffey MD, Grünwald NJ, Martin FN, Lévesque CA, Blair JE (2010) The promise and pitfalls of sequence-based identification of plantpathogenic fungi and oomycetes. Phytopathology 100:732-737

Kim CS, Jo JW, Kwag YN, Sung GH, Lee SG, Kim SY, Shin CH, Han SK (2015) Mushroom flora of Ulleung-gun and a newly recorded Bovista species in the Republic of Korea. Mycobiology 43(3):239-257

Kiss L (2012) Limits of nuclear ribosomal DNAinternal transcribed spacer (ITS) sequences as species barcodes for Fungi. Proc Natl Acad Sci USA 109(27):E1811

Knudsen H, Vesterhold J (2008) Funga Nordica. Nordsvamp, Copenhagen, pp 1-965

Ko Ko TWK, Stephenson SL, Bahkali AH, Hyde KD (2011) From morphology to molecular biology: can we use sequence data to identify fungal endophytes? Fungal Divers 50:113-120

Kokkonen K (2015) A survey of boreal Entoloma with emphasis on the subgenus Rhodopolia. Mycol Progress 14:1-52

Kõljalg U, Nilsson RH, Abarenkov K et al (2013) Towards a unified paradigm for sequence-based identification of Fungi. Mol Ecol 22:5271-5277

Korf RP (2007) Reinventing taxonomy: a curmudgeon's view of 250 years of fungal taxonomy, the crisis in biodiversity, and the pitfalls of the phylogenetic age. Mycotaxon 93:407-415

Kotiranta H, Larsson K-H (2013) Sistotrema luteoviride sp. nov. (Cantharellales, Basidiomycota) from Finland. Acta Mycol 48(2):219-225

Kühner R, Romagnesi H (1953) Flore Analytique des Champignons Supérieurs. Masson, Paris

Larsson E, Örstadius L (2008) Fourteen coprophilous species of Psathyrella identified in the Nordic countries using morphology and nuclear rDNA sequence data. Mycol Res 112(10):1165-1185

Lentz PL (1955) Stereum and allied genera of fungi in the Upper Mississippi Valley. Agriculture Monograph, vol 24. U.S. Department of Agriculture, Washington, pp 1-74. https://doi. org/10.5962/bhl.title.63676

Lindahl BD, Nilsson RH, Tedersoo L, Abarenkov K, Carlsen T et al (2013) Fungal community analysis by high-throughput sequencing of amplified markers-a user's guide. New Phytol 199:288-299

Lipscomb D, Platnick N, Wheeler QD (2003) The intellectual content of taxonomy: a comment on DNA taxonomy. Trends Ecol Evol 18:57-59

Lu B, Druzhinina IS, Fallah P, Chaverri P, Gradinger C, Kubicek CP, Samuels GJ (2004) Hypocrea/Trichoderma species with pachybasium-like conidiophores: teleomorphs for T. minutisporum and T. polysporum and their newly discovered relatives. Mycologia 96(2):310-342 
Ludwig E (2000) Pilzkompendium. Band 1. Abbildungen, vol 1. IHW Verlag, Eching

Ludwig E (2001) Pilzkompendium. Band 1. Beschreibungen, vol 1. IHW Verlag, Eching

Maddison DR, Maddison WP (2005) MacClade 4: analysis of phylogeny and character evolution. Version 4.08a. http:// macclade.org

Maharachchikumbura SSN, Larigon P, Hyde KD, Al-Sadi AM, Liu Z (2016) Characteriztion of Neopestalotiopsis, Pestalotiopsis and Truncatella species associated with grapevine trunk disease in France. Phytopathol Mediterr 55:380-390

Martin GW (1951) The numbers of fungi. Proc Iowa Acad Sci 58:175-178

Martini E (2016) Excerpts from crusts and jells. Descriptions and reports of resupinate Aphyllophorales and Heterobasidiomycetes. Nr. 97. Sistotrema sernanderi. http://www.aphyllo. net

Matheny PB, Curtis JM, Hofstetter V, Aime MC, Moncalvo J, Ge ZW, Yang ZL, Slot JC, Ammirati JF, Baroni TJ, Bougher NL, Hughes KW, Lodge DJ, Kerrigan RW, Seidl MT (2006) Major clades of Agaricales: a multilocus phylogenetic overview. Mycologia 98(6):982-995

Melera S, Ostellari C, Roemer N, Avis PG, Tonolla M, Barja F, Narduzzi-Wicht B (2017) Analysis of morphological, ecological and molecular characters of Russula pectinatoides Peck and Russula praetervisa Sarnari, with a description of the new taxon Russula recondita Melera \& Ostellari. Mycol Prog 16(2):117-134

Menkis A, Allmer J, Vasiliauskas R, Lygis V, Stenlid J, Finlay R (2004) Ecology and molecular characterization of dark septate fungi from roots, living stems, coarse and fine woody debris. Mycol Res 108(8):965-973

Miettinen O, Vlasák J, Rivoire B, Spirin V (2018) Postia caesia complex (Polyporales, Basidiomycota) in temperate Northern Hemisphere. Fungal Syst Evol 1:101-129

Moreau P-A (2003) Mycena plumipes (Kalchbr.) P.-A. Moreau. Bull Mycol Bot Dauphiné-Savoie 43(171):5

Moreau P-A, Vila J, Aime MC, Antonin V, Horak E, Perez Butron JL, Richard F, Urban A, Welti S, Vizzini A (2015) Cibaomyces and Cyptotrama, two new genera for Europe, and an emendation of Rhizomarasmius (Basidiomycota, Physalacriaceae). Mycol Prog $14: 4$

Moser M (1953) Kleine Kryptogamenflora von Mitteleuropa Die Blätter-und Bauchpilze (Agaricales und Gastromycetes). Gustav Fischer Verlag, Jena

Moser M (1983) Die Röhrlinge und Blätterpilze. In: Gams W (ed) Kleine Kryptogamenflora, vol 2b/2, 5th edn. Springer, New York

Muñoz G, Caballero A (2013) Contribución al conocimiento del género Psathyrella (incluidos taxones ahora transferidos a los géneros Coprinopsis y Parasola) en la Península Ibérica (II). Boletín Micológico de FAMCAL 8:17-46

Münzmay T, Oertel B, Schmidt-Stohn G, Saar G (2009) Cortinarius laberiae Münzmay, B. Oertel \& Saar nov. spec. und zwei weitere, wenig bekannte Arten aus der Gattung Cortinarius, Untergattung Phlegmacium in Europa. J JEC 11:32-40

$\mathrm{Na}$ Q, Bau T (2019) Mycena section Sacchariferae: three new species with basal discs from China. Mycol Prog 18:483-493. https:// doi.org/10.1007/s11557-018-1456-8

Nguyen NH, Song Z, Bates ST, Branco S, Tedersoo L, Menke J, Schilling JS, Kennedy PG (2016) FUNGuild: an open annotation tool for parsing fungal community data sets by ecological guild. Fungal Ecol 20:241-248

Niemelä T, Ryvarden L (1983) Antrodiella citrinella, a new polypore species. Karstenia 23:26-30

Nilsson RH, Kristiansson E, Ryberg M et al (2005) Approaching the taxonomic affiliation of unidentified sequences in public databases-an example from the mycorrhizal fungi. BMC Bioinform 6:178

Nilsson RH, Ryberg M, Kristiansson E, Abarenkov K, Larsson K-H et al (2006) Taxonomic reliability of DNA sequences in public sequence databases: a fungal perspective. PLoS ONE 1(1):e59. https://doi.org/10.1371/journal.pone.0000059

Nilsson RH, Kristiansson E, Ryberg M, Hallenberg N, Larsson K-H (2008) Intraspecific ITS variability in the kingdom Fungi as expressed in the international sequence databases and its implications for molecular species identification. Evol Bioinform 4:193-201

Nilsson RH, Tedersoo L, Lindahl BD, Kjoller R, Carlsen T, Quince C, Abarenkov K, Pennanen T, Stenlid J, Bruns T, Larsson KH, Koljalg U, Kauserud H (2011) Towardsstandardization of the description and publication of next-generation sequencing datasets of fungal communities. New Phytol 191:314-318

Nilsson RH, Tedersoo L, Abarenkov K, Ryberg M, Kristiansson E, Hartmann M, Schoch CL, Nylander JAA, Bergsten J, Porter TM, Jumpponen A, Vaishampayan P, Ovaskainen O, Hallenberg N, Bengtsson-Palme J, Eriksson KM, Larsson K-H, Larsson E, Kõljalg U (2012) Five simple guidelines for establishing basic authenticity and reliability of newly generated fungal ITS sequences. MycoKeys 4:37-63. https://doi.org/10.3897/myco keys.4.3606

Nilsson RH, Hyde KD, Pawłowska J, Ryberg M, Tedersoo L et al (2014) Improving ITS sequence data for identification of plant pathogenic fungi. Fungal Divers 67(1):11-19. https://doi.org/10. 1007/s13225-014-0291-8

Nilsson RH, Sánchez-García M, Ryberg M, Abarenkov K, Wurzbacher C, Kristiansson E (2017) Read quality-based trimming of the distal ends of public fungal DNA sequences is nowhere near satisfactory. MycoKeys 26:13-24

Nilsson RH, Taylor AFS, Adams RI, Baschien C, Bengtsson-Palme J et al (2018) Taxonomic annotation of public fungal ITS sequences from the built environment-a report from an April 10-11, 2017 workshop (Aberdeen, UK). MycoKeys 28:65-82

O'Brien BL, Parrent JL, Jackson JA, Moncalvo JM, Vilgalys R (2005) Fungal community analysis by large-scale sequencing of enviromental samples. Appl Environ Microbiol 71:5544-5550

Olariaga I, Pérez-de-Gregorio MA, Arrillaga P (2015) Porpoloma aranzadii is a synonym of Mycena dura, further notes in Mycena sect. Calodontes. Crypto Myco 36(6):253-264

Örstadius L, Ryberg M, Larsson E (2015) Molecular phylogenetics and taxonomy in Psathyrellaceae (Agaricales) with focus on psathyrelloid species: introduction of three new genera and 18 new species. Mycol Prog 14(25):1-42

Ortiz-Santana B, Lindner DL, Miettinen O, Justo A, Hibbett DS (2013) A phylogenetic overview of the antrodia clade (Basidiomycota, Polyporales). Mycologia 105(6):1391-1411

Osmundson TW, Robert VA, Schoch CL, Baker LJ, Smith A et al (2013) Filling gaps in biodiversity knowledge for macrofungi: contributions and assessment of an herbarium collection DNA barcode sequencing project. PLoS ONE 8(4):e62419. https://doi. org/10.1371/journal.pone.0062419

Peay KG (2014) Back to the future: natural history and the way forward in modern fungal ecology. Fungal Ecol 2:4-9

Peintner U, Moncalvo J-M, Vilgalys R (2004) Toward a better understanding of the infrageneric relationships in Cortinarius (Agaricales, Basidiomycota). Mycologia 96:1042-1058

Persoon CH (1797) Tentamen dispositionis methodicae Fungorum. Wolf, Leipzig, pp 1-76

Pervanchon F (2004) Modélisation de l'effet des pratiques agricoles sur la diversité végétale et la valeur agronomique des prairies permanentes en vue de l'élaboration d'indicateurs agri-environnementaux. PhD thesis, INPL, Nancy 
Piatek M (2003) Notes on Polish polypores. 1. Oligoporus alni, comb. nov. Polish Bot J 48(1):17-20

Piepenbring M, Hofmann TA, Unterseher M, Kost G (2012) Species richness of plants and fungi in western Panama: towards a fungal inventory in the tropics. Biodivers Conserv 21:2181-2193

Quake, S. (2009). Letting scientists off the leash. The New York Times Blog, February 10. https://opinionator.blogs.nytimes.com/ 2009/02/10/guest-column-letting-scientists-off-the-leash/. Accessed 04 Jan 2019

Raposo MA, Stopiglia R, Brito GRR, Bockmann FA, Kirwan GM, Gayon J, Dubois A (2017) What really hampers taxonomy and conservation? A riposte to Garnett and Christidis. Zootaxa 4317(1):179-184

Robich G (2016) Mycena d'Europa. Associazione Mycologica Bresadola, Trento

Roy M, Vasco-Palacios A, Geml J, Buyck B, Delgat L, Giachini A, Grebenc T, Harrower E, Kuhar F, Magnago A, Rinaldi AC, Schimann H, Selosse MA, Sulzbacher MA, Wartchow F et al (2017) The (re)discovery of ectomycorrhizal symbioses in neotropical ecosystems sketched in Florianópolis. New Phytol 214(3):920-923. https://doi.org/10.1111/nph.14531

Ryberg M, Nilsson RH, Kristiansson E, Töpel M, Jacobsson S, Larsson E (2008) Mining ecological metadata in GenBank: a case-study from Inocybe (Agaricales). BMC Evol Biol 8:50

Samson RA (1995) Constraints associated with taxonomy of biocontrol fungi. Can J Bot 73(Suppl. 1):S83-S88

Santos D, Samproha S, Santos C, Morphy D (2017) Advances on Dipterology in the 21th century and extinction rates. Pap Avulsos Zool 57(33):433-444

Sarnari M (1994) Russula nuovo o interessanti dell'Italia centrale e mediterranea-XXV contributo. Boll Ass Micol Ecol Romana 33:3-26

Scheffers BR, Joppa LN, Pimm SL, Laurance WF (2012) What we know and don't know about Earth's missing biodiversity. Trends Ecol Evol 27(9):501-510

Schoch CL, Seifert KA, Huhndorf S, Robert V, Spouge JL, Levesque CA, Chen W, Barcoding Fungal (2012) Nuclear ribosomal internal transcribed spacer (ITS) region as a universal DNA barcode marker for fungi. Proc Natl Acad Sci USA 109(16):6241-6246

Schoch CL, Robbertse B, Robert V, Vu D, Cardianli G (2014) Finding needles in haystacks: linking scientific names, reference specimens and molecular data for Fungi. Database. https://doi. org/10.1093/database/bau061

Seberg O, Humphries CJ, Knapp S, Stevenson DW, Petersen G, Scharff N, Andersen NM (2003) Shortcuts in systematics? A commentary on DNA-based taxonomy. Trends Ecol Evol 18:63-65

Seifert KA (2009a) Progress towards DNA barcoding of fungi. Mol Ecol Res 9(Suppl 1):83-89

Seifert KA (2009b) Progress towards DNA barcoding of fungi. Mol Ecol Res 9(1):83-89

Selosse M-A, Vincenot L, Öpik M (2016) Data processing can mask biology: towards better reporting of fungal barcoding data? New Phytol 210:1159-1164

Senn-Irlet B, Bieri G, Egli S (2007) Rote Liste Grosspilze. Rote Liste der gefährdeten Arten der Schweiz. Umwelt-Vollzug. 07/18. Bern, Bundesamt für Umwelt BAFU, Birmensdorf, Eidgenössische Forschungsanstalt für Wald, Schnee und Landschaft WSL. $92 \mathrm{~S}$

Sevcikova H, Borovicka J (2015) Pluteus floccipes, a new species from the Czech Republic. Sydowia 67:157-165

Shashok, K. (2017). Can scientists and their institutions become their own open access publishers? https://arxiv.org/pdf/1701.02461. pdf. Accessed 04 Jan 2019
Shehan B (2017) Mushroom Citizen Science in USA: from species lists to Mycofloras 2.0. Fungi 10(1):28-36

Shivas R, Cai L (2012) Cryptic fungal species unmasked. Microbiol Aust 33:35-36

Siddig AAH, Ellison AM, Ochs A, Villar-Leeman C, Lau MK (2016) How do ecologists select and use indicator species to monitor ecological change? Insights from 14 years of publication in Ecological Indicators. Ecol Indic 60:223-230

Stoeckle M (2003) Taxonomy, DNA, and the bar code of life. Bioscience 53(9):796-797

Taylor DL, Herriott IC, Stone KE, McFarland JW, Booth MG, Leigh MB (2010) Structure and resilience of fungal communities in Alaskan boreal forest soils. Can J Res 40:1288-1301

Tedersoo L, Smith ME (2017) Ectomycorrhizal fungal lineages: detection of four new groups and notes on consistent recognition of ectomycorrhizal taxa in high-throughput sequencing studies. Ecol Stud 230:125-142

Tedersoo L, Sánchez-Ramírez S, Kõljalg U, Barham M, Döring M, Schigel D, May T, Ryberg M, Abarenkov K (2018) High-level classification of the Fungi and a tool for evolutionary ecological analyses. Fungal Divers 90:135-159

Tijdink JK, Verbeke R, Smulders YM (2014) Publication pressure and scientific misconduct in medical scientists. J Empir Res Hum Res Ethics 9:64

Van der Heijden MAG, Martin F, Selosse MA, Sanders IR (2015) Mycorrhizal ecology and evolution: the past, the present, and the future. New Phytol 205(4):1406-1423

Van Noorden R (2010) Metrics: a profusion of measures. Nature 465:864

Vasǔtová M, Antonín V, Urban A (2008) Phylogenetic studies in Psathyrella focusing on sections Pennatae and Spadiceae-new evidence for the paraphyly of the genus. Mycol Res 112(10): 1153-1164

Velenovský J (1939) Novitates mycologicae. L. Souček, Praha, pp 1-211

Vellinga EC, Kuyper TW, Ammirati J, Desjardin DE, Halling RE, Justo A, Læssøe T, Lebel T, Lodge DJ, Matheny PB, Methven AS, Moreau P-A, Mueller GM, Noordeloos ME, Nuytinck J, Ovrebo CL, Verbeken A (2015) Six simple guidelines for introducing new genera of fungi. IMA Fungus 6(2):65-68

Vilgalys R (2003) Taxonomic misidentification in public DNA databases. New Phytol 160(1):4-5

Vu D, Groenewald M, de Vries M, Gehrmann T, Stielow B, Eberhardt U, Al-Hatmi A, Groenewald JZ, Cardinali G, Houbraken J, Boekhout T, Crous PW, Robert V, Verkley GJM (2019) Largescale generation and analysis of filamentous fungal DNA barcodes boosts coverage for kingdom fungi and reveals thresholds for fungal species and higher taxon delimitation. Stud Mycol 92:135-154

Wang J, Buyck B, Wang X-H, Bau T (2019) Visiting Russula (Russulaceae, Russulales) with samples from southwestern China fins one new subsection of R. subg. Heterophyllidia with two new species. Mycol Progress (accepted)

Werner R (2015) The focus on bibliometrics makes papers less useful. Nature 517:245

Wheeler QD (2004) Taxonomic triage and the poverty of phylogeny. Philos Trans R Soc Lond B 359:571-583

Wijayawardene NN, Pawlowska J, Letcher PM, Kirk PM, Humber RA et al (2018) Notes for genera: basal clades of fungi (including Aphelidiomycota, Basidiobolomycota, Blastocladiomycota, Calcarisporiellomycota, Caulochytriomycota, Chytridiomycota, Entomophthoromycota, Glomeromycota, Kickxellomycota, Monoblepharomycota, Mortierellomycota, Mucoromycota, Neocallimastigomycota, Olpidiomycota, Rozellomycota and Zoopagomycota). Fungal Divers 92:43-129 
Wisitrassameewong K, Looney BP, Le HT, De Crop E, Das K, Van de Putte K, Eberhardt U, Jiayu G, Stubbe D, Hyde KD, Verbeken A, Nuytinck J (2016) Lactarius subgenus Russularia (Basidiomycota, Russulales): novel Asian species, worldwide phylogeny and evolutionary relationships. Fungal Biol 120(12):1554-1581
Yuan H-S (2014) Molecular phylogenetic evaluation of Antrodiella and morphologically allied genera in China. Mycol Prog 13(2):353-364

Yuan H-S, Li J, Huang MY, Dai YC (2006) Antrodiella stipitata sp. nov. from Heilongjiang Province, northeast China, and a critical checklist of polypores from the area. Crypto Mycol 27(1):21-29 